
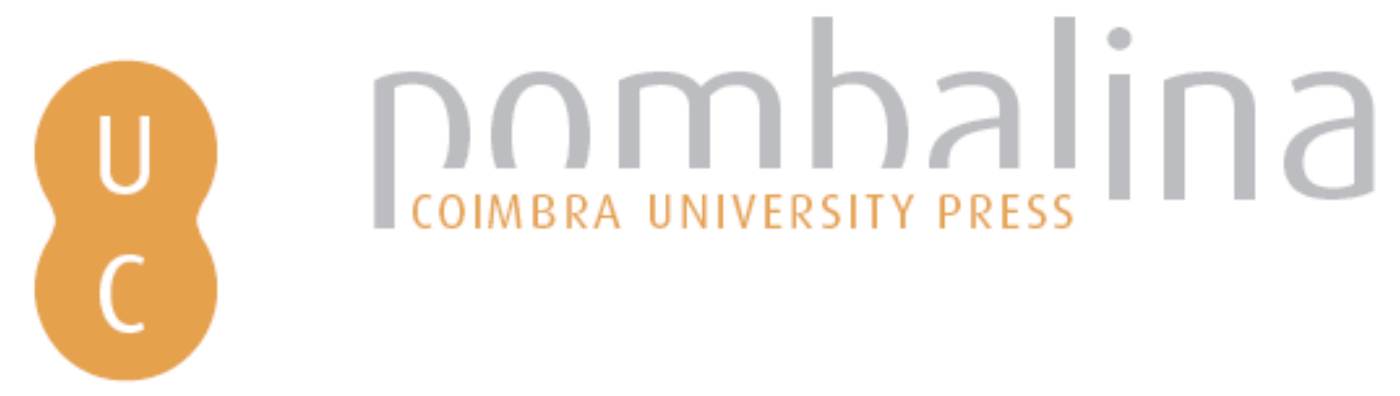

\title{
Realidades e desafios na gestão dos riscos: diálogo entre ciência e utilizadores
}

Publicado por: $\quad \begin{aligned} & \text { Imprensa da Universidade de Coimbra; Núcleo de Investigação } \\ & \text { Científica de Incêndios Florestais }\end{aligned}$

URL

persistente:

URI:http://hdl.handle.net/10316.2/35745

DOI:

DOI:http://dx.doi.org/10.14195/978-972-8330-23-1

Accessed : $\quad$ 26-Apr-2023 11:33:52

A navegação consulta e descarregamento dos títulos inseridos nas Bibliotecas Digitais UC Digitalis, UC Pombalina e UC Impactum, pressupõem a aceitação plena e sem reservas dos Termos e Condições de Uso destas Bibliotecas Digitais, disponíveis em https://digitalis.uc.pt/pt-pt/termos.

Conforme exposto nos referidos Termos e Condições de Uso, o descarregamento de títulos de acesso restrito requer uma licença válida de autorização devendo o utilizador aceder ao(s) documento(s) a partir de um endereço de IP da instituição detentora da supramencionada licença.

Ao utilizador é apenas permitido o descarregamento para uso pessoal, pelo que o emprego do(s) título(s) descarregado(s) para outro fim, designadamente comercial, carece de autorização do respetivo autor ou editor da obra.

Na medida em que todas as obras da UC Digitalis se encontram protegidas pelo Código do Direito de Autor e Direitos Conexos e demais legislação aplicável, toda a cópia, parcial ou total, deste documento, nos casos em que é legalmente admitida, deverá conter ou fazer-se acompanhar por este aviso. 


\section{REALIDADES E DESAFIOS NA GESTÃO DOS RISCOS}

\section{Diálogo entre Ciência e Utilizadores}

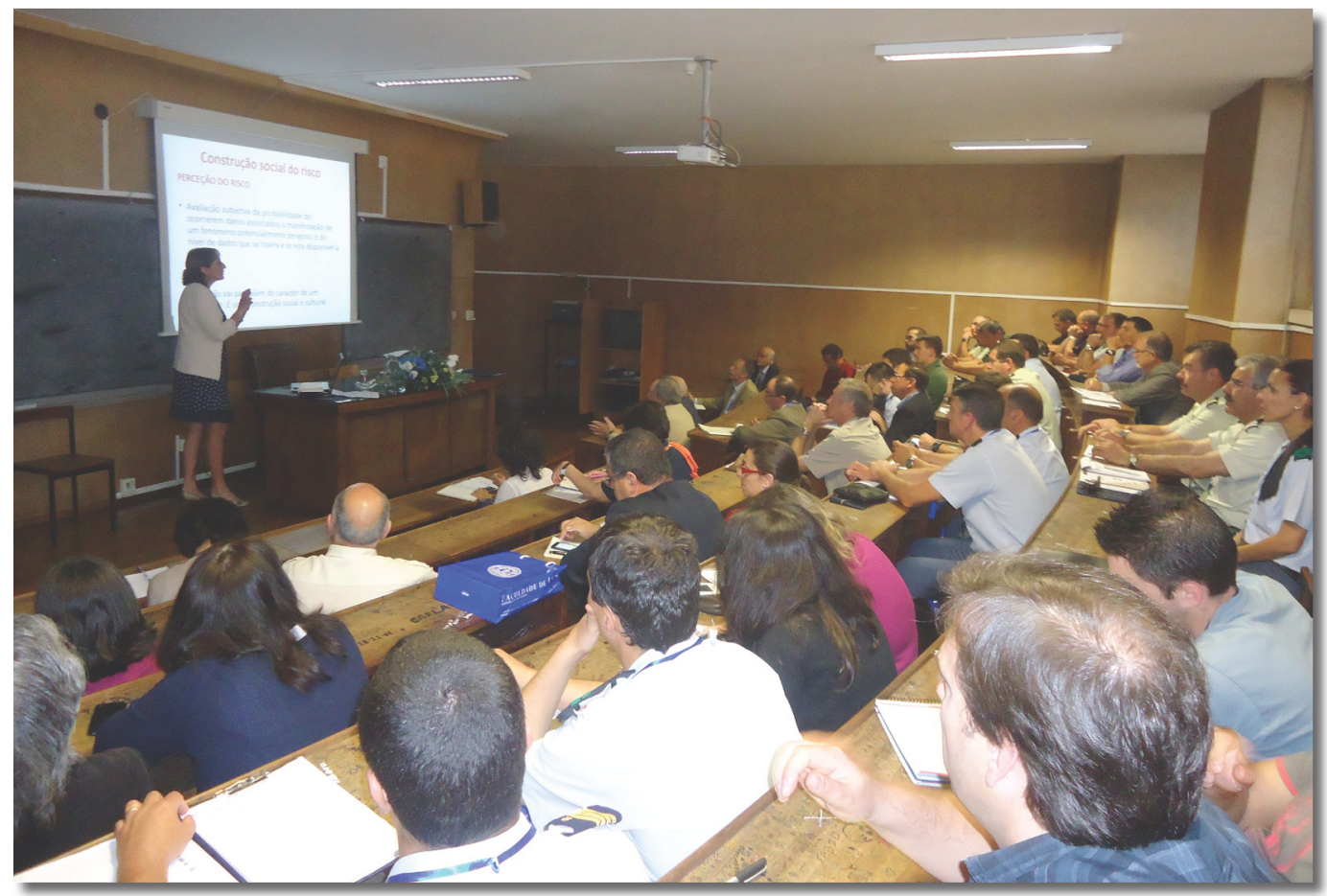

Núcleo de Investigação Científica de Incêndios Florestais

Faculdade de Letras da Universidade de Coimbra

Coimbra 



\section{REALIDADES E DESAFIOS \\ NA \\ GESTÃO DOS RISCOS}

Diálogo entre Ciência e Utilizadores

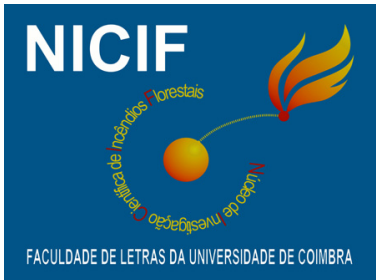

Núcleo de Investigação Científica de Incêndios Florestais Faculdade de Letras da Universidade de Coimbra Coimbra 2014 
Ficha Técnica

\author{
Propriedade e Edição \\ NICIF - Núcleo de Investigação Científica de Incêndios Florestais \\ Faculdade de Letras da Universidade de Coimbra \\ Largo da Porta Férrea \\ 3004-530 Coimbra - Telf. 239992251 \\ E-mail: nicif@uc.pt \\ Direção Editorial \\ Luciano Lourenço e Fantina Tedim \\ Em cooperação com a Imprensa da Universidade de Coimbra
}

\title{
Processamento de texto
}

Fernando Félix

Design da Capa

Fernando Félix

\section{Impressão e Acabamentos}

Simões \& Linhares, Lda.

Tiragem

100 exemplares

ISBN

978-972-8330-22-4

978-972-8330-23-1

DOI

http://dx.doi.org/10.14195/978-972-8330-23-1

Coimbra

2014

Este trabalho é financiado por Fundos Nacionais através da FCT - Fundação para a Ciência e a Tecnologia, no âmbito do projeto com a referência PEst-OE/SADG/UI4084/2014. 


\section{NOTA DE ABERTURA}

Durante o VII Encontro de Geografia Física e Ambiente, subordinado ao tema grandes incêndios florestais e erosão e degradação dos solos, que decorreu em Guimarães, nos dias 10 e 11 de outubro de 2013, no debate com que finalizou uma das sessões, abordou-se a questão da terminologia, tendo-se gerado alguma discussão em torno do conceito de perigosidade, discussão que se prolongou pelo intervalo que se seguiu à sessão, tendo-se concluído do interesse em organizar um debate com vista a refletir sobre alguns dos pontos de discussão.

Ora, a organização de um "Diálogo ente Ciência e Utilizadores" foi a resposta encontrada para esse desafio assumido no Encontro de Guimarães e que se traduziu numa reunião técnicocientífica levada a efeito no dia 16 de maio de 2014, na Faculdade de Letras da Universidade de Coimbra, para a qual foram convidados representantes das Universidades de Lisboa (Nova, Clássica e Instituto Superior Técnico), do Porto, do Minho e, naturalmente, de Coimbra, bem como das três entidades que constituem os pilares institucionais de defesa da floresta contra incêndios, a Autoridade Nacional de Proteção Civil (ANPC), o Instituto de Conservação da Natureza e das Florestas (ICNF) e a Guarda Nacional Republicana (GNR), que esteve representada pelo Serviço de Proteção da Natureza (SEPNA) e pelo Grupo de Intervenção, Proteção e Socorro (GIPS) da Unidade de Intervenção (UI). Nesta reunião técnico-científica participaram também representantes do Serviço Regional de Proteção Civil da Madeira, de Autarquias Locais, Corpos de Bombeiros (sapadores, municipais e voluntários), bem como profissionais e estudantes de Geografia.

Após a sessão de abertura, o primeiro painel, dedicado à "Ciência", contou com intervenções de três especialistas, oriundos de outras tantas áreas de saber e provenientes de três universidades distintas. O Prof. Doutor Fernando Rebelo, da Universidade de Coimbra, especialista em riscos naturais e um dos grandes divulgadores da teoria do risco em Portugal, proferiu uma conferência sobre Terminologia do risco. Origens, dificuldades de tradução e bom senso. Seguiu-se-lhe a palestra do Prof. Doutor Eng. ${ }^{\circ}$ Betâmio de Almeida, do Instituto Superior Técnico de Lisboa, outro conceituado especialista em matéria de riscos, que tratou da Gestão do Risco e da Incerteza. Conceitos e Filosofia Subjacente. A Prof. ${ }^{\text {a }}$ Doutora Fantina Tedim, da Universidade do Porto, uma especialista mais vocacionada para a abordagem dos aspetos sociais dos riscos, encerrou o painel com uma intervenção sobre $A$ conceptualização nos riscos naturais e antrópicos: impactes na ciência e na ação.

Depois de um breve intervalo, seguiu-se o painel designado por "Ação", mais voltado para a aplicação, que também contou com três intervenções. A primeira delas, da autoria do Prof. Doutor Rui Pedro Julião, da Universidade Nova de Lisboa, fez a apresentação do Guia Metodológico para a Cartografia de Risco - um produto do diálogo Ciência/Utilizadores, que coordenou e que é considerado um importante instrumento orientador na produção de cartografia de risco, mas que à luz desta reflexão, poderá carecer de revisão num ou noutro aspeto terminológico.

Aliás, a terminologia foi o aspeto central deste "Diálogo" e teve o seu ponto mais alto na conferência da Prof. ${ }^{a}$ Doutora Isabel Pedro, da Faculdade de Letras da Universidade de Coimbra, uma reputada linguista e tradutora, que dissertou sobre os Riscos e Perigos em Tradução. Considerações sobre terminologia nas ciências cindínicas.

Para fechar este painel, o Prof. Doutor Luciano Lourenço, também da Universidade de Coimbra, apresentou o tema Riscos e Crises: Reflexão e proposta de um modelo conceptual-operacional, através do qual procurou que se refletisse sobre a lógica sequencial e a hierarquia dos três principais conceitos em apreço: risco, perigo e crise, bem como sobre a forma de os organizar em termos de resposta operacional.

Após um intervalo para almoço, os trabalhos foram retomados ao início da tarde, com uma sessão sobre $A$ operacionalização do conceito do risco: dar a palavra aos utilizadores, em que os participantes foram distribuídos por quatro grupos, com o objetivo de, em cada um deles, se recolherem diversas opiniões e a argumentação que as sustenta, designadamente através 


\section{Realidades e desafios na gestão dos riscos \\ - Diálogo entre ciência e utilizadores -}

da resposta a cinco questões constantes de um breve inquérito, elaborado com o objetivo de se identificarem as potencialidades e as fragilidades do atual modelo de gestão do risco e das crises, bem como de avaliar em que medida o modelo agora proposto suportará uma melhor práxis, quer na prevenção dos riscos quer na gestão das crises.

A reunião terminou com uma mesa redonda sobre $O$ diálogo entre a ciência e a ação na gestão dos riscos, onde foram apresentadas as propostas e as conclusões de cada um dos grupos, que agora se dão à estampa, bem como os textos referentes às conferências proferidas.

Estamos certos de que este será mais um importante contributo para a reflexão sobre o significado dos principais conceitos usados na terminologia dos riscos.

Coimbra, 14 de dezembro de 2014

Luciano Lourenço

Fantina Tedim

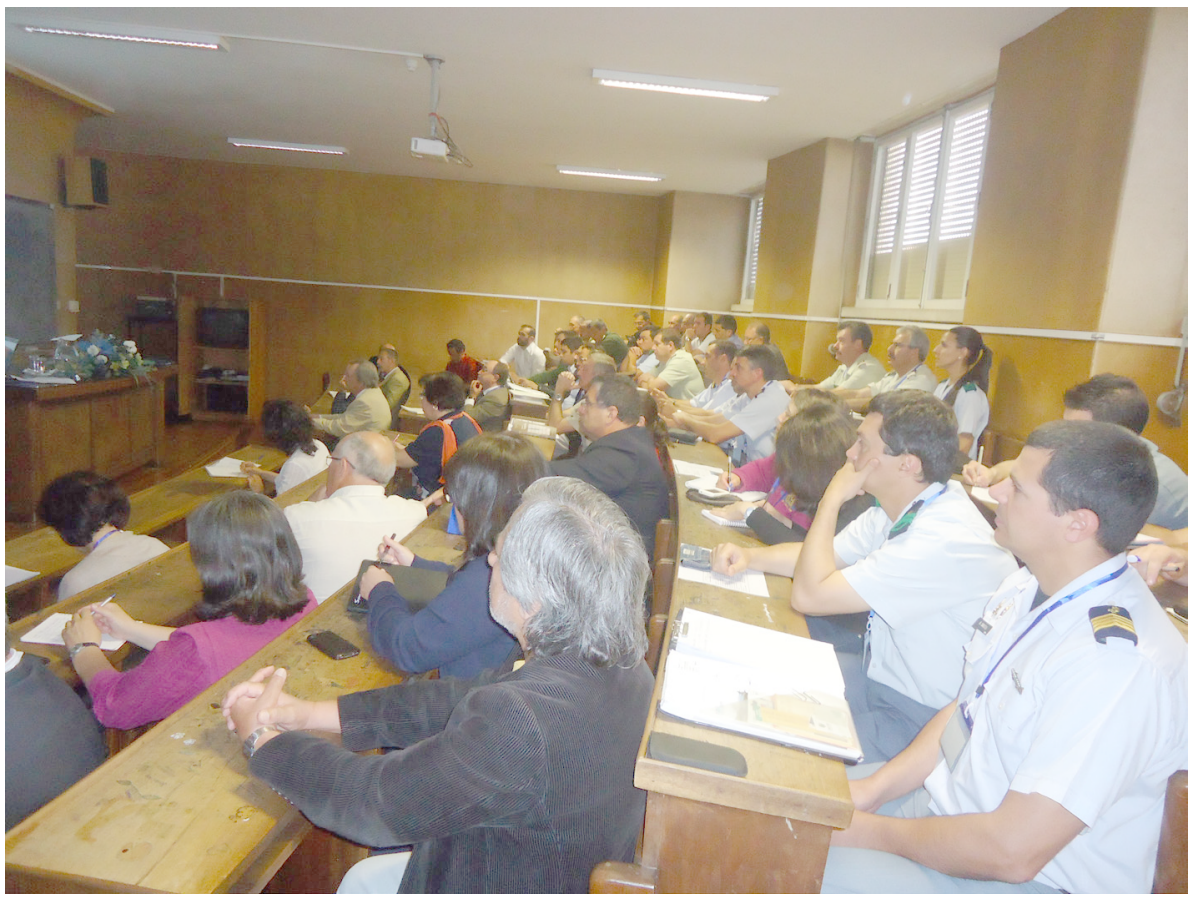




\title{
Capítulo I \\ TERMINOLOGIA DO RISCO. \\ ORIGENS, DIFICULDADES DE TRADUÇÃO E BOM SENSO
}

\author{
Fernando Rebelo \\ Professor Jubilado de Geografia da FLUC \\ Colaborador do CEGOT
}

\section{Introdução}

O termo risco, no sentido mais próximo do que se the atribui hoje, começa a ser utilizado em ligação com a vida do mar sendo que os mais antigos documentos referindo "risco" ou "rischio" foram produzidos no século XIII, em Génova (C. VILLAIN-GandossI, 1990). As fortes ligações estabelecidas entre navegadores e cartógrafos do Mediterrâneo e de Portugal, que desde o início do período das Descobertas se revelaram muito importantes, poderão relacionar-se com o facto, de por vezes, se afirmar que foram os navegadores portugueses que ensinaram a palavra risco aos ingleses, no século XVI.

Primeiro, associavam-se risco e fortuna, risco e perigo, risco e seguro. Só muito recentemente, parece terem-se associado risco e crise, tal como risco e catástrofe.

\section{Risco, perigo e crise}

O mais complexo painel sobre risco que tive a oportunidade de observar esteve exposto durante algum tempo em São Pedro de Moel, no início da estrada litoral de S. Pedro para a Nazaré, na área das matas nacionais. Fotografei-o em 2006 (fot. 1).

Tratava-se de uma quase transcrição de elementos constantes em diploma legal (Decreto Lei $156 / 2004$, de 30 de junho), no qual se dava ao termo risco uma aceção demasiado ampla, que incluía a noção de perigo e, de certo modo, até a de crise, estabelecendo-se uma série de proibições que, rapidamente, na sua maioria, se mostravam descabidas. Por exemplo, proibir o acesso, a circulação e a permanência de pessoas naquela estrada, ou noutra de caraterísticas semelhantes, no "período crítico" definido, ou seja entre 1 de julho a 30 de setembro, no caso de risco máximo de incêndio, poderia corresponder à interdição de acesso a residências, na sua maioria de férias, e de praias, dias seguidos. Claro que no caso de o risco se ter manifestado em incêndio de grandes proporções, haveria lugar a essas interdições durante o período de combate. Mas, aí, já se estaria a falar em crise. 0 perigo, que deveria levar ao deslocamento para o local de meios para combate se tal viesse a ser necessário, não justificaria tão duras interdições. Será que a noção de perigo também aí estava envolvida? Estaria aí incluída toda a sequência temporal do risco embora não se fale expressamente em crise? Estaria, portanto, o risco considerado no seu sentido mais amplo?

Muito mais fácil de ler e entender, todavia, é um dos painéis mais conhecidos nas estradas próximas de florestas portuguesas ou mesmo em estradas que as atravessam e que se assume com o título de "Risco de incêndio florestal".

Fotografei um deles (fot. 2) no mesmo verão em que fotografei o anterior (2006).

A simples existência deste painel indica a presença de um risco de incêndio florestal, o que muito bem se compreende pelo facto de estarmos numa área arborizada, com verões de caraterísticas mediterrâneas, quentes e quase sem chuva. Mas o painel em causa permite a indicação do grau de risco que, no caso concreto, será tanto maior quanto mais elevadas forem as temperaturas, mais baixas as humidades relativas e mais fortes os ventos secos de leste. Daí que os graus previstos sejam reduzido, moderado, elevado, muito elevado e máximo. Será que o risco máximo, só por si, indica uma situação de perigo? 


\section{Realidades e desafios na gestão dos riscos \\ - Diálogo entre ciência e utilizadores -}

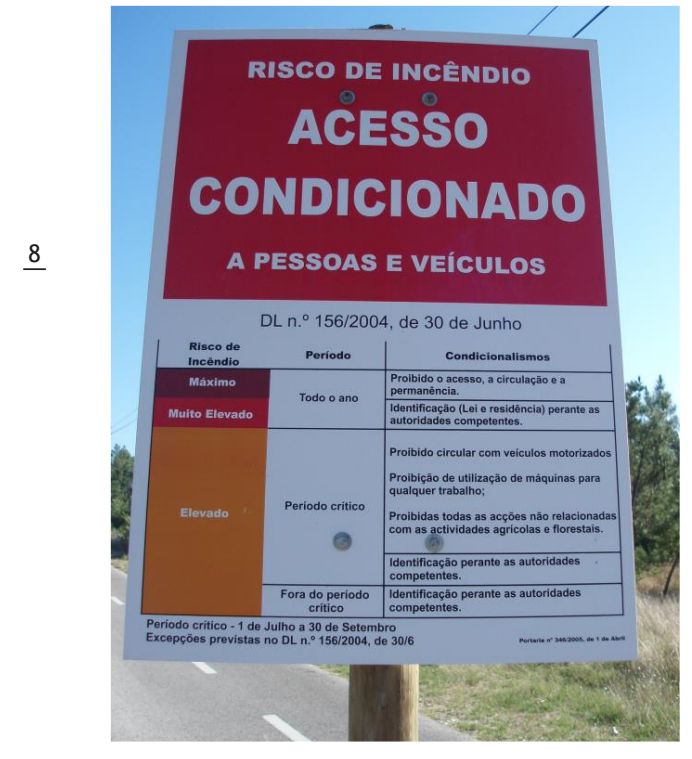

Fot. 1 - Risco de incêndio florestal? Painel regulador localizado em S. Pedro de Moel no verão de 2006.

Alguns anos antes, no centro do Canadá, em área de clima continental seco, com verões curtos, mas relativamente quentes e com pouca chuva, tinha visto um painel semelhante (fot. 3), embora apenas com quatro graus de intensidade do risco: "low", "moderate", "high" e "extreme" (F. Rebelo, 2001 a).

Em vez de 5 graus de intensidade do risco, este painel canadiano tinha 4, mas a designação "fire hazard" talvez levasse alguns cientistas a equacionarem a má tradução dos equivalentes painéis em português, na medida em que optaram por outros termos, com grande frequência para "perigosidade". A verdade, porém, é que, posteriormente, também vi painéis intitulados "risco de incêndio" no Brasil, Estado de Goiás, em pleno "cerrado", tal como anteriormente tinha visto painéis intitulados "riesgo de fuego forestal" nas Canárias, ilha de Tenerife. Curiosamente, nestes dois exemplos, tal como no da floresta canadiana, não havia casas por perto. Tudo era bosque ou floresta, com o seu próprio valor económico e ambiental.

"Hazard" e risco aparecem aqui com o mesmo significado. No entanto, ainda há casos em que o mesmo significado aparece ligado a outro termo.

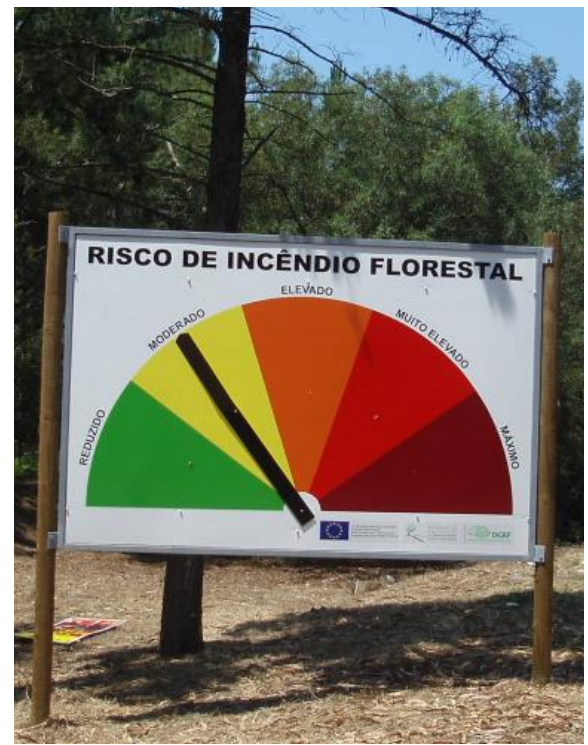

Fot. 2 - Painel intitulado "Risco de incêndio florestal”, fotografado na área de Dunas de Mira em 2006 e ainda em utilização (2014).

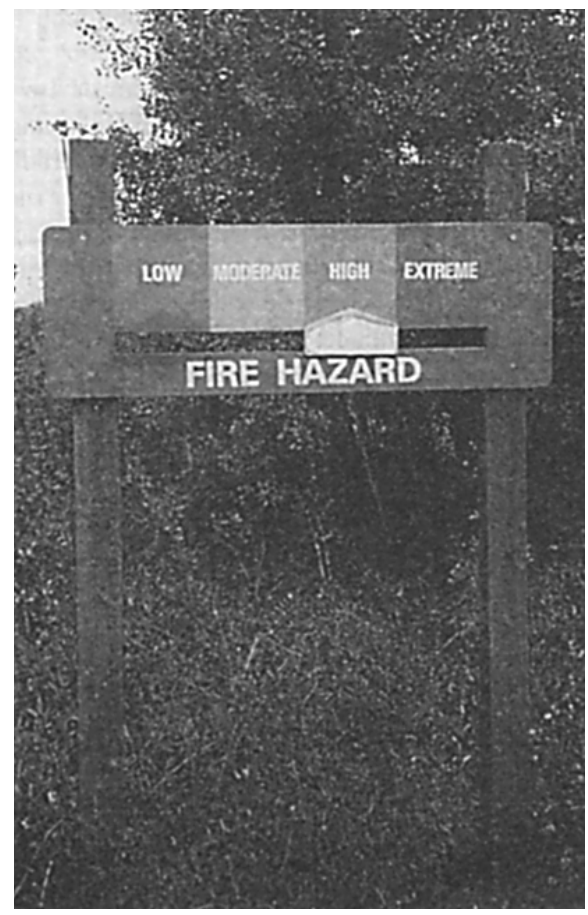

Fot. 3 - Painel informativo do mesmo tipo do da fotografia anterior (extraído de F. ReBELo, 2001). 
A cidade de Coimbra, para além de elevados e dispersos riscos de incêndio urbano, também apresenta riscos de incêndio de interface urbano-florestal e mesmo de incêndio florestal. Não é de admirar que, por exemplo, este risco se coloque na Mata do Jardim Botânico da Universidade de Coimbra, onde, depois de um longo período de proibição de passagem ao público, se achou, e bem, que as pessoas deveriam ter a hipótese de usufruir do ambiente criado por uma floresta de grande beleza, que pode considerar-se urbana. Quando aconteceu poder visitá-la livremente, encontrei um pequeno painel alertando para "perigo de incêndio" (fot. 4). Perguntei a mim próprio qual seria o motivo para utilizar a palavra perigo ("danger", em francês ou em inglês) quando os serviços oficiais preferiam risco.

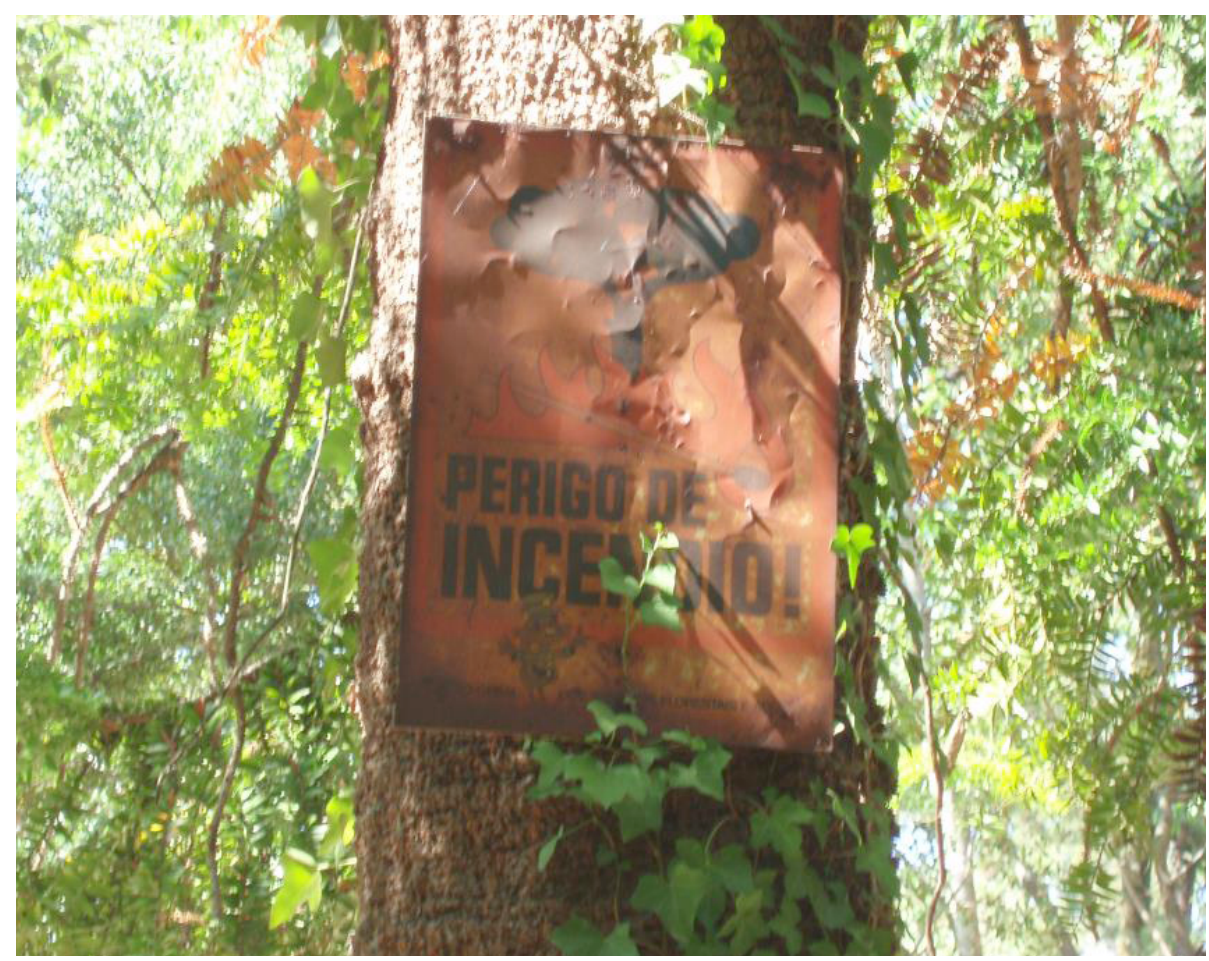

Fot. 4 - Painel intitulado "Perigo de incêndio", fotografado na Mata do Jardim Botânico da Universidade de Coimbra em 2012.

Haverá diferenças entre "hazard" (ou "aléa", seu equivalente em francês) e risco ("risk", em inglês, ou "risque" em francês)? E entre "hazard" e perigo. Será tudo a mesma coisa? Nos exemplos analisados, verifica-se que se trata do mesmo problema - nos locais referidos há possibilidade de se desencadear um incêndio.

Os estudos comparativos sobre a utilização de termos para significar esta possibilidade, especialmente em França, mas também noutros países europeus, como por exemplo em Portugal, demonstraram que a palavra risco era quase sempre utilizada para referir a probabilidade de ocorrência de um acontecimento danoso, que a palavra perigo se utilizava para situações de grande proximidade da manifestação de um risco e que a palavra crise era frequentemente utilizada nas situações de manifestação completa de um risco, fora do controlo do Homem (L. Faugères, 1990, 1991; F. Rebelo, 1995, 1997, 2001 a, 2003, 2005, 2010; L. Lourenço, 2008, entre outros) 


\section{Realidades e desafios na gestão dos riscos \\ - Diálogo entre ciência e utilizadores -}

\section{Sinais de perigo}

Quando se fala em risco, fala-se em algo de danoso para o homem ou para as suas realizações que pode acontecer - associam-se então termos como possibilidade ou probabilidade. Quando se fala em perigo, fala-se de um risco devidamente identificado, estudado, analisado, que pode estar muito perto de se manifestar, causando danos - e isso deduzir-se-á do facto de já existirem sinais.

No caso do risco de incêndio, o sinal de perigo poderá ser a observação de uma coluna de fumo na floresta - as pessoas das proximidades ou os responsáveis pela vigia dos fogos, apercebendose, darão o alarme para que uma primeira intervenção elimine o problema o mais depressa possível. Assisti a casos em que um helicóptero levantava voo imediatamente com profissionais aptos a resolver o problema.

Sinais de perigo encontram-se nas estradas, alertando para curvas, lombas, cruzamentos, perdas de prioridade, obras, etc., que se consideram suscetíveis de originar a manifestação de riscos inerentes à utilização das estradas, acidentes mais ou menos graves (crises). Os responsáveis pelas estradas apercebem-se de que nesses locais os automobilistas têm de reduzir a velocidade para que a crise não aconteça.

Em Portugal, com os seus $848 \mathrm{~km}$ de costa marítima e os seus verões claramente mediterrâneos (O. Ribeiro, 1963; F. Rebelo, 2013), há dias que convidam ao banho de mar desde que se veja um pouco de areia disponível para uma paragem e alguma descontração; mas nem sempre há longas praias de areia - muitas vezes a areia é pouca e encontra-se na base de arribas.

As arribas podem ser de grande beleza, atraindo também os turistas para caminhadas de observação e sessões de fotografia. 0 risco de desabamentos de pequenas ou de grandes dimensões está presente. Frequentemente, este risco parece estar quase a manifestar-se. Mesmo consciente do risco, nem sempre o turista se apercebe das fendas, apesar de visíveis, donde se soltam pedaços de pedra e, a qualquer momento, por falta de base de apoio, podem desencadear-se movimentos suscetíveis de ferir ou matar pessoas. Não faltam exemplos concretos de quedas individuais de pedras, tanto como de grandes desabamentos, ocorridos um pouco por todo o lado, às vezes, nas mais belas arribas do litoral, tanto ocidental, como meridional, de consequências por vezes dramáticas. Há casos de turistas que são atingidos quando deitados na praia, tal como casos de turistas que caem pela arriba envolvidos no desabamento. Por isso, para prevenir a crise, têm-se multiplicado os painéis de aviso.

Alguns, são muito simples na explicação - "arribas instáveis" - e eficazes no conselho "mantenha uma distância de segurança". No caso da Praia da Marinha, no Algarve (fot. 5), são especialmente importantes para os turistas estrangeiros que, na maior parte do ano, ali estacionam os carros para fazerem percursos a pé pelo limite superior das arribas. Outros painéis, de nova geração, são cientificamente confusos, por sugerirem traduções incorretas, e de eficiência discutível, por estarem mal colocados. Começam a ver-se muito pelo Algarve, tendo-os observado, em especial, nas praias da Galé e da Oura, perto de Albufeira. Neste último local (fot. 6) o painel diz "perigo" e logicamente traduz por "danger". Mas no seu lado esquerdo também diz "perigo" que traduz então por "hazard". Porque não "risco" de desmoronamento? E onde está o perigo se por trás está uma esplanada e o painel assenta numa descida suave em areia coberta com vegetação? A fotografia aérea do conjunto mostra arribas, representadas de um e de outro lado da praia, mas para lá chegar é necessário andar largas dezenas de metros.

Outros painéis são mais completos, parecendo dirigir-se em especial aos turistas nacionais, em regra mais distraídos ou talvez mais aventureiros. Na realidade, desde há muito que se sabe que o português é aventureiro por natureza. Julieta Lamber ADAM (1896), citada por J. L. de Vasconcelos (1958), dizia textualmente "Les Portugais sont braves jusqu'à la témérité". Talvez por isso, em vez de conselhos, dão-se-lhes ordens - "Não aproximar" (fot. 7) - e até se acrescenta a expressão "ZONA INTERDITA" (fot. 8). 


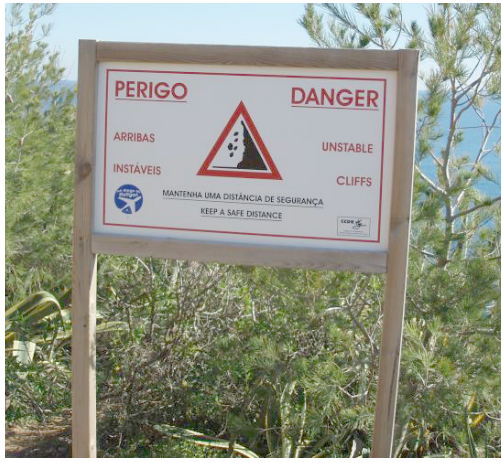

Fot. 5 - Praia da Marinha, Algarve (1 janeiro de 2006).

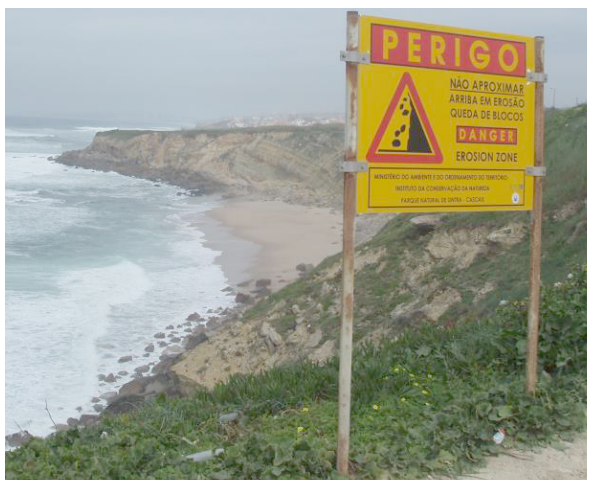

Fot. 7 - Praia Grande, Sintra (março de 2007).

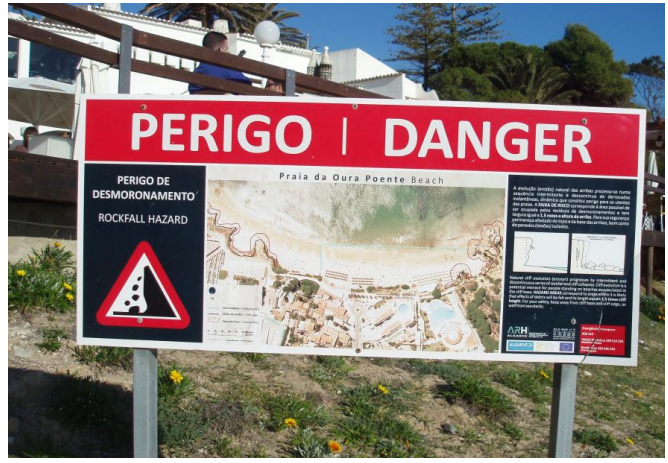

Fot. 6 - Praia da Oura, Algarve (junho de 2011).

\section{Prevenir a crise com mais do que simples avisos de perigo}

$\mathrm{Na}$ costa ocidental portuguesa, a Nazaré pode ser o caso de estudo mais interessante para se falar de prevenção de risco, subentendendo-se que esta expressão significa na realidade prevenção da crise. Na realidade, o que se pretende é evitar que o risco se manifeste, ou que, manifestando-se, não provoque vítimas, reduzindo-se eventuais danos ao mínimo possível (F. Rebelo, 2012).

São facilmente observáveis os vestígios de grandes e de pequenos desabamentos na arriba do chamado "promontório" da Nazaré. As cornijas calcárias do Sítio dominam a praia, "ameaçando-a". Para baixo, os riscos são também muito evidentes, mesmo para quem nada perceba de geologia e de geomorfologia (fot. 9).

Assim, além dos tradicionais avisos de perigo, a crise previne-se aqui mais eficazmente com outros três tipos de ações - trabalhos de engenharia civil (fot. 10), trabalho de demarcação de áreas perigosas (fot. 11) e até simples trabalhos de silvicultura ou de simples jardinagem.

A demarcação de áreas perigosas através de estacaria no caso da arriba do promontório da Nazaré foi acompanhada com a criação de uma duna artificial, paralela à estacaria e à arriba, que dificultará um eventual movimento de blocos até às estacas. Mesmo assim, na época de mais forte procura por banhistas, apesar da eficácia para a maioria, alguns não respeitam as indicações (fot. 12). 


\section{Realidades e desafios na gestão dos riscos \\ - Diálogo entre ciência e utilizadores -}

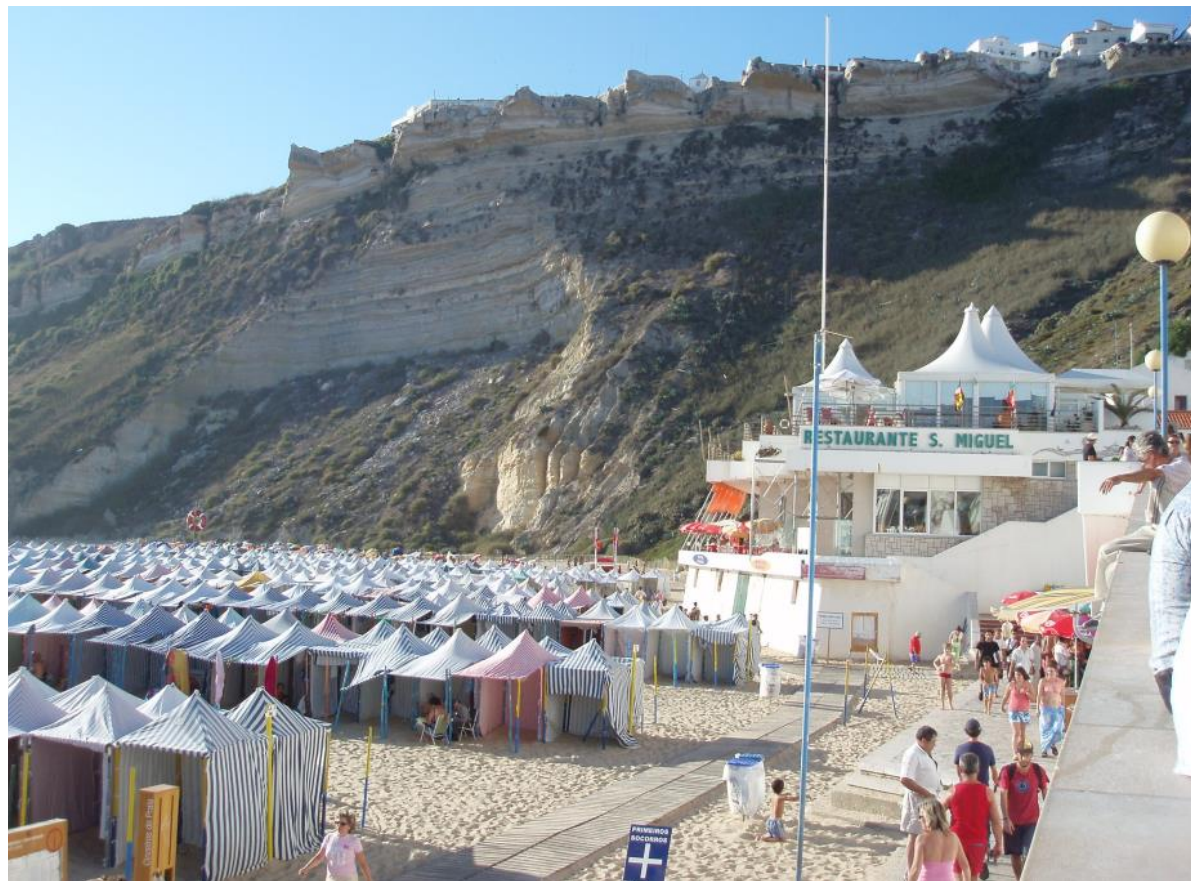

Fot. 9 - Praia da Nazaré (2006). Abaixo da cornija calcária do Sítio, salienta-se a grande cicatriz de arranque de um antigo deslizamento com desabamentos associados e ravinas laterais profundas.

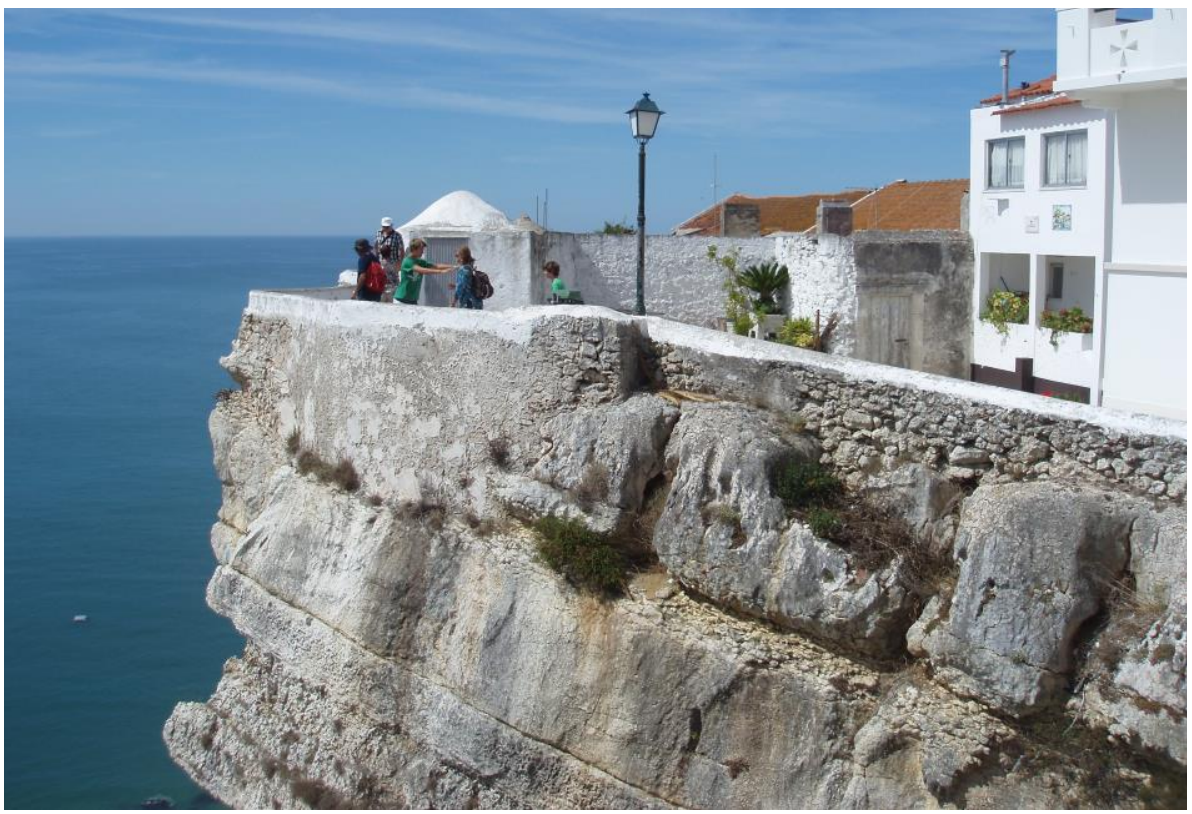

Fot. 10 - Sítio da Nazaré (2012). Alguma consolidação com cimento para prevenção de queda de pequenos blocos e proteção de habitantes e turistas. 
Terminologia do risco.

Origens, dificuldades de tradução e bom senso

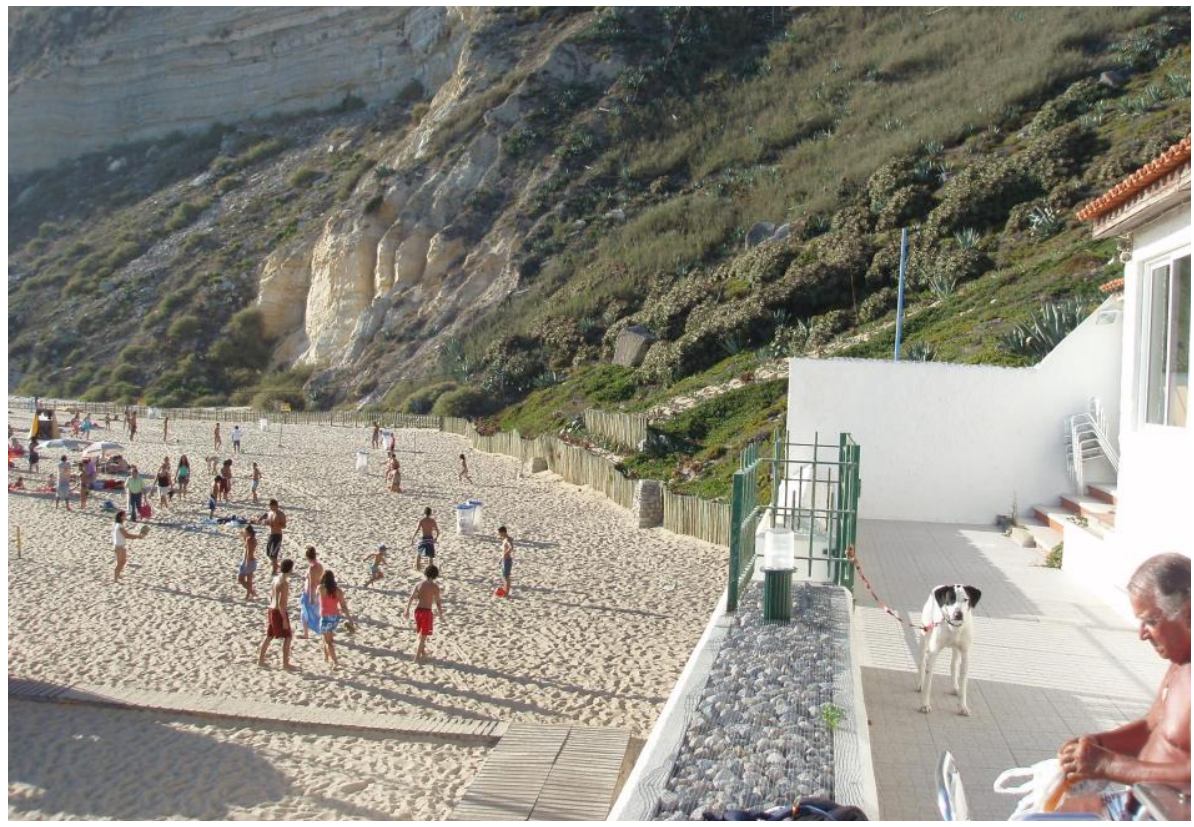

Fot. 11 - Praia da Nazaré (2006). Alinhamento de estacas delimitando a área considerada perigosa.

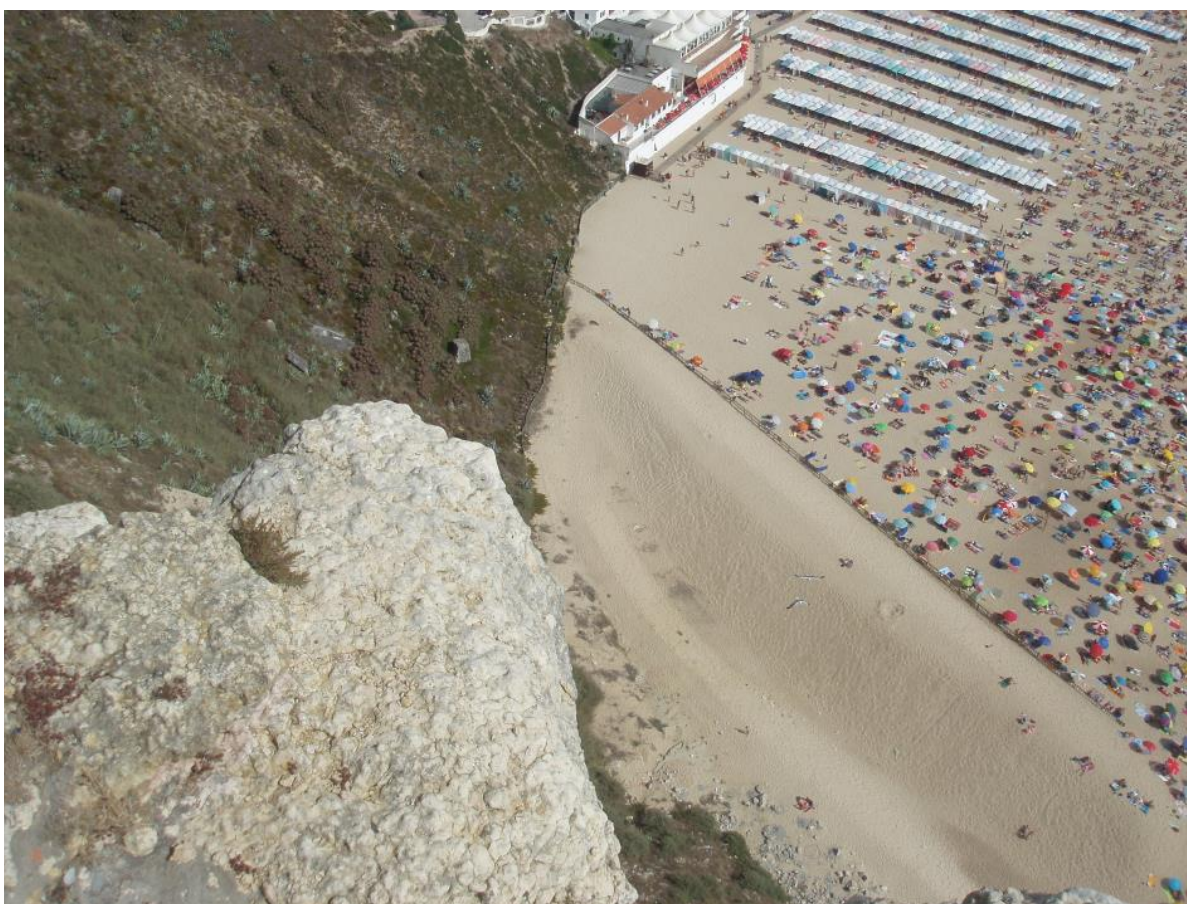

Fot. 12 - Praia da Nazaré no dia 10 de agosto de 2010 - a estacaria de prevenção para desabamentos funciona para a maioria dos banhistas. 


\section{Realidades e desafios na gestão dos riscos \\ - Diálogo entre ciência e utilizadores -}

Por outro lado, a proteção contra movimentos de vertente que mais se pode observar nas nossas estradas corresponde à colocação de pedras em blocos paralelepipédicos criados por redes de arame resistente, encostados a barreiras desequilibradas pelo trabalho humano. A sua eficácia nem sempre é a desejável, como, infelizmente já é possível observar em algumas barreiras de estrada. Mesmo assim, por vezes exige-se-lhes muito, como num caso urbano, observado em Mora, Alentejo, onde têm por finalidade defender um conjunto de casas demasiado próximas de uma barreira (fot. 13).

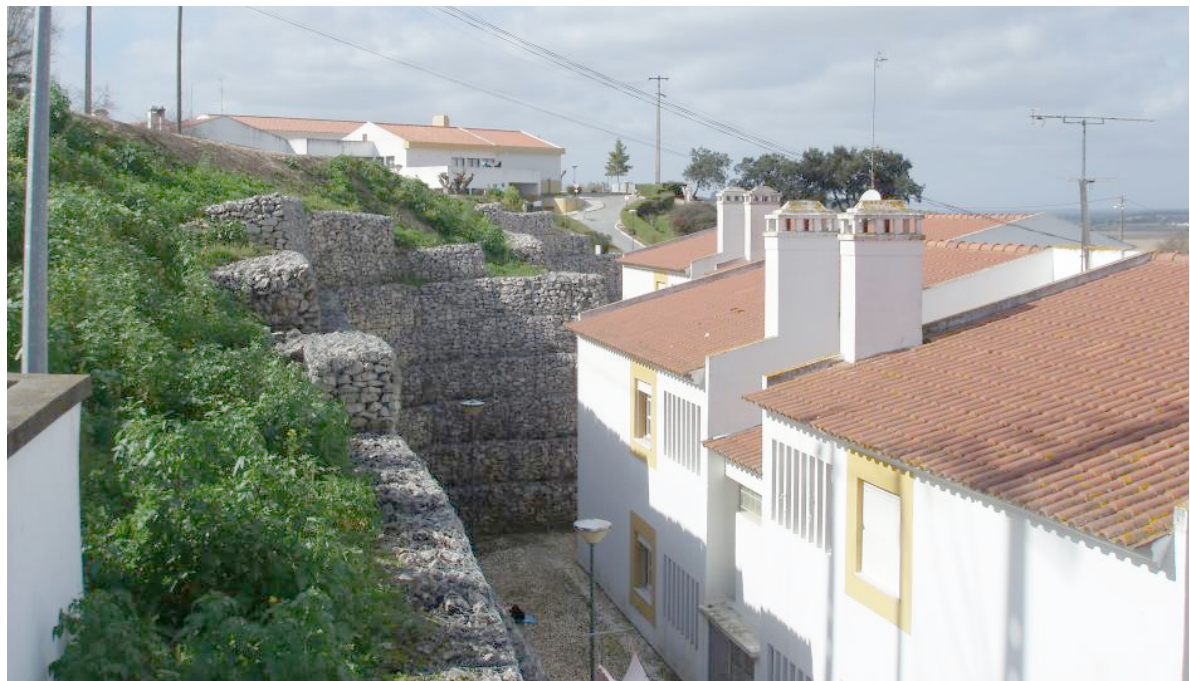

Fot. 13 - Mora (fevereiro 2007) - prevenir crises que possam ser provocadas por deslizamentos ou desabamentos.

Um outro caso, aliás bem conhecido, na cidade do Porto (F. ReBeLo, 2001 b), corresponde a uma construção basicamente em cimento, que tem servido, desde há anos, como proteção relativamente à queda de blocos de granito que ocorria com certa frequência sobre um dos passeios da Rua da Restauração (fot. 14).

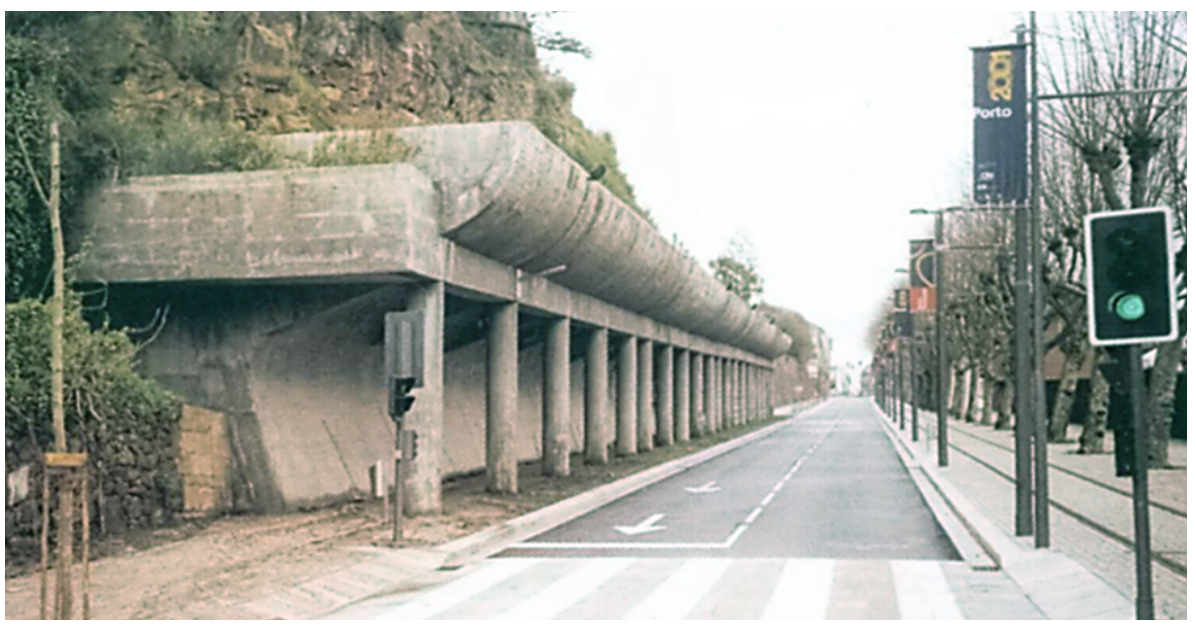

Fot. 14 - Rua da Restauração, Porto - prevenir crises provocadas por desabamentos (obras terminadas em janeiro de 2001 - fotografia extraída de F. Rebelo, 2001 b). 
Mas há proteções bem mais complexas, com intervenções diversas, utilizando redes de arame, barras de ferro e cimento, como é possível observar, num dos casos mais interessantes e minuciosos, na arriba de Ponta do Sol, na ilha da Madeira (fot. 15), prevenindo a queda de calhaus e blocos de dimensões variadas sobre a estrada marginal.

Aengenharia civil tem vindo a estudar soluções cada vez mais eficazes para prevenir crises provocadas por deslizamentos, desabamentos ou simples quedas de pedras em vertentes naturais ou barreiras artificiais. Em todos os casos há fenómenos naturais que podem já ter ocorrido nos locais em causa ou que se deduz que possam vir a ocorrer, seja através de conclusões tiradas de análises de risco, seja após a perceção de situações de perigo, a partir de sinais claros da proximidade da manifestação completa do risco.

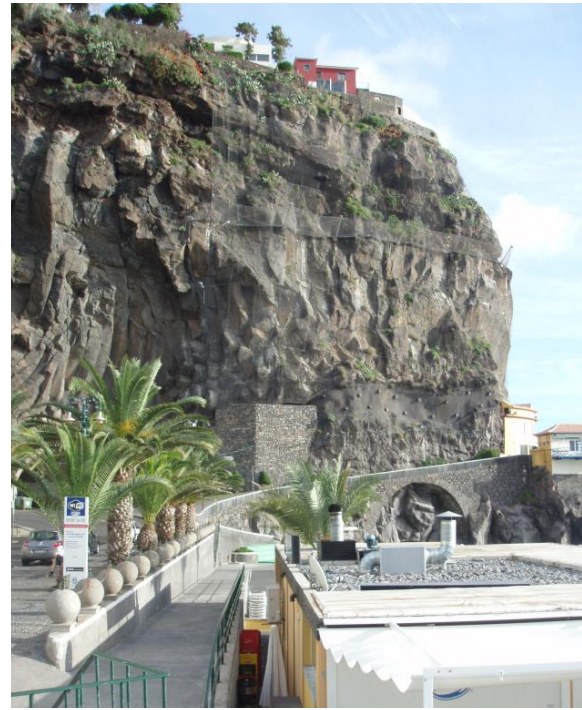

Fot. 15 - Ponta do Sol, Madeira (2009) - arriba basáltica, com elementos frágeis, totalmente trabalhada por obra de proteção complexa, tendo em vista prevenir crises provocadas por desabamentos.

\section{Conclusão - Riscos e vulnerabilidades? Riscos e catástrofes?}

Vai sendo habitual encontrar expressões como estas em títulos de trabalhos, não na forma de dúvida, mas como afirmação.

Keith SMITH, embora aceitasse que "hazard" podia ser tomado como sinónimo de risco (K. SMITH, 2001), o que resolvia o problema já acima tratado da equivalência entre "fire hazard" e "risco de incêndio", definia bem as diferenças entre as duas noções - "hazard" é o processo potencialmente perigoso, risco aparece com uma maior complexidade porque inclui a componente vulnerabilidade. André DAUPHINÉ definiu o risco como uma relação entre "aléa" ("hazard") e vulnerabilidade, relação que depende do problema analisado DAUPHINÉ (2001), ou seja, o risco aparece como função do "aléa" (processo potencialmente perigoso) e da vulnerabilidade (caraterísticas da presença do homem). Na verdade, quando se estudam manifestações de riscos de grandes proporções vão encontrar-se, para a mesma força do processo ou processos envolvidos as consequências são mais graves em certas áreas e menos graves noutras. Sem a isso se referir, André DAUPHINÉ juntava sob a designação de vulnerabilidade tanto as caraterísticas da população como aquilo que agora se vai definindo como a exposição ao risco dessa mesma população. Na realidade, a exposição ao risco é um dos muitos aspetos que ajuda a definir a vulnerabilidade

A noção de risco contém, portanto, a noção de vulnerabilidade, não sendo desde há muito legítimo falar em risco e vulnerabilidade como se fossem noções diferentes perfeitamente separáveis.

Quanto à associação riscos e catástrofes o problema tem outras implicações. Seguimos atrás a sequência temporal do risco - risco, perigo, crise. Só há risco porque pode ocorrer uma crise. Mas uma crise pode corresponder a um pequeno acidente ou a uma grande catástrofe. Quantos exemplos se poderiam dar em termos naturais ou em termos tecnológicos. A pedra que cai da arriba e atinge o banhista pode feri-lo mais ou menos gravemente, mas a vertente que numa região montanhosa desliza sobre uma cidade pode matar milhares de pessoas. 0 automóvel que não reduz a velocidade perante um sinal de perigo de curva perigosa, pode seguir em frente e ter um acidente, ferindo-se o seu condutor, mas se o mesmo acontecer com um autocarro 


\section{Realidades e desafios na gestão dos riscos \\ - Diálogo entre ciência e utilizadores -}

cheio de gente podem morrer dezenas de pessoas. Há graus a considerar quando se trata de crises. Se, em Portugal, Espanha e França, há alguns anos atrás, fôssemos ler os jornais diários encontraríamos sempre referência a muitos acidentes, alguns desastres, raras catástrofes.

A pouca utilização do termo crise, salvo no que diz respeito a economia e finanças, vem contrastando com o uso excessivo das designações catástrofe ou desastre. A catástrofe que, para alguns autores, exige um mínimo de 100 vítimas mortais, para outros é apenas sinónimo da manifestação de um risco, o que não pode considerar-se correto. 0 desastre, que para uns, mais influenciados por escolas europeias, é uma crise com menos de 100 mortos, para outros, mais influenciados por escolas americanas, aparece como uma catástrofe de grandes dimensões. Em Portugal, fala-se em acidente, por exemplo, quando se cai de uma bicicleta motorizada, em acidente grave quando há feridos ou mesmo mortos num choque de automóveis, mas muitas vezes aqui já se diz também desastre de automóvel; no entanto, se é um avião de passageiros que se despenha e morrem todos os passageiros, quase ninguém deixa de falar numa catástrofe aérea, embora alguns comecem a preferir falar de desastre aéreo.

Nota-se já alguma confusão nas notícias do dia a dia, mas especialmente nas revistas científicas - tudo é desastre... por influência do estudo por livros escritos em inglês.

Curiosamente, A. Dauphiné (2001) prefere dizer catástrofe em vez de crise. Daí cair numa contradição. Na escala das catástrofes quanto ao número de vítimas começa por apresentar 7 níveis (p. 34). Depois (p. 36) na escala sintética das catástrofes reduz tudo a 5 níveis - acidente $(0$ a 9 mortos), desastre (10 a 99), catástrofe (100 a 9999$)$, catástrofe maior (10 000 a 99999$)$ e super catástrofe (> 100000$)$. Um acidente ou um desastre pode ao mesmo tempo ser uma catástrofe?

"A mais importante ferramenta de um geógrafo é a sua língua", dizia Alfredo Fernandes MARTINS aos seus alunos na Universidade de Coimbra. Acrescentarei que a maior riqueza de um povo é a sua cultura. A língua faz parte da cultura. Os povos têm de aprender a respeitar as culturas uns dos outros. Por isso, não será nada de grave utilizar uma palavra estrangeira quando não temos uma claramente equivalente na nossa cultura. Nisto, os músicos deram-nos grandes lições. É também uma forma de respeito.

\section{Referências bibliográficas}

Adam, Julieta Lamber (1896) - La Patrie Portugaise. Paris.

DAUPHINÉ, André (2001) - Risques et Catastrophes. Observer - Spatialiser - Comprendre - Gérer. Paris, Armand Colin, 288 p.

Faugères, Lucien (1990) - "La dimension des faits et la théorie des risques". Le Risque et la Crise, Malta, Foundation for International Studies, p. 31-60.

Faugères, Lucien (1991) - "La Géo-Cindynique, Géo-Science du Risque”. Bull. Assoc. Géogr. Français, Paris, 3, p. 179-193.

Lourenço, Luciano (2008) - “'Perigos' das 'cartas de risco'. Comentários ao modelo proposto no Guia Técnico para Elaboração do PMDFCl”. Territorium, 15, p. 122-126. Disponível em: http://www.uc.pt/fluc/nicif/riscos/Documentacao/Territorium/T15_artg/T15NNR11.pdf.

ReBelo, Fernando (1995) - "Os conceitos de risco, perigo e crise e a sua aplicação ao estudo dos grandes incêndios florestais". Biblos, Coimbra, 71, p. 511-527.

REBELo, Fernando (1997) - "Risco e crise nas inundações rápidas em espaço urbano. Alguns exemplos portugueses analisados a diferentes escalas". Territorium, Coimbra, 4, p. 29-47. Disponível em: http://www.uc.pt/fluc/nicif/riscos/Documentacao/Territorium/T04_artg/T04_ Artg04.pdf.

Rebelo, Fernando (2001 a) - Riscos Naturais e Acção Antrópica. Coimbra, Imprensa da Universidade, $274 \mathrm{p}$. 
Terminologia do risco.

Origens, dificuldades de tradução e bom senso

Rebelo, Fernando (2001 b) - "Os movimentos em massa na perspectiva da teoria do risco". Revista Técnica e Formativa ENB, Escola Nacional de Bombeiros, 5 (17), p. 7-15.

Rebelo, Fernando (2003) - Riscos Naturais e Acção Antrópica. Estudos e Reflexões, $2^{\mathrm{a}}$ edição revista e aumentada. Coimbra, Imprensa da Universidade, 286 p.

Rebelo, Fernando (2005) - Uma Experiência Europeia em Riscos Naturais. Coimbra, MinervaCoimbra, 123 p. +23 fotografias a preto e branco

Rebelo, Fernando (2010) - Geografia Física e Riscos Naturais. Coimbra, Imprensa da Universidade, $215 \mathrm{p}$.

Rebelo, Fernando (2012) - "Crises e catástrofes (ditas) naturais. Reflexões a partir de alguns exemplos portugueses". Biblos, $2^{\text {a }}$ Série, 10, p. 131-153.

Rebelo, Fernando (2013) - Portugal. Geografia, Paisagens e Interdisciplinaridade. Coimbra, Imprensa da Universidade de Coimbra, $170 \mathrm{p}$.

RibeIRo, Orlando (1963) - Portugal, o Mediterrâneo e o Atlântico. Lisboa, Livraria Sá da Costa, $2^{\text {a }}$ edição, revista e actualizada, 176 p. + VI mapas (1 ${ }^{\text {a }}$ edição, Coimbra, 1945).

SмITH, Keith (2001) - Environmental Hazards. Assessing Risk and Reducing Disaster. Third Edition. Routledge, London and New York.

VAsconcellos, José Leite de (1958) - Etnografia Portuguesa. Vol. IV. Lisboa, Imprensa Nacional. $671 \mathrm{p}$.

VIllain-Gandossi, Christiane (1990) - "Origines du concept de risque en Occident. Les risques maritimes ou fortune de mer et leur compensation: les débuts de l'assurance maritime". Le Risque et la Crise, Malta, Foundation for International Studies, p. 71-84.

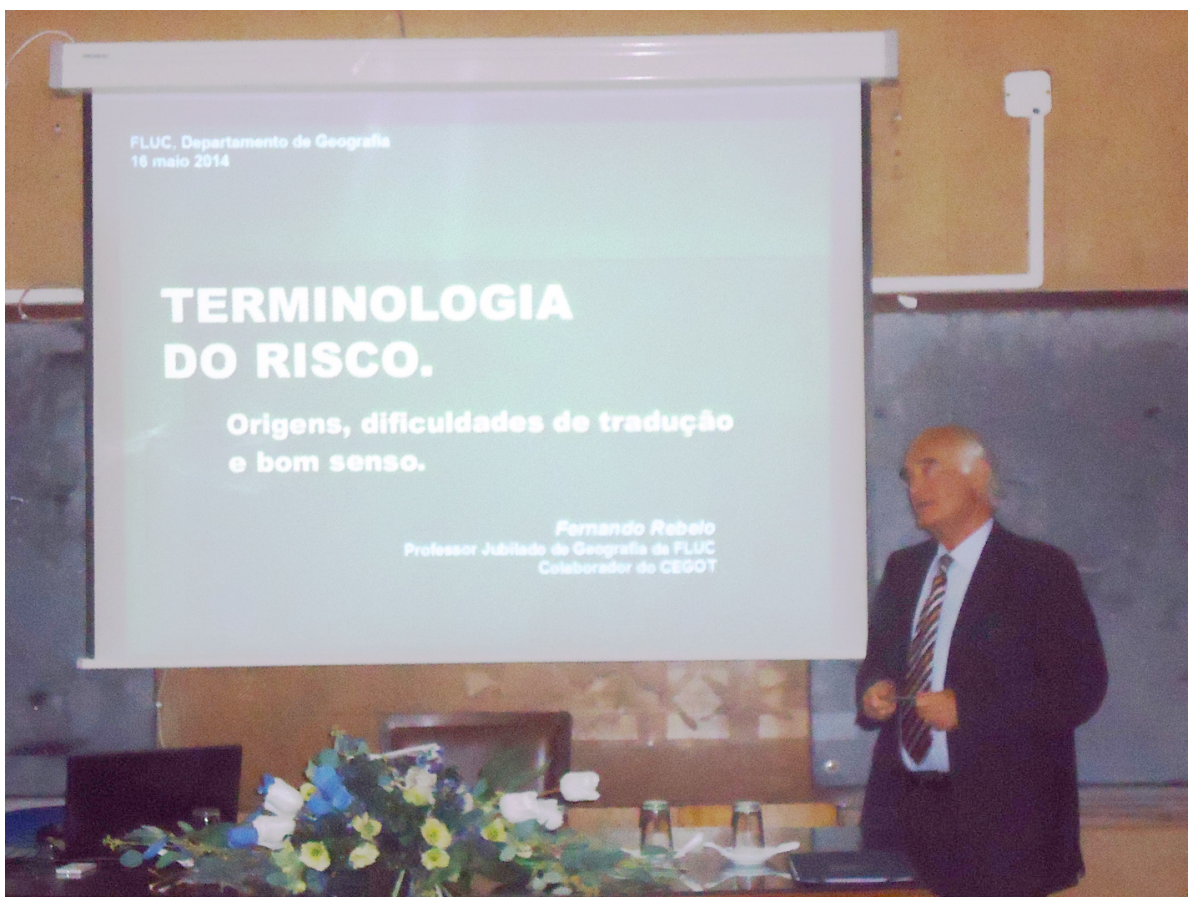





\title{
Capítulo II \\ GESTÃO DO RISCO E DA INCERTEZA. \\ CONCEITOS E FILOSOFIA SUBJACENTE
}

\author{
A. Betâmio de Almeida \\ Instituto Superior Técnico \\ Universidade de Lisboa \\ betamio.almeida@ist.utl.pt
}

\section{Apresentação}

0 conceito de risco é relativamente recente mas tem, atualmente, um lugar privilegiado na Sociedade contemporânea. Há um razoável consenso em considerar a época do Renascimento, das descobertas e do comércio marítimo de longo curso, como um marco na consolidação inicial da análise de riscos. Na Idade Moderna, uma catástrofe numa capital europeia, o terramoto de 1755 em Lisboa, suscitou na Europa um debate de ideias sobre a providência e o destino. 0 evento fez desencadear, por parte do poder político, um conjunto de medidas para atenuar os efeitos sociais e ações de proteção contra a atuação futura de sismos. As decisões então tomadas podem ser consideradas como um exemplo histórico de resposta a uma calamidade natural e uma primeira organização de gestão de crise (A. ALMEIDA, 2005).

Controlar o risco sob diversas formas, gestão, análise, avaliação, mitigação ou tratamento, entre outras, tornou-se agora um ato normal, quase indispensável numa governança adequada. Podemos já perguntar-nos como poderíamos enfrentar o presente e o futuro sem estes instrumentos operacionais.

A proteção contra os perigos que possam afetar o público ou o ambiente passou a constituir um direito reconhecido e exigido pela opinião pública e um indicador da qualidade de vida e de cidadania. Da aceitação resignada dos acontecimentos passou-se para uma fase de intervenção dos cidadãos e dos Estados na regulação da vida e de atividades públicas e privadas, em defesa da saúde e segurança públicas. É reconhecida uma crescente responsabilização social pelos efeitos resultantes do impacto dos diferentes perigos, de origem natural ou antrópica. Os poderes políticos passaram também a instrumentalizar o conceito de risco como um dispositivo de apoio ao controlo da sociedade e um dispositivo complementar ao da segurança.

Em Portugal, a divulgação e a promoção da análise e gestão de riscos teve um incremento relevante a partir da década de 90 do século XX (e.g. A. Almeida e T. VISEu, 1997; A. AlmeidA et al., 2003; F. Rebelo, 2003; L. LouRenço, 2004). Atualmente, a gestão de riscos é encarada como um processo de atuação eficaz para responder a perigos e incertezas nos mais variados domínios da Sociedade.

Muito associado ao risco é o conceito de vulnerabilidade que caracteriza a potencialidade de perda resultante do impacto de um evento perigoso num determinado património. Em determinadas circunstâncias e condições de incerteza, a estimação das probabilidades pode tornar problemática a credibilidade ou validade de uma análise quantitativa do risco. Nestas circunstâncias, a análise e gestão de vulnerabilidades pode constituir uma alternativa adequada e eficaz.

O conceito de incerteza, por seu turno, por acompanhar sempre o nosso conhecimento incompleto, nomeadamente o relativo aos sucessivos "futuros", foi sempre reconhecido como um ónus permanente que se pretende evitar e que, durante muito tempo, foi sendo frequentemente ignorado. Pelo objeto e natureza da análise dos riscos, a incerteza nos resultados e nos elementos que servem de base a decisões no âmbito da gestão dos riscos pode ser muito significativa e ter consequências importantes.

Nesta comunicação apresenta-se uma síntese de algumas questões relevantes colocadas pelos conceitos do risco, vulnerabilidade e incerteza. 


\section{Realidades e desafios na gestão dos riscos \\ - Diálogo entre ciência e utilizadores -}

\section{Quantificar o risco}

Como é de esperar, nos conceitos associados a entidades complexas existem sempre definições e pontos de vista filosóficos diferentes para caracterizar o "risco" como objeto de análise e decisão credível. Pode dizer-se, contudo, que a noção de risco é baseada numa subtil combinação entre conhecimento possível e incerteza. Ou seja, envolve sempre uma combinação de conhecimento e de desconhecimento. Eis a grande dificuldade prática mas, também, o fascínio do risco como conceito teórico.

Do ponto de vista da natureza intrínseca do conceito, existem dois pontos de vista substancialmente diferentes para o risco:

- O risco é uma realidade objetiva que existe independentemente dos valores e das opiniões subjetivas das pessoas - tal como noutras situações, a aplicação de uma metodologia científica permitirá a identificação da relação entre factos, a quantificação, a previsão e o controlo do risco - uma posição positivista do risco.

- Uma construção humana face a acontecimentos incertos com consequências danosas. 0 risco pode até ser considerado como reação subjetiva a fenómenos da experiência pessoal e social - uma posição relativista do risco.

Nas duas óticas, interessa definir uma grandeza quantificável que possa corresponder ao conceito do risco e que possibilite a análise quantitativa do risco de uma forma generalizada. $\mathrm{Na}$ verdade, inspirado em comportamentos humanos face às realidades, aos perigos, a análise do risco pode ser considerada uma construção da mente humana.

Uma das dificuldades nesta tarefa de definir a grandeza risco consiste na caracterização de acontecimentos incertos que são ameaças a um determinado objetivo.

São acontecimentos futuros mais ou menos frequentes, possivelmente excecionais, únicos e de grande intensidade, com consequências variáveis, tangíveis e (ou) intangíveis.

Exemplos de definições gerais do conceito de risco:

- "Efeito de incertezas em objetivos" (ISO 31000:2009).

- “Incerteza de uma atividade e da severidade das respetivas consequências” (T. Aven, 2009).

\section{Definição Canónica do Risco}

A base da definição canónica do risco está um conceito antigo: o valor expectável VE de uma variável. A este conceito está ligado Christiaan Huygens (1657):

$$
V E=\sum_{i} p i x V i
$$

valor no presente de um conjunto de valores alternativos $\mathrm{Vi}$ incertos no futuro, com probabilidades pi. Para o risco consideram-se os valores de consequências $\mathrm{Ci}$ (perdas ou ganhos) resultantes de um determinado tipo de acontecimento:

$$
\text { Risco }=\sum_{i} p_{i} \times C_{i}
$$

Sendo $i$ o número de cenários, ou as diferentes formas de ocorrer o acontecimento e as respetivas consequências, considerados para a análise do risco. No presente texto consideramse só consequências negativas (perdas).

Esta definição canónica não está imune a uma crítica filosófica: será que o valor expectável pxC é uma quantificação adequada do que pode ser perdido no futuro em situação incerta? 


\section{O risco, uma construção}

0 risco é um conceito abrangente, motivador e ambíguo, com diferentes dimensões e uma potencialidade especial para:

- Caracterizar ocorrências incertas associadas a desvios relativamente a situações de referência;

- Justificar opções e ações, como variável de decisão face a potenciais ameaças;

- Incentivar a proteção de pessoas e bens e melhorar, assim, a "qualidade de vida";

- Constituir uma representação simbólica do "mundo contemporâneo".

Uma das preocupações fundamentais da construção em causa, tendo em conta os processos de decisão, decorre da necessidade de comparar, num presente, determinados efeitos cuja ocorrência em "futuros" é considerada com diferentes graus de incerteza ou de convicção. O conceito de probabilidade surge, assim, associado ao risco e, em particular, à análise quantitativa do risco.

Frank KNIGHT (1885-1927) defendeu com firmeza o seguinte princípio: risco implica conhecimento com probabilidades (mensurável), caso contrário é desconhecimento ou incerteza em sentido restrito (F. KNIGHT, 1921).

Assim, a construção da análise quantitativa do risco implica a graduação da plausibilidade de eventos incertos através da avaliação de probabilidades. Para algumas linhas de pensamento, a probabilidade do evento perigoso é tão importante que quase se confunde com a noção do risco associado (conceção probabilística). No processo de construção conceptual dominante, a prática e a reflexão permitiram reduzir os três fatores intervenientes, incerteza, intensidade e consequência, a dois:

- Probabilidades de ocorrência do acontecimento (caracterizando a incerteza da realização do processo perigoso com uma determinada intensidade e gerador de uma cadeia de causalidade até ao impacto no alvo ou recetor).

- Consequências (resultantes da intensidade do processo através dos danos ou perdas envolvidos em resultado do impacto).

Assim, o valor estimado das consequências é "atenuado", em função do grau de incerteza, pela multiplicação pela respetiva probabilidade $(\mathrm{P})$ de ocorrência. Deste modo, a variável risco tem um valor quantificável que pode ser comparado com outros num processo de apreciação e de decisão quantitativo. Riscos com natureza diferente (as unidades de risco quantitativo indicam o tipo de valor: vítimas/ano ou euros/ano, a título de exemplo) podem assim ser comparados por classes de consequências.

Tem-se que reconhecer que a solução encontrada é simples e quase genial: o conceito tem resistido séculos! De MolvRe, no seu livro "De Mensura Sortis", publicado em 1711, explicita, pela primeira vez, este conceito do risco: "A medida do risco de perda de uma quantia é o produto do montante colocado em jogo pela probabilidade de perda” (P. BERNSTEIN, 1998).

Com a definição canónica, a análise quantitativa do risco possibilita a consideração e a internalização dos riscos em análises de "custo-benefício" e em processos multi-critérios de decisão. Esta capacidade é apreciada nos projetos de sistemas tecnológicos complexos ou no planeamento de medidas de proteção dispendiosas contra riscos naturais.

A expressão canónica da definição do risco quantitativo é apresentada, atualmente, de diversas formas. Uma das mais eficazes na análise e na gestão de riscos quantitativas é a seguinte:

$$
\text { Risco }=\operatorname{Prob}(M) \times \text { Exposição }(M) \times \text { Vulnerabilidade }(M)
$$

$$
\text { Risco }=\text { PxExV }
$$




\section{Realidades e desafios na gestão dos riscos \\ - Diálogo entre ciência e utilizadores -}

onde $\mathrm{P}=$ Perigosidade, ou probabilidade do processo ocorrer com magnitude $M$ (potencial destruidor); $\mathrm{E}=$ Exposição, "valor" inicial dos bens expostos aos potenciais impactos perigosos com uma determinada magnitude $M ; \mathrm{V}=$ Vulnerabilidade (física), grau de dano ou perda do valor, em exposição, em resultado do impacto e em função da magnitude $M(\%$ ou $0<V<1)$, também designado, em alguns domínios, por operador de danos ou de "Fragilidade", o qual caracteriza a perda de valor resultante do impacto. Salienta-se que a distinção entre Exposição (ainda sem danos ou "vulnerável" em potência) e Vulnerabilidade física (operador de danos em ato), função da intensidade do impacto em cada cenário, é de grande eficácia operacional e uma base para enquadramento de medidas de mitigação (J. DougLAs, 2007):

$$
V=\text { valor }- \text { do }- \text { dano } / \text { valor }- \text { do - exposto }
$$

\section{Equivalências de narrativas descritivas}

A análise quantitativa faz uso, de um modo muito marcante, da descrição matemática dos processos que traduzem o desenrolar dos cenários. A prática tem feito sugerir diversas definições de conceitos ou de grandeza associados ao risco e à análise e gestão do mesmo.

Em geral, constata-se que é possível uma equivalência de descrições entre a descrição matemática e outros tipos de descrições não matemáticas. A título de exemplo, considerese o termo "suscetibilidade" ou "... a propensão ou a tendência de uma zona ser afetada fisicamente por um perigo...” (J. CANTOS et al., 2002) que pode ser quantificada utilizando uma probabilidade condicionada:

$$
\mathrm{S}=\operatorname{prob}\left(\mathrm{V}>0 \mid \mathrm{I}_{0}, E_{0}\right)
$$

ou, para i cenários,

$$
\mathrm{S}=\sum_{i}^{N} \operatorname{prob}_{\mathrm{i}}\left(\mathrm{V}_{\mathrm{i}}>0 \mid \mathrm{I}_{\mathrm{i}}, E_{i}\right)
$$

em que $S$ = suscetibilidade, $V$ = vulnerabilidade física, $I$ = intensidade ou magnitude do agente perigoso e $\mathrm{E}$ = valor exposto na zona potencialmente afetada, para um cenário isolado ou para um conjunto de $\mathrm{N}$ cenários.

A severidade de um processo, por exemplo, está associada à capacidade de um processo para provocar danos em função da sua magnitude e características quando atua sobre bens expostos.

Contudo, o significado e a emoção associadas a uma narrativa ou descrição não poderão ser totalmente transcritos, e sentidos, para uma linguagem matemática. Para além de poder ser redutora a exigência de quantificar valores, a operacionalização do conceito pode revelarse difícil, nomeadamente no que respeita o cálculo ou a estimação de probabilidades. Para ultrapassar algumas das dificuldades sem perda de eficácia, é frequente a consideração de classes de probabilidades, caracterizadas por opiniões subjetivas, e a aplicação de matrizes de risco com a quantificação qualificativa da importância de danos ou ainda de caracterização baseada em lógicas difusas.

A representação gráfica, por classes e por cores, tenta amenizar, de certo modo, algumas barreiras de comunicação na análise quantitativa.

Sem dúvida que, no contexto de um processo de decisão racionalizado, a análise e a avaliação quantitativa é útil, mas não é o único modo de caracterização de uma situação de risco.

Existem mesmo perspetivas opostas: Mary Douglas insistiu que o risco não pode ser um conceito objetivo e mensurável mas sim um conceito construído social, cultural e politicamente: o risco não deveria ser reduzido a uma dimensão técnica (M. Douglas, 1985 e 1992; M. Douglas et al., 1982).

Em contraponto à análise quantitativa do risco refere-se frequentemente a perceção (social) do risco e ao uso de probabilidades subjetivas que capturam outras dimensões do risco. 


\section{Gestão do risco}

"Mais vale prevenir do que remediar"

Este aforismo pode ser um bom exemplo de filosofia prática e popular. Quase tudo o que é essencial para um comportamento humano sensato está dito nesta frase geral, aplicável a todas as situações de perigo:

- Uma apreciação comparativa, valoração e critério de decisão.

- A atuação proposta, para ao presente, de modo a evitar um "futuro" associado a um cenário de perigo ("prevenir").

- Avaliação de potenciais consequências e de medidas de proteção e recuperação do valor exposto ("remediar").

O aforismo pressupõe a possibilidade da perceção de um perigo que se pode vir a estruturar em risco e a realizar-se (hipoteticamente) mas que pode ser supostamente atenuado por uma ação antecipada. Na verdade, cada ser humano aplica, no quotidiano, de um modo mais ou menos consciente, táticas de avaliação de situações de risco, ou perigosas, nos atos de decisão associados á sua sobrevivência e desenvolvimento.

Esta possibilidade automática deixou de ser a característica normal na sociedade contemporânea. Os perigos tornaram-se difusos e são dificilmente percecionados numa sociedade fortemente dependente de sistemas de tal complexidade que a maioria dos cidadãos não pode entender completamente as vulnerabilidades e os perigos associados.

É um dos aspetos da designada "sociedade de risco" (U. BECK, 1986, 1999, 2000 e 2001) e tema de análises culturais (A. GidDens, 1990 e 2002; N. LuHmAnN, 1993). A estruturação do processo desde a identificação até à decisão e à implementação de medidas torna-se então necessária. É a função da análise e da gestão de riscos.

Esta estruturação foi muito influenciada pelos desenvolvimentos nas áreas da gestão financeira e de gestão de seguros durante o séc. XX. A título de curiosidade, registe-se que o temo "risk manager" é proposto em 1956 na Havard Business Review num artigo de Russel GallagheR (R. Gallenger, 1956) tendo, desde então, vindo-se a impor um quadro organizativo geral que inclui a análise de riscos e a gestão de crises.

De acordo com a norma internacional ISO 31000 "Risk Management Principles and Guidelines" (2009), a gestão de riscos compreende o "conjunto de actividades para orientar e controlar uma organização no que respeita o risco". No comportamento futuro de um sistema natural ou construído (e.g. um produto tecnológico) somos levados a admitir um padrão normal de expectativas, uma referência ou um conjunto de objetivos a cumprir. Diz-nos a experiência que estas condições, estas expectativas, nem sempre se cumprem: acontecimentos, previsíveis ou não, podem ocorrer num futuro mais ou menos próximo e provocar "desvios" no esperado com consequências (positivas ou negativas). De acordo com este quadro conceptual, a referida norma ISO define risco do seguinte modo: "efeito da incerteza nos objetivos". Esta definição alerta-nos, de uma forma elegante, para a necessidade de identificar os objetivos que se pretendem atingir (e.g. a preservação da vida humana), as incertezas a considerar (epistémicas e aleatórias) e os efeitos ou consequências prováveis.

Numa gestão de riscos não se prevê o futuro que irá ocorrer mas consideram-se diversos cenários de "futuros" possíveis ou plausíveis e avaliam-se as respetivas probabilidades de ocorrência e as potenciais consequências, tangíveis ou não-tangíveis. O processo de aplicação de uma gestão de riscos compreende um conjunto de procedimentos e de componentes e um formalismo de análise quantitativa relativamente consensual (fig. 1). Podem existir diferenças de léxico (avaliação /apreciação; cálculo/estimação; perigo/risco; vulnerabilidade/ fragilidade; vulnerabilidade/suscetibilidade, a título de exemplo) nomeadamente na tradução de alguns termos mais relevantes ("assessment"/ "evaluation"; "hazard"/"danger"/"threat"; 


\section{Realidades e desafios na gestão dos riscos \\ - Diálogo entre ciência e utilizadores -}

“chance"/"probability", a título de exemplo) mas, no essencial, os conceitos podem ser entendidos, sem prejuízo de uma análise crítica e de adaptações adequadas a cada domínio de aplicação. Não é, contudo, um processo técnico trivial pois baseia-se num conceito imaterial (o risco) com reflexos em medidas e ações bem reais. 0 referido processo é a base de programas de ação e de organização nos mais diversos aspetos da sociedade contemporânea.

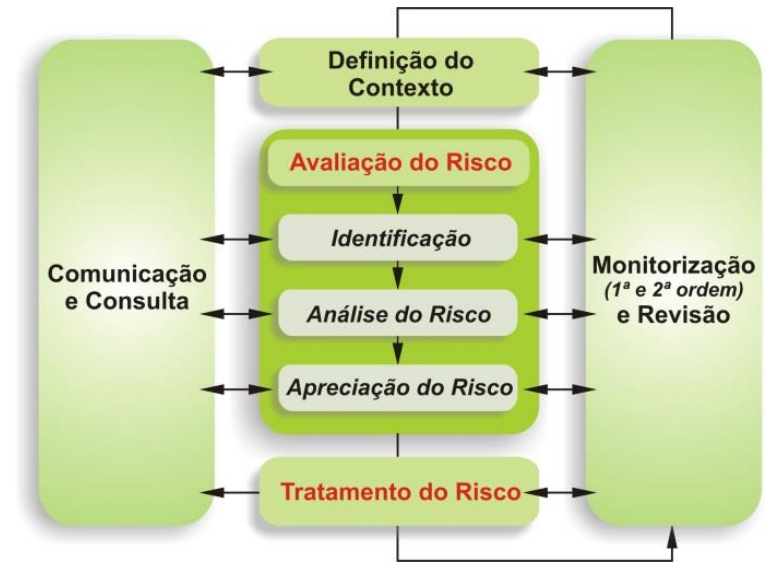

Fig. 1 - Processo geral da gestão do risco segundo a Norma ISO 31000:2009.

\section{Reflexões filosóficas}

A análise e a gestão de riscos são suscetíveis de serem objeto de reflexões filosóficas baseadas em temas muito diversos tais como:

Nas infraestruturas complexas de engenharia é frequente obterem-se para probabilidades de falha ou de rotura valores da ordem de $10^{-6}$ ou $10^{-8}$. Na engenharia, é difícil atingir, com garantia, objetivos com probabilidades inferiores a $10^{-6}$. Será admissível ou prudente considerar estes eventos como impossíveis?

- Significados, realidade e objetividades;

- Perigo, medo, tabu, segurança, valor e sociedade;

- Epistemologia, indeterminismo, ignorância, incerteza e causalidade;

- Possibilidade, aleatoriedade e probabilidade;

- Precaução, prevenção, proteção e remediação;

- Moral, ética, ação política e responsabilidade;

- Aceitação e tolerabilidade ao risco (risco socialmente aceitável).

1 - A definição quantitativa do risco permite uma harmonização de critérios de comparação e decisão. Com efeito, a expressão do valor expectável de consequências ou danos indica que, para cada cenário, o risco se manterá com um valor constante no caso do produto P D se mantiver constante. Isto significa que, neste quadro de avaliação quantitativa, existe um contínuo de situações envolvendo probabilidades baixas e danos elevados até probabilidades elevadas e danos baixos em que o risco se mantém.

Será esta definição a mais adequada, abrangente ou útil em todas as situações? A perceção e aceitação social de um valor concreto de risco não é indiferente aos diferentes pares de valores P e C, não obstante o produto manter constante esse valor de risco (P. SLovic, 2001). 
O valor absoluto de determinado tipo de consequência pode influenciar a disponibilidade para aceitar um determinado nível de risco calculado. A psicologia social pode fornecer elementos para esta análise e para os critérios gerais de aceitação social de riscos. Acresce ainda a dificuldade em integrar danos tangíveis e intangíveis.

2 - A estimação de probabilidades da ocorrência, e das cadeias de causalidade associadas aos cenários, constitui um aspeto central da análise quantitativa do risco. Constitui, também, uma dificuldade em muitos casos práticos, nomeadamente quando não existem dados referentes a comportamentos análogos no passado ou quando não se tem um conhecimento seguro do "processo de geração" do perigo e da sua propagação (cadeias de causalidade e resposta). É o caso de cenários associados a eventos isolados únicos, para os quais a interpretação frequencial direta não é possível.

O recurso a probabilidades de tipo subjetivo, à decomposição "forçada" do cenário em componentes causais elementares com probabilidades relativamente conhecidas ou, ainda, à seleção de conjuntos de casos considerados semelhantes e com frequências mais fáceis de estabelecer, torna-se, então, inevitável mas coloca a questão sobre o significado da probabilidade, ou mesmo da validade do conceito de probabilidade aplicado a um evento único.

3 - Uma outra situação difícil é a seleção dos cenários associados a acontecimentos raros, únicos ou com valores extremos de variáveis aleatórias. As probabilidades correspondentes a estes casos, nomeadamente as probabilidades com valores muito pequenos, colocam questões de significado e de interpretação prática, nomeadamente no caso da apreciação de investimentos relevantes em medidas de mitigação. Haverá um limiar inferior da probabilidade a partir do qual o acontecimento pode ser considerado impossível? (discussão exaustiva em A. COURnot, 1851 e T. MARTIN, 1996). Nas infraestruturas complexas de engenharia é frequente obterem-se para probabilidades de falha ou de rotura valores da ordem de $10^{-6}$ ou $10^{-8}$. Na engenharia, é difícil atingir, com garantia, objetivos com probabilidades inferiores a $10^{-6}$. Será admissível ou prudente considerar estes eventos como impossíveis?

É frequente, nos cenários de catástrofes ou de acidentes com infraestruturas importantes, a probabilidade do evento ser muito pequena mas os danos associados serem muito elevados. As incertezas nos valores de $\mathrm{P}$ e $\mathrm{C}$ refletem-se com elevada sensibilidade no valor do risco tornando a apreciação do mesmo muito difícil. A avaliação das incertezas torna-se então indispensável para evitar ilusões e decisões desproporcionadas.

4 - A comunicação dos riscos é, cada vez mais crítica para o sucesso das ações de proteção civil. A credibilidade e rigor do agente emissor deve ser balanceado com a perceção e o senso comum do recetor. Dois exemplos:

- A caracterização da perigosidade baseada no conceito de "período de retorno" será a mais adequada? Não será uma fonte de ambiguidade e de erro conforme se constata frequentemente, mesmo em afirmações de responsáveis?

A análise e a reflexão suscitadas pelo processo movido a responsáveis da proteção civil italiana na sequência do sismo de L'Aquila (2009) colocam alguns desafios com interesse para a comunidade científica e os serviços de proteção civil:

- Em situação de crise, quais são os modos aconselháveis de comunicar situações de risco associadas a uma forte incerteza científica? Quando é que é pertinente e aconselhável utilizar um discurso baseado em probabilidades? De que modo a informação probabilística deve ser elaborada para ser entendida por leigos e proporcionar uma perceção "correta" da situação?

- Que tipo de "protocolo" deve ser seguido em situações de crise (emergência), a nível nacional, para proporcionar uma comunicação científica mais eficaz e segura para o público?

- Quais são as recomendações genéricas que devem ser transmitidas aos especialistas e técnicos no que respeita a responsabilidade (pessoal, civil e institucional) resultante de afirmações públicas no contexto da comunicação do risco? 


\section{Realidades e desafios na gestão dos riscos \\ - Diálogo entre ciência e utilizadores -}

- Como deveremos encarar a responsabilidade social e política de comissões consultivas de especialistas (cientistas), de apoio a autoridades políticas ou administrativas, em particular no caso das comunicações num contexto de riscos públicos e de situações de crise?

5 - Um processo de gestão de riscos pode interferir com valores sociais e culturais colocando a questão da responsabilidade ética e moral. Os critérios de aceitação ou de tolerabilidade pública dos riscos são componentes importantes do processo de decisão e de responsabilização mas não podem ser considerados como simples produtos racionais.

As questões relativas aos critérios de apreciação envolvendo probabilidades de ocorrência e consequências que se podem colocar são, entre outras, as seguintes:

- Os critérios de aceitabilidade poderão ser universais ou válidos para qualquer tipo de risco ou deverão ser específicos, em função do tipo de perigo e de efeitos?

- Poderão esses critérios ser absolutos ou deverão resultar de processos de escolha entre opções alternativas? Será mesmo admissível considerar uma aceitação de um risco acrescido ou o que se aceita são sempre opções com compensações?

A fixação do risco socialmente aceitável ou tolerável coloca questões muito delicadas de índole política e ética.

\section{Análise e gestão de Vulnerabilidades}

A análise de vulnerabilidades pode ser uma resposta a dificuldades na estimação do risco, permitindo atenuar os inconvenientes associados a incertezas significativas, em particular na estimação de probabilidades, e ser mais eficaz operacionalmente:

- Pode ser independente de probabilidades de ocorrência;

- Tem um enfoque em mitigação de danos e na capacidade de recuperação (resiliência) face a ameaças futuras possíveis;

- Pode incluir a perceção social dos riscos e o controlo da Exposição;

- Inclui cenários holísticos e cadeias de causalidade física simplificadas (Vulnerabilidade Social).

Dificuldades potenciais da análise de vulnerabilidades:

- Possibilidade de análises de custo/benefício no presente, sem a moderação dos valores expectáveis ou das probabilidades de cada cenário;

- Pode empolar consequências possíveis mais pouco prováveis;

- Pode tornar mais difícil de hierarquizar as ações na qualidade de variável de decisão!

Uma situação onde se pode justificar a aplicação da análise e gestão de vulnerabilidades é a associada aos efeitos da mudança climática global: elevada incerteza, alteração de padrões de comportamento de variáveis climáticas e hidrológicas, horizontes temporais relativamente dilatados, cenários com consequências muito relevantes difíceis de quantificar no presente.

Existem dezenas de definições de vulnerabilidade aplicáveis a domínios ou dimensões diferentes.

Destacamos duas, aplicáveis a dois tipos de domínios de vulnerabilidade:

- A Vulnerabilidade física, já referida, que caracteriza com precisão (funções de vulnerabilidade) o pós-impacto (danos) numa zona de impacto bem definida: um vale, uma cidade, uma zona costeira...

- Vulnerabilidade social que caracteriza os fatores negativos no presente que propiciam um desastre social (numa comunidade) no futuro resultante de determinado tipo de impactos. 


\section{Gestão do risco e da incerteza. \\ Conceitos e filosofia subjacente}

A gestão da vulnerabilidade física baseia-se no controlo da exposição e da diminuição da propensão aos danos tendo em conta cenários possíveis (J.P. DupuY, 2002).

A Vulnerabilidade social caracteriza os referidos fatores negativos de um forma sintética e integrada podendo ser definida de diversos modos, nomeadamente os seguintes:

- A característica de uma pessoa ou de um grupo de pessoas de ter capacidade para antecipar, enfrentar, resistir e recuperar do impacto de um evento natural e perigoso.

- O grau de suscetibilidade e de capacidade para superar os efeitos adversos da alteração climática, incluindo a variabilidade climática e a ocorrência de situações extremas. A vulnerabilidade é uma função das características, da magnitude e do ritmo, das alterações a que um sistema está exposto, da sua sensibilidade e da sua capacidade adaptativa (IPCC Glossary, 2013).

- Análise da propensão ou predisposição para um sistema ser adversamente afetado (IPCC, 2012).

Os indicadores de vulnerabilidade função de fatores sócio-económicos são, em geral, do seguinte tipo, envolvendo o PIB, género, escolaridade, demografia, condições sanitárias, emprego...

$$
V_{S H}=V_{1}^{\alpha_{1}} V_{2}^{\alpha_{2}} \ldots V_{i}^{\alpha_{1}}
$$

De um modo geral, a função de vulnerabilidade social contém os seguintes fatores de controlo:

$$
\text { Função }\left(\frac{\text { Severidade; Suscetibilidade - Preparação - Adaptação }}{\text { Resiliência (Recuperação) }},\right. \text { tempo }
$$

em que:

Severidade - capacidade do processo em provocar danos em função da sua magnitude.

Suscetibilidade - propensão para um determinado bem exposto ser afetado por um perigo.

Preparação - planeamento e gestão de emergências.

Adaptação - implementação de estratégias ou de respostas a perigos evolutivos com elevada incerteza por forma a reduzir a vulnerabilidade ou fragilidade de um sistema.

Resiliência - Capacidade de ser perturbado sem perder a sua funcionalidade, capacidade de absorver e recuperar com eficiência dos impactos: capacidade de regeneração (tempo de recuperação).

\section{Vantagens na análise de incerteza}

A caracterização das incertezas inerentes ao processo de análise e avaliação dos riscos é cada vez mais uma exigência e tem as seguintes vantagens principais:

- Mostrar ao decisor que o nosso conhecimento é incompleto ou impreciso e que as decisões serão baseadas nos conhecimentos disponíveis, incompletos ou aleatórios.

- Avaliar e apreciar o grau de incerteza (ou de ignorância) em causa e decidir se o mesmo é aceitável ou não.

- Permitir saber atuar eficazmente (ou de um modo mais eficiente) para reduzir a incerteza resultante (identificação das fontes de incerteza mais relevantes para os resultados).

- Permitir separar as incertezas aleatórias das epistémicas para intervir (gerir) com eficácia no controlo de incertezas finais.

- Adaptar o processo de decisão ao tipo e valor das incertezas (implicações éticas). 


\section{Realidades e desafios na gestão dos riscos \\ - Diálogo entre ciência e utilizadores -}

A caracterização sistemática das incertezas propagadas (e.g. aplicação do método de Monte Carlo) ao longo dos cálculos é da maior importância para justificar decisões equilibradas.

\section{Conclusão}

O conceito risco é baseado na combinação das dimensões Consequências e Incertezas.

A análise quantitativa de riscos, não obstante os grandes benefícios que a sua aplicação pode trazer em determinados contextos, não deve ser considerada como uma panaceia para garantir "seguranças" quase absolutas. Análises qualitativas ou semi-quantitativas podem revelar-se mais adequadas em algumas circunstâncias.

As metodologias da gestão e análise dos riscos têm a seu favor o facto, muito positivo, de colocarem as consequências ou os efeitos incertos, resultantes de uma exposição a um perigo, no centro das decisões. Podem, assim, contribuir para se evitarem danos ou perdas irreparáveis e, de um modo global, melhorar a segurança da uma comunidade, de uma empresa ou de um empreendimento.

A análise e a gestão de riscos não devem ser aplicadas por metodologias e estruturas rígidas ou dogmáticas, geradoras de ilusões ou de mitos relativos a uma racionalidade e eficiência sem limites. Em algumas circunstâncias, pode ser aconselhável adotar a gestão de duas das variáveis que compõem a definição quantitativa do risco, para além da probabilidade do evento, a exposição e, em particular, a vulnerabilidade: as probabilidades nem sempre são a ferramenta útil para caracterizar as incertezas.

Em qualquer dos casos, a caracterização das incertezas envolvidas nos cálculos para avaliação do risco deve ser levada a cabo tendo em vista uma tomada de decisões mais adequada com o grau de conhecimentos disponível. Sem uma análise das incertezas epistémicas embebidas nos cálculos, o aparente rigor dos resultados de uma avaliação quantitativa dos riscos pode conduzir a decisões desproporcionadas.

\section{Referências bibliográficas:}

Almeida, A. B., Ramos, C. M., Santos, M. A., Viseu, T. (2003) - “Dam Break Flood Risk Management in Portugal". LNEC, Lisboa, 265 p.

AlmeidA, A. B. (2005) - "The 1755 Lisbon Earthquake and the Genesis of the Risk Management Concept". International Conference 25th Anniversary of the 1775 Lisbon Earthquake, Proceedings, November, Lisboa, p. 57-64.

Almeida, A. B. e Viseu, T. (1997) - "Dams and Safety Management at Downstream Valleys". (Editors), A.A. Balkema, Rotterdam, 247p.

Aven, T. (2009) - "Risk Analysis and Management. Basic Concepts and Principles", R\&RATA, $\mathrm{n}^{\circ} 1$ (12), Vol. 2, p.57-73.

BEck, U. (1986) - "Risk society. Towards a New Modernity". Sage Publications (edição 2003), $260 \mathrm{p}$.

BECK, U. (1999) - “World Risk society”. Polity (edição de 2003), 184 p.

Beck, U. (2000) - "Risk society Revisited: Theory, Politics and Research Programs". The Risk Society and Beyond (B. Adam, U. Beck e J. VAN Lonn, editors), Sage Publications (edição de 2005), p. 211-229.

Beck, U. (2001) - “Un Mondo a Rischio”. Discurso na Duma de Moscovo publicado pela Einaudi, Torino (2003).

Bernstein, P. L. (1998) - “Against the Gods. The Remarkable Story of Risk”. J. Wiley, New York, 383 p. 


\section{Gestão do risco e da incerteza. \\ Conceitos e filosofia subjacente}

Cantos, J. O. e Ayala-Carcedo (2002) - "Riesgos Naturales. Conceptos fundamentales y clasificación”. In Cantos, J. O e Ayala-Larcedo, F. Javier (Ed.) - Riesgos naturales, Ariel Ciencia, Barcelona, p. 41-74.

Cournot, A. (1851) - "Essai sur les Fondements de nos Connaissances”. Vrin (edição de 1975).

Douglas, J. (2007) - "Physical Vulnerability Modelling in Natural Hazard Risk Assessment”. Nat. Hazards Earth Syst. Sci., 7, p. 283-288.

Douglas, M. (1985) - "Risk Acceptability According to the Social Sciences". New York, Russel Sage Foundation.

Douglas, M. (1992) - "Risk and Blame: Essays in Cultural Theory”. London, Routlege.

Douglas, , M. E WildavSKY, A. (1982) - "Risk and Culture”. Berkeley, University of California Press.

DupuY, J. P. (2002) - “Pour un Catastrophisme Éclairé. Quand l'impossible est certain”. Edition du Seuil, 216 p.

Gallagher, R. ,(1956)- "Risk Management: A New Phase of Cost Control”. Harvard Business Review (Vol. 34), p.75-86.

GIDDENS, A. (2002) - "Runaway World. How Globalisation is Reshaping our Lives”. Profile Books, 104 p.

KNIGHT, F. H. (1921) - "Risk, Uncertainty and Profit”. Hort, Schaffner and Marx Co., Boston.

Lourenço, L. (2004) - “Riscos Naturais e Protecção do Ambiente”. F.L.U.C., Colecção Estudos, 180 p.

Luhmann, N. (1993) - "Risk. A Sociological Theory”. Aldine Transaction (edição de 2005), 236 p.

MARTIN, T. (1996) - "Probabilités et Critique Philosophique selon Cournot”, Vrin, 362 p.

Rebelo, F. (2003) - "Riscos Naturais e Acção Antrópica. Estudos e Reflexões". (2 Edição), Imprensa da Universidade, Coimbra, $286 \mathrm{p}$.

SLovic, P. (2000) - “The Perception of Risk”. Earthscan (terceira impressão, 2002), 473 p.

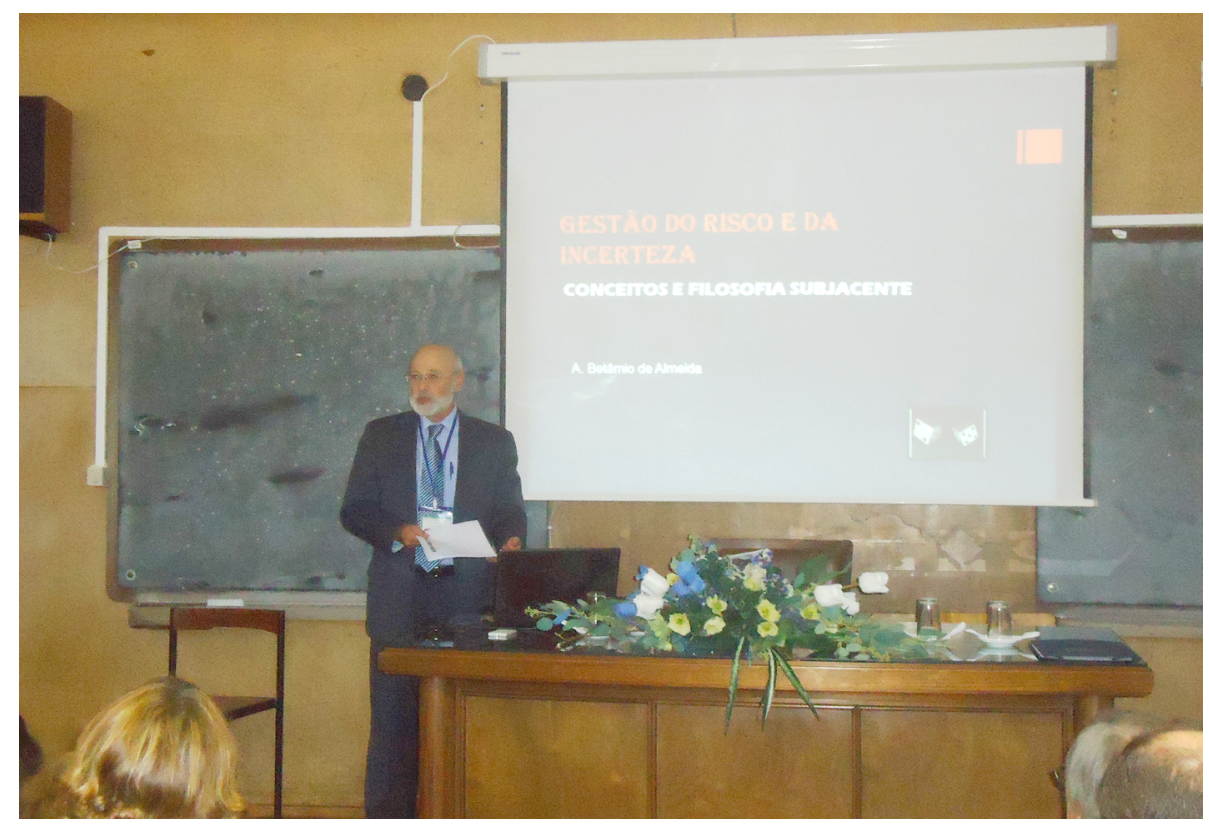





\title{
Capítulo III
}

\section{A CONCEPTUALIZAÇÃO NOS RISCOS NATURAIS: IMPACTES NA CIÊNCIA E NA AÇÃO}

\author{
Fantina Tedim \\ CEGOT e Departamento de Geografia \\ Faculdade de Letras da Universidade do Porto \\ ftedim@letras.up.pt
}

\section{Introdução}

Nas últimas duas décadas, a problemática da avaliação e gestão dos riscos naturais assumiu uma importância crescente na investigação científica portuguesa, assim como na agenda política, no ordenamento do território e na vida quotidiana dos cidadãos. O Programa Nacional da Política de Ordenamento do Território, aprovado pela Lei n. ${ }^{\circ}$ 58/2007, de 4 de setembro, considerou a prevenção dos riscos, nomeadamente os naturais, como um dos vetores do modelo territorial.

Neste processo, a interação entre a ciência, os decisores políticos e os utilizadores finais teve marcos significativos em que a ciência procurou responder a problemas concretos da sociedade. Um desses marcos foi a publicação do Guia metodológico para a produção de cartografia municipal de risco (JuLião et al., 2009).

O objetivo deste trabalho não foi fazer uma análise e avaliação da prática da gestão dos riscos naturais em Portugal, identificar resultados, constrangimentos ou desafios. Apenas é pretendido realçar que:

- Os desastres naturais não existem;

- O risco é uma construção social;

- O conceito de vulnerabilidade é fundamental na prevenção do risco;

- Na mitigação dos impactos dos desastres é fundamental desenvolver a resiliência.

A abordagem realizada não assenta numa revisão bibliográfica exaustiva, mas na identificação de alguns avanços e lacunas no conhecimento científico nesta temática.

\section{Os desastres "naturais" não existem}

O sismo do $1^{\circ}$ de novembro de 1755 constitui até hoje a maior catástrofe registada em Portugal. Este sismo que originou um tsunami, terá tido então um custo direto de 32 a $48 \%$ do Produto Interno Bruto do país (Pereira, 2006).

Este evento é considerado, a nível internacional, um marco incontornável no estudo dos desastres. Foi o primeiro a ser gerido de uma forma moderna porque houve uma resposta coordenada do Estado e no processo de reconstrução de Lisboa procurou-se mitigar as consequências de futuros eventos (DYNES, 2003), tendo sido Portugal um dos primeiros países do mundo a introduzir códigos de boas práticas para edifícios construídos em zonas de risco sísmico (CHESTER, 2008). Representou, igualmente, um momento de viragem na consideração dos sismos como eventos sobrenaturais para uma explicação mais neutral ou mesmo secular (DYNES, 1997). Nessa altura houve um intenso debate em torno da causa do fenómeno que foi objeto de interpretações distintas:

- Como uma ação divina em resultado dos pecados dos homens que requeria o arrependimento, a mudança de comportamento e a penitência como o caminho para acalmar a fúria divina (LIMA, 2008); 


\section{Realidades e desafios na gestão dos riscos \\ - Diálogo entre ciência e utilizadores -}

- Como um fenómeno com origem na natureza (ver por ex. Udias e ArRoyo, 2009; ALMEIDA, 2009);

- Como uma construção social, consequência das ações e do comportamento humano (Almeida, 2009; BAsSnett, 2006; Dynes, 2000).

A interpretação visionária da catástrofe como construção social foi proposta por Jean-Jacques RousSEAU que na correspondência que trocou com Voltaire, em 1756, argumentou que não tinha sido a natureza a construir edifícios de 6 e 7 andares e que se os habitantes de Lisboa se tivessem dispersado e construído casas mais pequenas as consequências seriam muito diferentes. Ao mesmo tempo salientou que muitas pessoas morreram quando tentavam salvar roupas, documentos e dinheiro (VoltalRE, 2005) o que evidencia que parte das consequências da catástrofe resultou de desadequados comportamentos humanos.

Não obstante a reflexão de RousSEAU, o paradigma de explicação dos desastres como resultantes de fenómenos geofísicos extremos tornou-se desde então dominante e só no século XX surgiu o trabalho inovador de Lowell Juilliard CARR (1932) que foi o primeiro a tentar compreender os desastres "naturais" como resultado da ação humana e não de forças naturais ou sobrenaturais, pois é "o colapso das construções humanas que constitui o próprio desastre" (p. 211). Embora seja usual referir que a investigação académica sobre os desastres se iniciou com o sociólogo Samuel Henry PRINCE (1920), o seu estudo sobre o desastre de Halifax, ocorrido em 6 de dezembro de 1917, centrou-se em compreender as mudanças sociais que ocorreram após a explosão.

Algumas décadas mais tarde, Paul Richards (1975) constatou que os processos naturais influenciavam as estruturas sociais e que os processos sociais também podiam afetar os sistemas naturais causando, por exemplo, fomes e erosão de solo. Por conseguinte, defendeu que em vez de se falar em desastres naturais deveria referir-se desastres sociais ou políticos. Este estudo assim como as evidências do sismo da Guatemala, ocorrido no início do ano de 1976, foram muito importantes para que Phil O'KeEfe, Ken Westgate e Ben Wisner (1976) argumentassem que os desastres são mais uma consequência de fatores sociais e económicos do que naturais. Passou a entender-se os desastres como problemas de desenvolvimento não resolvidos já que não eram eventos da natureza per se mas situações resultantes da relação entre a natureza e a estrutura organizativa da sociedade (CARDONA, 2004). Efetivamente, a explicação mais comum é que a causa reside nos fatores e processos sociais e económicos associados à evolução do capitalismo e neo-colonialismo que foi criando desigualdades entre grupos sociais, nomeadamente, forçando as populações mais pobres a ocuparem os locais mais perigosos (WHITE et al., 2001).

Os desastres naturais não existem pois são uma construção social, mas a centralidade da ação humana apresenta variantes que compreende desde erros individuais e societais (p. ex. as populações que se colocam no caminho dos fenómenos naturais ao ocupar, por exemplo, os leitos de cheia de cursos de água), até à exposição de populações que são colocadas em risco por imposições do mercado ou de grupos com poder politico (WHITE et al., 2001; WISNER e GaILlARD, 2009). Os desastres ditos "naturais" não são uma fatalidade mas uma das evidências "da desumanidade dos homens para com outros homens" (Steinberg, 2000, p.XIV). Para Calossi et al. (2012) a severidade dos desastres é também uma consequência da corrupção que encontra em situações de pós-desastre um contexto favorável ao seu desenvolvimento, pois há vários fatores que contribuem para a falta de transparência e de responsabilidade nos processos de decisão durante períodos de crises humanitárias.

\section{Da gestão do desastre à gestão do risco}

Os desastres representam uma rutura no normal funcionamento de uma comunidade ou sociedade provocando danos sociais, económicos e ambientais que excedem a capacidade da comunidade ou sociedade afetada responder e recuperar pelos seus próprios meios (ISDR, 2009). 


\section{A conceptualização nos riscos naturais: impactes na ciência e na ação}

Desde os anos setenta do século XX o modelo do "ciclo do desastre" tem sido um instrumento crucial na gestão dos desastres. Coloca a centralidade na gestão do evento assente numa abordagem reativa de mitigação que procura limitar as consequências da materialização do risco (ou ocorrência do desastre). Coetzee e van Niekerk (2012) consideram que a origem deste modelo pode ser encontrada nos trabalhos de PRINCE (1920), CARR (1932) and STODDARD (1968). 0 exemplo do "ciclo do desastre" proposto por BAIRD et al. (1975) era composto por seis fases diferentes, mas desde então várias propostas foram feitas (ver CoetzeE e van Niekerk, 2012). Um dos modelos existentes utiliza as noções temporais de antes, durante e após a manifestação do fenómeno para classificar diferentes tipos de ações (LAVELL, 1996):

- Anterior à ocorrência - caracteriza-se pela realização de atividades de prevenção do risco (p.ex., construção de esporões em áreas costeiras, código de construção antisísmica, realização de campanhas de sensibilização das populações) e preparação (p.ex., elaboração de planos de emergência);

- Durante a ocorrência - refere-se a atividades de resposta e socorro como a busca e salvamento de pessoas, prestação de cuidados médicos, garantir a segurança dos cidadãos, fornecimento de alojamento, satisfação de necessidades primárias de alimentação e vestuário. Tem uma complexidade e duração variável (p. ex., algumas horas no caso de uma avalanche, vários dias no caso de um sismo);

- Após a ocorrência - desenvolve-se a reabilitação e recuperação para repor o normal funcionamento da sociedade. A primeira refere-se ao restabelecimento de serviços e funções básicas, o que pode demorar dias, semanas ou mesmo meses. A recuperação refere-se à completa reconstrução, completa reposição de serviços e implementação de medidas preventivas.

o "ciclo do desastre", que foi muito criticado nomeadamente por adotar um enfoque reativo e subalternizar a prevenção do risco, prevaleceu como o modelo de intervenção dominante até ao início dos anos noventa do século XX. Os progressos na compreensão da relação entre o subdesenvolvimento e o impacto dos processos geofísicos nos países do Terceiro Mundo, assim como a emergência do conceito de vulnerabilidade foram determinantes para demonstrar a

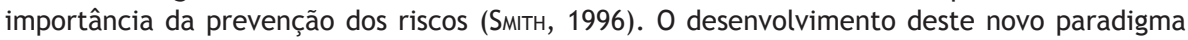
pressupõe que os desastres são uma situação extraordinária resultante da incapacidade de eliminar e prevenir completamente os riscos. Um dos quadros conceptuais que foi desenvolvido é o do "risco continuum" que põe em evidência que os riscos mudam constantemente exigindo diferentes modalidades de intervenção adaptadas à variabilidade das condições ( LAVELL, 2003, citado por LAVELL et al., 2012).

\section{A conceptualização do risco}

Ao contrário dos desastres que são acontecimentos reais, que ocorrem num local mais ou menos extenso, num dado momento do tempo, têm uma determinada duração e intensidade, o risco é potencial, não tem existência real. Está relacionado com a possibilidade aleatória de algo que ainda não aconteceu, pois se houver certeza não há risco (CARDonA, 2004). 0 desastre é o resultado da materialização do risco. Para o IPCC (2012) o risco representa a probabilidade de ocorrer um desastre.

0 risco natural tem sido frequentemente assumido como a probabilidade de ocorrência de um processo que pela sua magnitude põe em perigo as populações e os bens que estas valorizam, e das suas prováveis consequências quer sejam diretas ou indiretas. Neste caso, considera-se que a magnitude do processo geofísico é determinante na justificação dos danos. No entanto, as características dos elementos expostos são fundamentais para compreender a intensidade de um desastre pelo que a ISDR (2009) considera que risco são os danos potenciais (económicos, sociais, materiais e ambientais) que podem ocorrer numa determinada comunidade ou sociedade num determinado momento. Esta definição atribui centralidade aos potenciais impactos e ao papel da vulnerabilidade na explicação 


\section{Realidades e desafios na gestão dos riscos \\ - Diálogo entre ciência e utilizadores -}

dos mesmos, assim como identifica claramente que o risco natural é o resultado de uma convolução entre um processo geofísico perigoso e o processo social perspetivado através da componente vulnerabilidade.

\section{As componentes do risco natural: o fenómeno perigoso}

O geógrafo Harlan BarRows foi pioneiro no estudo das relações entre o homem e o meio na perspetiva do "ajustamento humano" ao atribuir um papel central às escolhas humanas (KoelsCH, 1969), mas o estudo dos natural hazards começou, efetivamente, com Gilbert WHITE. O natural hazard foi definido por WHITE como uma interação da sociedade e da natureza governada pela presença do sistema humano na ocorrência de eventos naturais (MARANDola e Hogan, 2004). Tratase, assim, de um evento que se manifesta na interface sociedade-natureza pois apenas os fenómenos naturais que ocorrem em áreas ocupadas pelo homem, ameaçando as populações e as suas estruturas vulneráveis, gerando danos e perdas, podem ser considerados como natural hazards (CAnnon, 2008; Marandola e Hogan,2004).

0 termo hazard tem sido traduzido para português por perigo (p.ex., Julião et. al., 2009; LimA, 2008; Marandola e Hogan, 2004; Ramos et al., 2010; Tedim 2013, Tedim e Carvalho 2013) e ameaça (LIMA, 2008).

Com a finalidade de procurar consensos ao nível académico como tradução de hazard propõe-se fenómeno perigoso. Este é um processo geofísico que ocorre na interface entre o ambiente e a sociedade, ameaçando as populações e as suas estruturas vulneráveis, gerando danos e perdas. Neste sentido parece adequado que perigosidade seja definida como a probabilidade de ocorrência de um fenómeno perigoso com uma determinada intensidade. Assim, a perigosidade é uma característica do fenómeno perigoso. Reduzir a perigosidade contribui para a redução do risco e, consequentemente, diminuir o risco significa uma menor possibilidade de um futuro desastre (CARDONA, 2004).

As componentes do risco natural: a vulnerabilidade

A comunidade científica está de acordo que a vulnerabilidade dos ecossistemas e das sociedades é determinante na explicação do surgimento e nas consequências dos desastres (Alexander, 2006; Birkmann et al., 2014; Cannon. 2008, Lavell et al., 2012; McEntire,2012; WISNER et al., 2012).

0 termo vulnerabilidade tem origem no termo latino vulnerare que quer dizer ferir, provocar danos. Surge na análise geográfica dos riscos nos anos setenta do século XX (BAIRD et al., 1975; Burton et al. 1978; Davis, 1978; HeWITt, 1983; O’KEefE et al.,1976; Wisner et al., 1977) e, um pouco mais tarde, nos estudos sobre a pobreza, segurança alimentar e desenvolvimento (CHAMBERS, 1989; WatTS e Bohle, 1993) e mudanças globais (Dow, 1992; KLeIN e Nicholls, 1999).

A diversidade conceptual reflete diversas abordagens epistemológicas, diferentes escalas de análise, enfoques sistémicos diferenciados (biofísico, social ou socio-ecológico) (CosTA e KROPP, 2013; Fekete et al., 2014; HufsChmidt, 2011; Wisner et al., 2004).

A Estratégia Internacional para Redução de Desastres e o Painel Intergovernamental sobre Mudanças Climáticas definem vulnerabilidade como a "propensão ou predisposição para ser negativamente afetado" (IPCC, 2012, p. 564) resultado de características internas dos elementos expostos ao perigo "que resultam de fatores físicos, sociais, económicos, e ambientais" (ISDR, 2009, p.16).

A vulnerabilidade refere-se às características inerentes aos sistemas sociais e ecológicos que criam o potencial para o dano em caso de ocorrência de fenómenos potencialmente perigosos. É socialmente construída pois está dependente de decisões humanas, reflexo da vida diária das pessoas (ERIKSEN e GILL, 2010) e de processos que se desenvolvem em distintas escalas temporais e espaciais. É influenciada por uma variedade de fatores históricos, sociais, económicos, 


\section{A conceptualização nos riscos naturais: impactes na ciência e na ação}

políticos e culturais com distintas escalas temporais e espaciais que essas pessoas, muitas vezes, não podem controlar mas que condicionam a sua capacidade para mitigar o risco e responder à ocorrência de um incêndio (WhItTAKeR et al., 2012). CARDONA (2004) refere que as causas subjacentes da vulnerabilidade afetam a distribuição de recursos entre grupos sociais e refletem as diferenças de poder na sociedade.

Várias conceptualizações têm sido propostas na área dos riscos naturais (ver p.ex. WISNER, 2004; Birkmann et al., 2014a). Neste estudo propõe-se um modelo que tem por base a conceptualização desenvolvida no âmbito do projeto europeu MOVE (BIRKMANN et al., 2013, 2014a) e que foi aplicado pela autora ao risco de incêndio florestal (TEDIM, 2013). Neste quadro a vulnerabilidade é composta por três componentes: exposição, fragilidade (ou sensibilidade) e capacidade de intervenção. A exposição refere-se ao contexto social e material representado, por exemplo, por pessoas, infraestruturas, estruturas económicas, bens, serviços e ecossistemas. É considerada por vários autores como uma componente externa à vulnerabilidade mas, efetivamente, é originada pelo sistema social pois é função das opções de localização que as comunidades e as sociedades fazem (Costa e KROPP, 2012; MustafA, 1998). A fragilidade (ou sensibilidade) advém de características internas dos elementos expostos que se revelam propensas a criarem danos e que resultam de fatores físicos, sociais, económicos, ecológicos, institucionais e culturais. A capacidade de intervenção é determinada pelo acesso e mobilização de recursos e competências para reduzir a exposição e a fragilidade. Apenas integra medidas de redução do risco. Refere-se ao "pré-evento" (CutTer et al., 2008).

Se há trabalhos que se focalizam na vulnerabilidade social (CUTTER e FINCH, 2008) ou das estruturas construídas (TotsCHNIG et al., 2011), outros adotam uma visão holística dos sistemas sociais e ecológicos (BIRKMANn et al., 2013). A vulnerabilidade é multidimensional, dinâmica e varia no espaço geográfico e entre grupos sociais.

A vulnerabilidade é, usualmente, considerada independentemente da manifestação dos fenómenos perigosos (HeWITT, 1983, 2007; O”BRIEN et al., 2007; WEICHSELGARTNER, 2001), mas no contexto dos riscos naturais a sua conceptualização deve também contemplar a relação entre esta e os processos geofísicos, para compreender a complexa interação que produz os desastres (WisNer et al., 2012).

\section{Resiliência: um conceito fundamental}

Embora tenha assumido visibilidade nos anos setenta com os trabalhos de Holuing (1973) na Ecologia, o termo resiliência tem uma história muito mais longa e diversificada (AlexANDER, 2013). Surgiu na temática dos riscos no final dos anos setenta do século XX (ToRRY, 1979) como o inverso da vulnerabilidade, isto é como "o outro lado da mesma moeda". A sua utilização por um grande espectro de disciplinas quer das ciências sociais quer das ciências naturais contribuiu para a proliferação de diferentes interpretações e de distintos níveis de aceitação como conceito (CutTer et al., 2008; Downes et al., 2013; Lavell et al., 2012; Manyena, 2006; Matyas e Pelling, 2014; Pelling, 2011).

Não obstante a diversidade de definições, uma das características comuns à maior parte delas é a existência de recursos e capacidades para enfrentar e reagir em situações adversas. Resiliência implica dispor de capacidades e recursos que permitam lidar com condições adversas, por vezes extremas. Se, inicialmente, se referia à capacidade de um sistema “voltar atrás" após uma perturbação, verificou-se que a situação anterior raramente pode ser restabelecida (BÉnÉ et al., 2012) e nem sempre se traduz num aumento do bem-estar das pessoas e no desenvolvimento das comunidades (MATYAs e PelLING, 2014). Além disso, aumentar a resiliência de uma componente pode ter um efeito contrário noutra componente e no sistema na sua globalidade (Mılıer et al., 2010).

Resiliência pode ser definida como a capacidade e os recursos dos indivíduos e dos sistemas (p.ex., comunidades, organizações, ecossistemas) para absorverem o impacto e responderem a eventos perigosos (p.ex., manifestação de um risco natural) assim como recuperar de uma 


\section{Realidades e desafios na gestão dos riscos \\ - Diálogo entre ciência e utilizadores -}

maneira eficiente e num período de tempo conveniente (CUTTER et al., 2008; IPCC, 2012; MitChell e HARRIS, 2012; PATON, 2008; ISDR, 2009), inclusive por meio de assegurar a preservação, restauração, ou a melhoria das suas estruturas e funções básicas (IPCC, 2012; ISDR, 2009).

Para alcançar estes objetivos importa desenvolver e manter os recursos e processos requeridos e assegurar que podem ser mantidos ao longo do tempo (PATON, 2007). A resiliência é dinâmica e multidimensional. Tem de ser construída nos níveis individual, coletivo e institucional que são interdependentes (Paton e Johnston, 2006) e deve capturar interações de processos que se desenvolvem a diferentes escalas espaciais e temporais.

Embora muito criticado, o conceito de resiliência tem-se tornado uma linguagem e um modo de governança assim como uma estratégia operacional na preparação da emergência, resposta a crises e de segurança nacional (Walker e Cooper, 2011; MAtyas e Peluing, 2012).

$\mathrm{Na}$ conceptualização da resiliência têm sido adotados diferentes enfoques (ver CutTer et al., 2008):

- Como um resultado que se pretende alcançar, sendo central compreender o que significa ser resiliente, como se pode medir e que indicadores utilizar;

- E como um processo dinâmico em permanente construção, o que requer compreender as componentes do processo. Na opinião de Matyas e PelLing (2014) estes dois enfoques não se excluem mutuamente, havendo vantagens, nomeadamente na operacionalização do conceito, em compreender a resiliência tanto como processo como um resultado.

Na Conferência Mundial para a Redução dos Desastres (UN, 1994) foi mencionado a importância de reforçar a resiliência para que as comunidades locais pudessem responder aos desastres, que foi muito reforçada no Quadro de Ação de Hyogo:2005-2015 (ISDR, 2005). Este propôs como objetivo aumentar a resiliência dos países e das comunidades aos desastres de modo a obter uma redução significativa dos danos. É esperado, para os próximos anos, que a resiliência seja um conceito orientador da redução dos riscos naturais embora seja espectável que um maior contributo para a formulação de políticas, requeira uma maior clareza e especificidade no tipo de mudança que se procura alcançar (Matyas e PelLING, 2014).

A relação entre resiliência e vulnerabilidade tem assumido interpretações diferentes (CUTTER et al., 2008; Galderesi et al., 2010; MANYenA, 2006; Miller et al 2010). Resiliência não é o oposto de vulnerabilidade e embora possam existir áreas de sobreposição é melhor considerá-los como "conceitos discretos" (MATYAs e PelLING, 2014). As estratégias para reduzir a vulnerabilidade não contribuem necessariamente para aumentar a resiliência e vice-versa (CuTter et al., 2008; MAYENA, 2006; GALDERESI et al., 2010).

\section{Conclusão}

Se a inexistência de estabilização da terminologia não condiciona a evolução do conhecimento científico dos riscos naturais em Portugal, é um fator de perturbação na transferência de conhecimento para os decisores políticos e os operacionais.

A política de redução dos riscos naturais em Portugal está, ainda, muito centrada na redução da perigosidade e na mitigação dos desastres. A avaliação e redução da vulnerabilidade surge como um grande desafio a enfrentar devido ao seu carácter multidimensional e dinâmico.

Como foi referido, as estratégias para reduzir a vulnerabilidade não contribuem necessariamente para aumentar a resiliência e vice-versa mas a diminuição da vulnerabilidade é uma das etapas para criar sociedades resilientes.

O outro desafio a enfrentar é compreender como operacionalizar o conceito de resiliência e de que forma este contribuirá para a definição de mais eficazes políticas de redução dos riscos naturais. 


\section{A conceptualização nos riscos naturais: impactes na ciência e na ação}

\section{Referências bibliográficas}

Almeida, A. B. de (2009) - The 1755 Lisbon earthquake and the genesis of the risk management concept, in Mendes-Victor, L.A., Oliveira, C.S., Azevedo, J., Ribeiro, A. (Eds) The 1755 Lisbon Earthquake: revisited, Geotechnical, Geological, and Earthquake Engineering, Springer, p. 147-166.

Alexander, D. (2006) - "Trends, problems and dilemmas", Journal of International Affairs, Vol. 59, n², p.1-24.

Alexander, D. E. (2013) - "Resilience and disaster risk reduction: an etymological journey", Natural Hazards Earth Systems Sciences, n¹3, p. 2707-2716.

Baird, A., O'Keefe, P., Westgate, K.N., Wisner, B. (1975) - Towards an explanation and reduction of disaster proneness, Occasional paper no.11, University of Bradford, Disaster Research Unit.

BASSNETT, S. (2006). 'Faith, doubt, aid and prayer: the Lisbon earthquake of 1755 revisited', European Review 14 (3), p. 321-328.

Béné, C., Godfrey-Wood R., Newsham A., Davies M. (2012) - Resilience: New Utopia or New Tyranny? Reflection about the Potentials and Limits of the Concept of Resilience in Relation to Vulnerability-Reduction Programmes, IDS Working Paper 405.

Birkmann, J., Cardona, O.D., Carreño, M.L., Barbat, A.H., Pelling, M., Schneiderbauer, S., KIenBerger, S., KeILeR, M. (2013) - "Framing vulnerability, risk and societal responses: The Move framework", Natural Hazards, n67, p. 193-211.

Birkmann, J, Kienberger, S, Alexander, D. E. (Eds) (2014a) - Assessment of Vulnerability to Natural Hazards. A European Perspective, Elsevier, Waltham, MA .ISBN: 978-0-12-410528-7.

Birkmann, J, Kienberger S, Alexander, D. E. (2014b) - Vulnerability: a key determinant of risk and its importance for risk management, in Assessment of Vulnerability to Natural Hazards. A European Perspective, Edited by Joern BiRkmann, Stefan KIEnberger, David ALEXANDER, Elsevier, Waltham, MA. pp. IX-XIII, ISBN: 978-0-12-410528-7.

Burton, I., Kates, R. W., White, G. F. (1978) - The environment as hazard, Oxford University Press, Oxford, UK.

Calossi, E., Sberna, S., Vannucci, A.(2012) - Disasters and Corruption, Corruption as Disaster, in Guttry A., Gestri, M., Venturinı, G. (Ed.) International Disaster Response Law, p. 651-683, Hague, Netherlands, Springer.

Chambers, R. (1989) - "Vulnerability, Coping and Policy", Institute of Development Studies Bulletin, $n^{\circ} 20$, p. 1-7.

Cannon, T. (2008) - Reducing People's Vulnerability to Natural Hazards: Communities and Resilience. WIDER Research Paper 34, United Nations University, Helsinki.

CARDonA, O.D. (2004) -The Need for rethinking the concepts of vulnerability and risk from a holistic perspective: A necessary review and criticism for effective risk management. In Mapping Vulnerability: Disasters, Development and People [Bankoff, G., G. Frerks, and D. Hilhorst (eds.)]. Earthscan Publishers, London, UK, p. 37-51.

CARR, L. J. (1932) - Disaster and the sequence-pattern concept of social change. American Journal of Sociology, 38, p. 207-218.

Chester, D. (2008) - The effects of the 1755 Lisbon earthquake and tsunami on the Algarve Region, Southern Portugal, disponível em http://repository.liv.ac.uk/742/5/742. pdf. 


\section{Realidades e desafios na gestão dos riscos \\ - Diálogo entre ciência e utilizadores -}

Coetzee, C., Van Niekerk, D. (2012) - "Tracking the evolution of the disaster management cycle: A general system theory approach”, Jàmbá: Journal of Disaster Risk Studies 4(1), Art. \#54, 9 pages, disponível em: http://dx.doi.org/10.4102/jamba.v4i1.54.

CostA, l., KRopp, j. P. (2013) - Linking operations and definitions of vulnerability: Lessons from case studies in climate-change and risk-hazard context. Sustainability Science 8(1): p. 1-9.

Cutter, S. L., Barnes, L., Berry, M., Burton, C., Evans, E., Tate, E., Webb, J. (2008) - "A placebased model for understanding community resilience to natural disasters", Global Environmental Change, $\mathrm{n}^{\circ} 18$, p. 598-606.

Davis, I., (1978) - Shelter after Disaster. Oxford Polytechnic Press, Oxford.

DYNES, R.R. (2000) - "The dialogue between Voltaire and Rousseau on the Lisbon earthquake: The emergence of a social science view", International Journal of Mass Emergencies and Disasters 18 (1), p. 97-115.

DYNEs R. R. (2003) - The Lisbon Earthquake In 1755: The First Modern Disaster, University of Delaware, Disaster Research Center. Disponivel em http://dspace.udel.edu/bitstream/ handle/19716/294/PP\%20333.pdf?sequence=1.

DYNES, R R. (1997) - The Lisbon Earthquake in 1755: Contested Meanings In The First Modern Disaster. Newark, DE: University of Delaware, Department of Sociology and Criminal Justice, Disaster Research Center, Preliminary Paper 255, disponível em http://udspace.udel.edu/bitstream/handle/19716/656/PP255.pdf?.

Dow, K. (1992) - "Exploring differences in our common future(s): the meaning of vulnerability to global environmental change", Geoforum, n²3, p. 417-436.

Downes, B. J., Miller, F., Barnett, J., Glaister, A., Ellemor, H. (2013) - "How do we know about resilience? An analysis of empirical research on resilience, and implications for interdisciplinary praxis", Environmental Research Letters, n 8, p. 1-8.

ERIKSEN, C. E, GiLL, N. (2010) - "Bushfire and everyday life: examining the awareness action, gap in changing rural landscapes". Geoforum, 41, p. 814-825;

Fekete, A., Hufschmidt, G., Kruse, S. (2014) - "Benefits and Challenges of Resilience and Vulnerability for Disaster Risk Management", International Journal of Disaster Risk Science, DOI 10.1007/s13753-014-0008-3.

Galderisi, A., Ferrara, F.F., Ceudech, A. (2010) - "Resilience and/or Vulnerability? Relationships and Roles in Risk Mitigation Strategies", in Ache P., ILmonen M., Space Is LuXuRY. Selected Proceedings 24th Annual AESOP Conference, p. 388-405.

Holuing, C.S. (1973) - "Resilience and stability of ecological systems", Annual Review of Ecology and Systematics, $\mathrm{n}^{\circ} 4, \mathrm{p} .1-23$.

Hufschmidt, G. (2011) - “A comparative analysis of several vulnerability concepts”, Natural Hazards, $\mathrm{n}^{\circ} 58$, p. 621-643.

INTERNGOVERNAMENTALPANEL ON CLIMATE CHANGE (IPCC) (2012) - Managing the Risks of Extreme Events and Disasters to Advance ClimateChange Adaptation. A Special Report of Working Groups I and II of the Intergovernmental Panel on Climate Change [Field, C.B., V. BARRos, T.F. Stocker, D. Qin, D.J. Dokken, K.L. Ebi, M.D. Mastrandrea, K.J. Mach, G.-K. Plattner, S.K. Allen, M. Tignor, and P.M. Midgley (eds.)]. Cambridge University Press, Cambridge, UK, and New York, NY, USA, $582 \mathrm{p}$.

INTERNATIONAL STRATEGY FOR DISASTER REDUCTION (ISDR) (2005) - Hyogo Framework for Action 2005-2015: Building the Resilience of Nations and Communities to Disasters, UN, disponível em http://www.unisdr.org/files/1037_hyogoframeworkforactionenglish. pdf. 


\section{A conceptualização nos riscos naturais: impactes na ciência e na ação}

INTERNATIONAL STRATEGY FOR DISASTER REDUCTION (ISDR) (2009) - 2009 UNISDR Terminology On Disaster Risk Reduction, UN, disponível em http://www.unisdr.org/files/7817 UNISDRTerminologyEnglish.pdf.

Julãá, R. P., Nery, F., Ribeiro, J. L., Branco, M. C. E Zêzeree, J. L. (2009) - Guia metodológico para a produção de cartografia municipal de risco e para a criação de sistemas de informação geográfica (SIG) de base municipal. Lisboa, Ed ANPC, co-Ed. DGOTDU e IGP, 91 p.

KLeIN, R.J.T., Nicholls, R.J. (1999) - "Assessment of coastal vulnerability to climate change”, Ambio, $\mathrm{n}^{\circ} 28$, p. $182-187$.

Koelsch, W. A. (1969) - "The historical geography of Harlan H. Barrows". Annals of the Association of American Geographers, Vol.59, $\mathrm{n}^{\circ}$ 4, p. 632-651.

Lavell, A. (1996) - Introducción, in Lavell A. and E. Franco (eds.), Estado, Sociedad y Gestión de los Desastres en América Latina. Red de Estudios Sociales en Prevención de Desastres en América Latina, La RED, Tercer Mundo Editores, Bogotá, Colombia, p.11-32.

LavelL, A. (2003) - Local Level Risk Management: Concept and Practices. CEPREDENAC-UNDP, Quito, Ecuador.

Lavell, A., M. Oppenheimer, C. Diop, J. Hess, R. Lempert, J. Li, R. Muir-Wood, and S. Myeong (2012) - Climate change: new dimensions in disaster risk, exposure, vulnerability, and resilience. In Managing the Risks of Extreme Events and Disasters to Advance Climate Change Adaptation [Field, C.B., V. Barros, T.F. Stocker, D. QIn, D.J. Dokken, K.L. Ebi, M.D. Mastrandrea, K.J.Mach, G.-K. Plattner, S.K. Allen, M. Tignor, and P.M. MIDGLEY (eds.)]. A Special Report of Working Groups I and II of the Intergovernmental Panel on Climate Change (IPCC). Cambridge University Press, Cambridge, UK, and New York, NY, USA, p. 25-64.

Lima, Maria Luísa Pedroso de (2008) - Tragédia, risco e controlo: uma releitura psico-social dos testemunhos do terramoto de 1755, Análise Social, vol. XLIII $\left(1 .^{\circ}\right)$, p. 7-28.

Matyas D., Pelling M. (2014) - Positioning resilience for 2015: the role of resistance, incremental adjustment and transformation in disaster risk management policy, Disasters 39(S1): S1-S18. (foi publicada em papel em 2015).

MAnyena, S. B. (2006): “The concept of resilience revisited”, Disasters, 30, p. 433-50.

Marandola, E. JR. E Hogan, D. J. (2004) - "Natural hazards: o estudo geográfico dos riscos e perigos”. Ambiente \& Sociedade, Vol. VII, nº 2 jul./dez., p. 95-109.

MCEnTIRE, D. (2012) - "Understanding and reducing vulnerability: from the approach of liabilities and capabilities". Disaster Prevention and Management, Vol. 21, $\mathrm{n}^{\circ} 2$, p. 206-221.

Miller, F., Osbahr, H., Boyd, E., Thomalla, F., Bharwani, S., Ziervogel, G.,. Walker, B., Birkmann, J., Van Der Leeuw, S., Rockström, J., Hinkel, J., Downing, T., Folke, C., Nelson, D. (2010) - "Resilience and vulnerability: complementary or conflicting concepts?". Ecology and Society, $\mathrm{n}^{\circ} 15$, art.11, disponível em: http://www. ecologyandsociety .org/ vol15/iss $3 /$ art11/.

Mitchell, T. e HaRRIS, K. (2012) - Resilience: A risk management approach. Overseas Development Institute. ODI Background Notes, disponível: www.odi.org.uk.

Mustafa, D. (1998) - "Structural causes of vulnerability to flood hazard in Pakistan". Economic Geography, Vol. 74, n 3, p. 289-305.

O’Keefe, P., Westgate, K., Wisner, B. (1976) - "Taking the naturalness out of natural disasters", Nature, $n^{\circ} 260$, p. 566-577. 


\section{Realidades e desafios na gestão dos riscos \\ - Diálogo entre ciência e utilizadores -}

Paton, D. (2007) - Measuring and monitoring resilience in Auckland, GNS Science Report 2007/18.

Paton, D. (2008) - “Community Resilience: Integrating Individual, Community and Societal Perspective", in Gow, K., Paton, D., eds., The Phoenix of Natural Disasters: Community Resilience, Nova Science Publishers.

Paton, D., Johnston, D. (2006) - Disaster Resilience: An Integrated Approach, Charles C. Thomas, Springfield, IL.

Peluing, M. (2011) - Adaptation to Climate Change: From Resilience to Transformation, Abingdon: Routledge.

PereirA, A.S. (2006) - The opportunity of a disaster: The economic impact of the 1755 Lisbon earthquake. University of York: CHERRY Discussion Paper Series, Centre for Historical Economics and Related Research, DP03/06.

Prince, S. H. (1920) - Catastrophe and Social Change Based Upon a Sociological Study of the Halifax Disaster, University of Columbia, New York, disponível em http://www. gutenberg.org/files/37580/37580-h/37580-h.htm.

Ramos, C.; Zêzere, J.L.; ReIs, E. (2010) - "Avaliação da susceptibilidade aos perigos naturais da Região de Lisboa e Vale do Tejo". Prospectiva e Planeamento. Ordenamento Territorial e Sustentabilidade. Vol. 17, Departamento de Prospectiva e Planeamento e Relações Internacionais, Lisboa, p. 57-73.

Richards, P. (ed.) (1975) - African Environment. Problems and Perspectives. London: International African Institute.

SмIтH, K. (1996) - Environmental Hazards: Assessing Risk and Reducing Disaster. Second Edition. Routledge, London, UK.

SteinBerg, T. (2006) - Acts of God. The unnatural history of Natural Disasters in America. Oxford UniversityPress, NewYork. $2^{\text {nd }}$ Edition, $1^{\text {st }}$ edition 2000.

Tedim, F.; Carvalho, S. (2013) - "A vulnerabilidade aos incêndios florestais: reflexões em torno de aspetos conceptuais e metodológicos". Territorium. 20, p. 85-99. disponível em: http://www.uc.pt/fluc/nicif/riscos/Documentacao/Territorium/T20_artigos/T20_ Artigo08.pdf.

Tedim, F. (2013) - O contributo da vulnerabilidade na redução do risco de incêndio florestal, in Lourenço, L. F. \& Mateus, M. A. (Eds.). Riscos naturais, antrópicos e mistos. Homenagem ao Professor Doutor Fernando Rebelo, Departamento de Geografia. Faculdade de Letras. Universidade de Coimbra, p. 653-666. ISBN: 978-989-96810-1-9.

ToRRY, W. (1979) - Intelligence, resilience and change in complex social systems: famine management in India. Mass Emergencies, 2, p. 71-85.

Udias, A., Arroyo, A.L. (2009) - The Lisbon earthquake of 1755 in the Spanish Contemporary authors, in Mendes-Victor L.A., Oliveira C.S., Azevedo J., Ribeiro A. (Eds) The 1755 Lisbon Earthquake: revisited, Geotechnical, Geological, and Earthquake Engineering, Springer, p. 7-24.

UN (1994) REPORT OF THE WORLD CONFERENCE ON NATURAL DISASTER REDUCTION (Yokohama, p. 23-27 May 1994), disponível em: http://www.preventionweb.net/files/10996_ N9437604.

VoltalRE, (2005) - O Desastre de Lisboa, seguido de Carta a Voltaire por Jean-Jacques Rousseau, Franesi,Lisboa.

WALKer ,J., Cooper, M. (2011) - "Genealogies of Resilience From Systems Ecology to the Political Economy of Crisis Adaptation”, Security Dialogue, n¹4, p. 143-160. 


\section{A conceptualização nos riscos naturais: impactes na ciência e na ação}

WatTs, M., Bohle. H. G. (1993) - "The space of vulnerability: the causal structure of hunger and famine", Progress in Human Geography, n¹7, p. 43-67.

White, G.F., Kates R.W., Burton I. (2001) - Knowing better and losing even more: the use of knowledge in hazards management, Environmental Hazards 3, p. 81-92.

Wisner, B., Blaikie, P., Cannon, T., Davis, I. (2004): At Risk: Natural Hazards, People'sVulnerability, and Disasters, $2^{\text {nd }}$ edition, Routledge, London, UK.

Wisner, B., O'keefe, P., Westgate, K. (1977) - "Global systems and local disasters: the untapped power of peoples' science”, Disasters, $\mathrm{n}^{\circ} 1$, p. 47-57.

Wisner, B., Gaillard JC. (2009) Un introduction to neglected disasters, Journal of Disaster Risk Studies, 2 (3), p. 151-158.

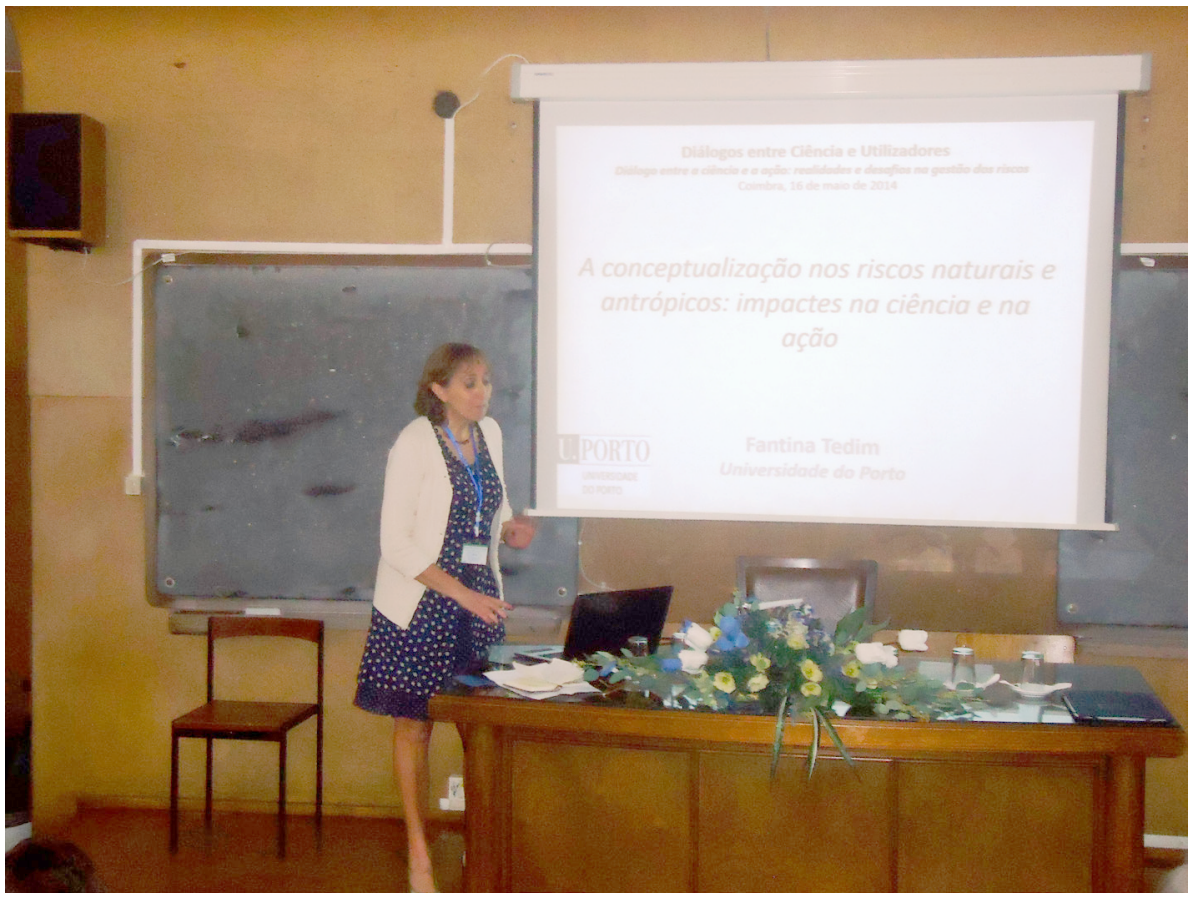





\title{
Capítulo IV
}

\section{GUIA METODOLÓGICO PARA A CARTOGRAFIA DE RISCO. UM PRODUTO DO DIÁLOGO CIÊNCIA/UTILIZADORES}

\author{
Rui Pedro Julião \\ e-GEO - Centro de Estudos de Geografia e \\ Planeamento Regional FCSH/UNL
}

rpj@fcsh.unl.pt

\section{Introdução}

O Território é a base espacial de suporte de qualquer Sociedade, conferindo-lhe parte da sua identidade e proporcionado recursos e oportunidades, e como tal, desde sempre foi importante para o Homem.

As intervenções humanas, em diferentes locais do globo, nas mais variadas escalas e pelas mais variadas razões - mas sobretudo devido ao desenvolvimento tecnológico - registaram, desde a segunda metade do século passado, uma acentuada transformação, quer pelo seu ritmo que acelerou e intensidade que aumentou, quer pelo significado da sua extensão territorial que se expandiu. As transformações espaciais realizaram-se, em muitos casos, a ritmos superiores à capacidade de análise, interpretação e correção por parte do próprio Homem, criando uma série de situações de crise (JuLı̃̃o, 2001).

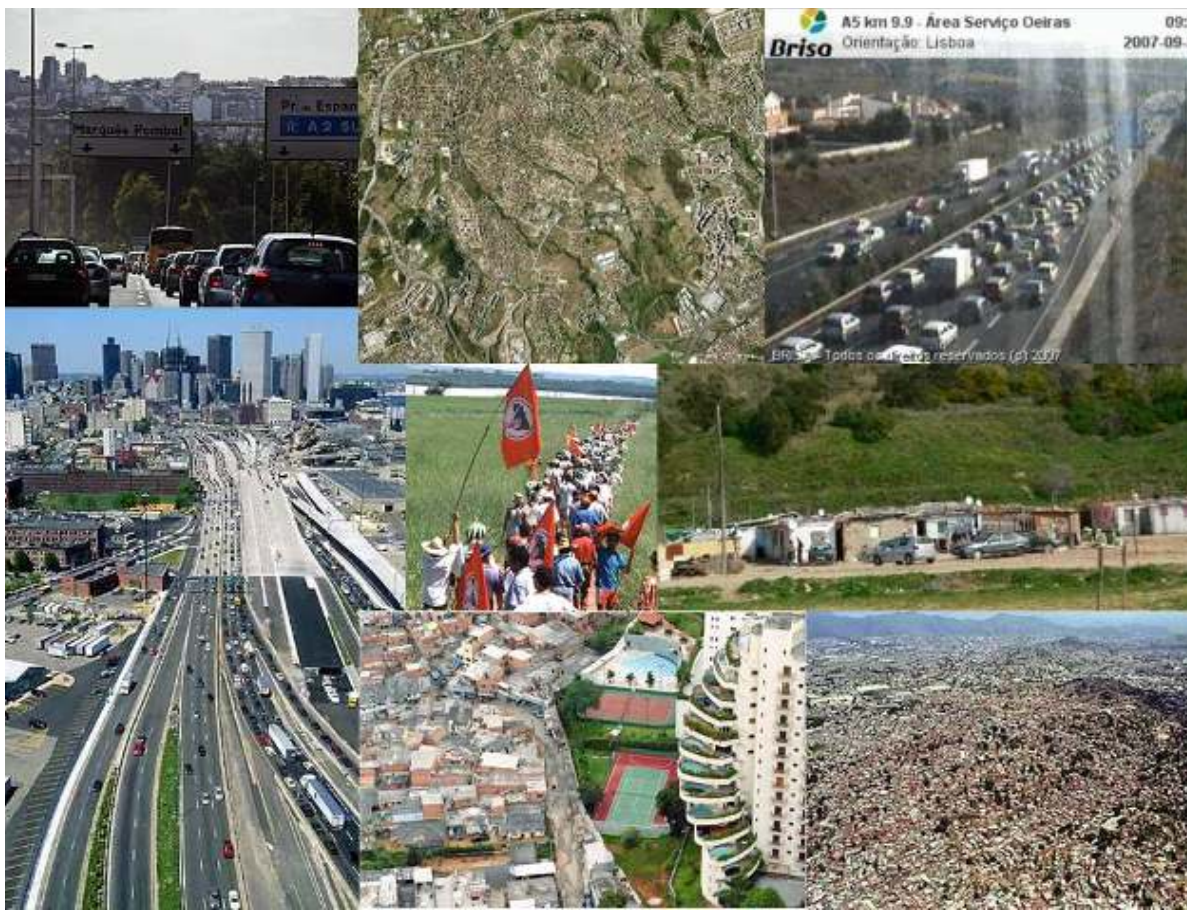

Fig. 1 - Estruturas territoriais complexas.

A dinâmica demográfica e urbana dos grandes centros urbanos sofreu nos últimos 50 anos uma forte acentuação, por via de crescimento natural, mas sobretudo por via de migrações (internas e externas). Como resultado, a pressão sobre o território das áreas mais atrativas atingiu níveis 


\section{Realidades e desafios na gestão dos riscos \\ - Diálogo entre ciência e utilizadores -}

críticos, com a produção de estruturas territoriais cada vez mais complexas e contrastadas, e também se geraram fenómenos de ocupação irregular do espaço, muitas vezes sem a garantia das condições mínimas de habitabilidade e sem o necessário respeito pelas condições ambientais. Consequentemente, foram produzidos territórios "insustentáveis" (entre aspas, dada a prevalência e mesmo crescimento de alguns deles ao longo dos últimos anos) do ponto de vista físico, humano e social.

A Organização das Nações Unidas (ONU) estima que cerca de $50 \%$ da população habite em áreas urbanas, com uma previsão na ordem dos $70 \%$ para 2020 , sendo que um terço o faz em áreas sem condições, designadas em língua Portuguesa por favelas, bairros de lata, musseques ou caniços. Chama também a atenção para a necessidade de analisar de forma cuidada e prospetiva a situação referindo que "Cities must create the conditions (and record accurate data) that will enable them to understand and anticipate trends, including the growth or decline of some areas or regions, if they are to be in a position to develop expansionary or recovery strategies" (UN-HABITAT, 2012: 26).

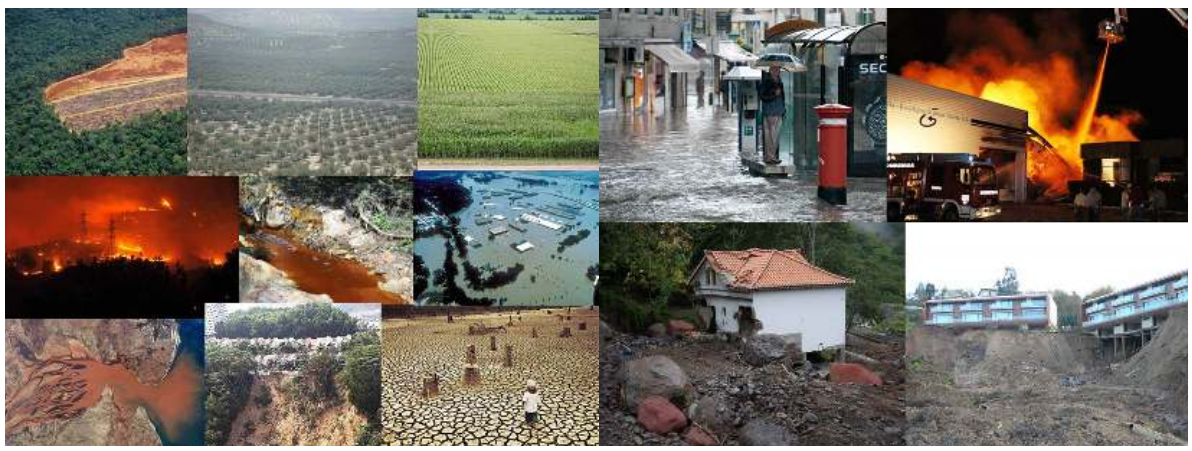

Fig. 2 - Exposição a vários fenómenos e perigos de diferentes tipologias.

Para além dos sobejamente conhecidos problemas das grandes cidades e respetivas áreas metropolitanas, também os restantes territórios se encontram expostos a fenómenos e perigos da mais variada natureza e tipologia, como é o caso das áreas rurais, das áreas litorais e também das grandes áreas de paisagem natural e/ou seminatural.

Por isso, todos os intervenientes nos processos de gestão e decisão territorial, nos seus múltiplos aspetos (físicos e humanos), sentem cada vez mais maiores dificuldades para conjugar a multiplicidade de perspetivas necessárias para uma abordagem territorial integrada e coerente. Essa conjugação é, no entanto, um passo imprescindível para a coordenação das diferentes ações, no sentido de se minimizarem os efeitos negativos de intervenções isoladas ou da falta de perceção dos potenciais impactes territoriais das decisões tomadas. Como salienta
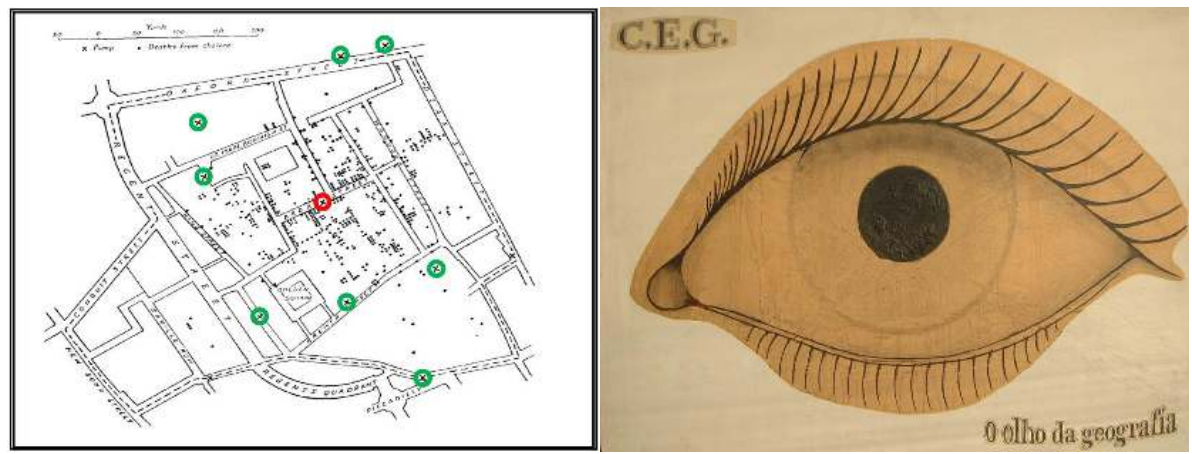

Fig. 3 - Metodologias e tecnologias “do passado". 


\section{Guia metodológico para a cartografia de risco. \\ Um produto do diálogo ciência/utilizadores}

FERRão (2011:40) há a necessidade de uma "nova concepção de Ordenamento do Território na promoção de uma maior integração das políticas sectoriais, tendo como referências visões partilhadas de base territorial".

Podemos assim dizer que, prevalecendo no essencial válidas, as metodologias e tecnologias "do passado", carecem da capacidade de suportar a nova forma e atuar no domínio da gestão territorial que implica necessariamente considerar e articular as múltiplas perspetivas e interesses que nele se conjugam, em tempo real e prospetivo, o que, no atual contexto, marcado por uma escassez de recursos, torna ainda mais determinante considerar-se estas perspetivas e interesses de uma forma integrada. Ou seja, importa reforçar o conceito e a prática de uma gestão territorial integrada, onde a informação é base do conhecimento de situação, suporte do planeamento e programação, bem como fundamento das decisões que em cada momento devem ser tomadas.

\section{Gestão Territorial e Informação}

Quando se fala da gestão integrada do território, efetua-se a fusão de dois conceitos chave.

O da "gestão" como o conjunto de tarefas que procuram garantir a afetação eficaz de todos os recursos disponibilizados a fim de serem atingidos os objetivos pré-determinados. Ou seja, a otimização do funcionamento, neste caso de um determinado território, através da tomada de decisões racionais e fundamentadas na recolha e tratamento de dados e informação relevante e, por essa via, contribuir para o seu desenvolvimento e para a satisfação dos interesses e necessidades dos seus atores e agentes no geral ou de um grupo em particular.

Mas não se trata de uma gestão individualizada, potencialmente ad-hoc, mas sim integrada. Ou seja, articulando as várias componentes do território e as diferentes perspetivas e interesses que os stakeholders têm sobre ele.

Resumindo, quando se fala de gestão integrada do território, fala-se efetivamente de um conjunto de políticas públicas articuladas que devem criar as condições de base para que, através das suas componentes instrumentais, se promova o desenvolvimento sustentável da sociedade.

No que se refere ao conjunto de políticas de Ordenamento do Território, houve a preocupação em criar uma base organizada que está materializada no PNPOT - Programa Nacional da Política de Ordenamento do Território, aprovado pela Lei n. ${ }^{\circ} 58 / 2007$, de 4 de setembro, que vem estabelecer um quadro orientador para os diferentes instrumentos de gestão territorial, bem como preconizar a necessidade de estes se suportarem em conjuntos de dados geográficos relevantes (MAOTDR, 2007).

Retomando a definição de gestão, é importante frisar que na mesma se dá particular destaque à necessidade de esta ser um conjunto de tomada de decisões racionais e fundamentadas na recolha e tratamento de dados e informação relevante. Ou seja, boa gestão pressupõe boa informação.

Sobre esta questão importa refletir sobre o papel da informação como base material para o estabelecimento e desenvolvimento de um quadro normativo de gestão integrada do território, pois sem antes possuir um conhecimento cabal do mesmo, através de informação integrada do território, tal não parece viável.

Ao invés do domínio das políticas públicas sobre ordenamento e gestão territorial, certo é que nem sempre reveladoras de um espírito integrador, no domínio da informação de base territorial verifica-se uma situação de ausência de políticas públicas consolidadas, quer no que se refere aos dados, quer no que se refere aos instrumentos.

Tal facto tem consequências graves na existência e disponibilidade de conjuntos de dados geográficos relevantes para suportar de forma adequada ações necessárias para uma correta e eficaz gestão integrada do território. 


\section{Realidades e desafios na gestão dos riscos \\ - Diálogo entre ciência e utilizadores -}

Mas a produção de dados geográficos integrados sobre o território baseia-se nalguns pressupostos de base que começam a ficar consolidados muito pelo esforço desenvolvido no plano internacional, mais do que no nacional.

A aprovação da Diretiva INSPIRE (Diretiva 2007/2/EC, do Parlamento Europeu e do Conselho, de 14 de março de 2007) e respetiva regulamentação, onde se incluem modelos de dados para um significativo conjunto de temas relevantes (ver http://inspire.jrc.ec.europa.eu/), a criação e aprovação de um conjunto de especificações ISO da família 19100 e o reconhecimento dos standards Open Geospatial Consortium por parte da esmagadora maioria dos fornecedores de tecnologia, criaram as condições mínimas para um ambiente de produção, gestão e disponibilização de dados geográficos interoperáveis.

No plano conceptual e tecnológico assiste-se a uma clara mudança de paradigma. 0 paradigma de cloud computing, preconizando a existência e a utilização de recursos distribuídos acessíveis através da Internet, tem hoje condições para se expandir ao domínio da informação geográfica e com efeito isso tem acontecido. Hoje é cada vez mais importante falar de Infraestruturas de Dados Espaciais (IDE) em vez de projetos SIG.

As IDE dão, a cada utilizador, a garantia de estar a aceder à informação de melhor qualidade (posicional, topológica e temporal) diretamente a partir do seu produtor. Mais, essa informação, uma vez que é produzida e disponibilizada de acordo com standards reconhecidos, é passível de ser diretamente integrada com outros dados que já existam localmente ou oriundos de diferentes produtores.

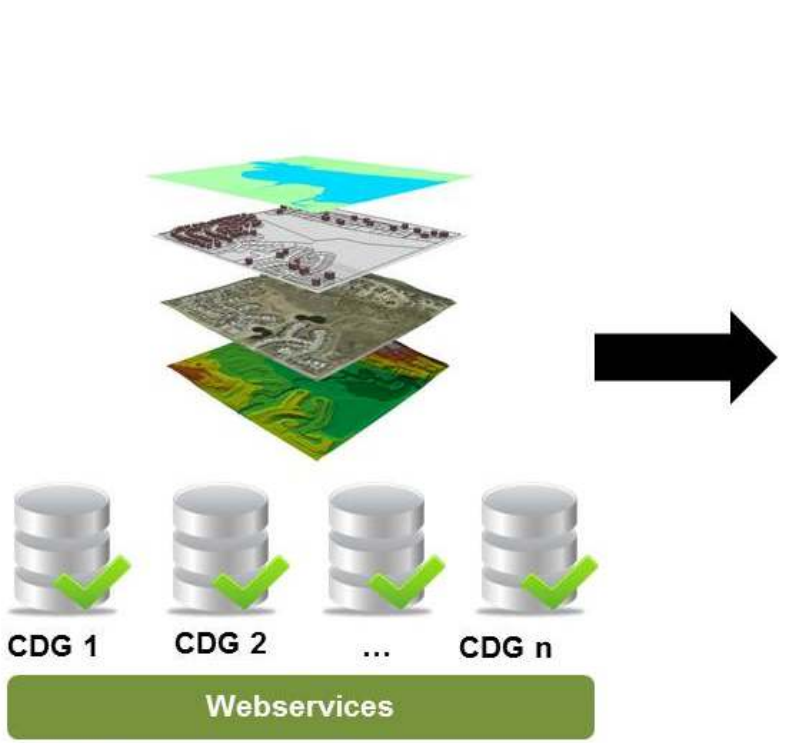

Fig. 4 - Boa gestão implica boa informação.

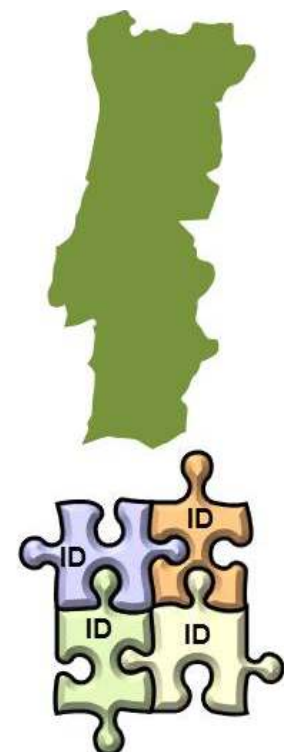

A representação estática do território (digital ou analógica) referente a um determinado momento temporal dos elementos que correspondem a um catálogo de objetos pré definido, base dos processos tradicionais de produção cartográfica, está claramente ultrapassada pela produção e atualização de conjuntos de dados geográficos determinados em função das necessidades dos utilizadores. A carta deixa de ser a base do processo de trabalho para ser o instrumento de comunicação do resultado das análises e decisões propostas. Morreu a "velha" cartografia, viva a "nova" geografia!

Sem uma verdadeira base de informação integrada sobre o território, não se pode promover a sua eficiente gestão. Já no âmbito do relatório do PNPOT foi identificado como um dos vinte e quatro problemas para o Ordenamento do Território a "Insuficiência das bases técnicas 


\section{Guia metodológico para a cartografia de risco. Um produto do diálogo ciência/utilizadores}

essenciais para o ordenamento do território, designadamente nos domínios da informação geo-referenciada sobre os recursos territoriais, da cartografia certificada, da informação cadastral e do acesso em linha ao conteúdo dos planos em vigor" (MAOTDR, 2007: 107). Ideia reforçada por Ferrão (2011:40) quando diz que assim, não é possível construir "visões partilhadas de base territorial".

\section{Guia Metodológico}

No contexto anteriormente enunciado e considerando que as sociedades contemporâneas, as populações, exigem um elevado nível de segurança e bem-estar nos espaços públicos e equipamentos urbanos, nas áreas industriais e nas comunicações, bem como a preservação da qualidade do ambiente, a avaliação e a caracterização metódica dos riscos naturais, tecnológicos e mistos é um dos passos fundamentais para o adequado desenvolvimento dos processos de planeamento de emergência e de ordenamento do território.

Também, do processo contínuo de revisão dos Planos Diretores Municipais (PDM) e dos Planos Municipais de Emergência (PME) a decorrer ao nível nacional, emerge a necessidade da existência de uma metodologia para a elaboração da cartografia de risco metodologicamente harmonizada e adequada princípios atuais de produção e disponibilização de dados geográficos.

Surgiu assim, o "GUIA METODOLÓGICO PARA A PRODUÇÃO DE CARTOGRAFIA MUNICIPAL DE RISCO E PARA A CRIAÇÃO DE SISTEMAS DE INFORMAÇÃO GEOGRÁFICA (SIG) DE BASE MUNICIPAL”, editado em 2009, como uma resposta adequada dos serviços com responsabilidade diretas nas matérias chave, quer no domínio temático (ANPC e DGOTDU), quer no domínio dos dados e tecnologias (IGP).

Este guia é o produto de um trabalho conjunto de um grupo, coordenado pelo Instituto Geográfico Português (IGP) que reuniu especialistas da Autoridade Nacional de Proteção Civil (ANPC) e da Direcção-Geral do Ordenamento do Território e Desenvolvimento Urbano (DGOTDU), em estreita colaboração com uma equipa de peritos da academia portuguesa, oriundos de várias escolas e com diferentes domínios de formação/especialização: Universidade de Lisboa, Universidade de Coimbra e Universidade do Porto.
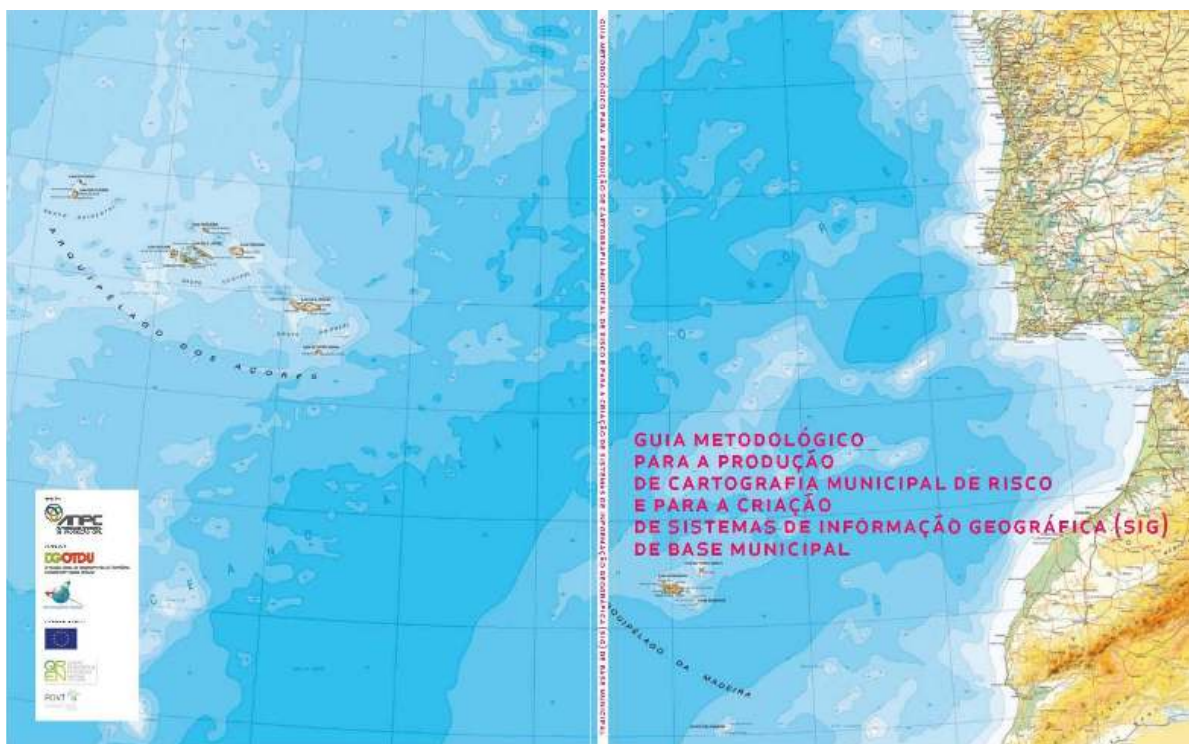

Fig. 5 - Guia Metodológico para a Produção de Cartografia de Risco. 


\section{Realidades e desafios na gestão dos riscos \\ - Diálogo entre ciência e utilizadores -}

O Guia Metodológico veio dar resposta aos objetivos prioritários estabelecidos pelos membros do Governo que criaram o grupo de trabalho, designadamente:

- Identificar e selecionar os tipos de perigos naturais, tecnológicos e mistos significativos a considerar na dupla vertente orientada para a análise e avaliação de riscos e para a definição das orientações metodológicas particulares na produção da cartografia;

- Definir normas técnicas para a produção de cartografia temática de risco de âmbito municipal, incluindo a harmonização dos conceitos, tipologias, designações e formas de representação gráfica;

- Definir orientações técnicas para a construção dos SIG de base municipal, no que respeita a levantamento, monitorização e validação dos dados sobre os riscos naturais e tecnológicos existentes, com o intuito de reforçar a prevenção e o apoio à decisão dos gestores municipais nas melhores soluções de ordenamento e de planeamento de emergência.

Em termos práticos, a solução preconizada pelo Guia Metodológico, é apresentada numa estrutura com um corpo principal, no qual, após um breve enquadramento inicial (capítulo 1), se definem os conceitos fundamentais a aplicar (capítulo 2), se identifica o conjunto global de riscos a partir do qual se fará a seleção dos riscos a cartografar em cada município (capítulo 3) e se explicitam os procedimentos a adotar para a produção da cartografia municipal de risco (capítulo 4). O último capítulo do guia estabelece as linhas de orientação para a criação dos SIG associados a esta temática (capítulo 5).

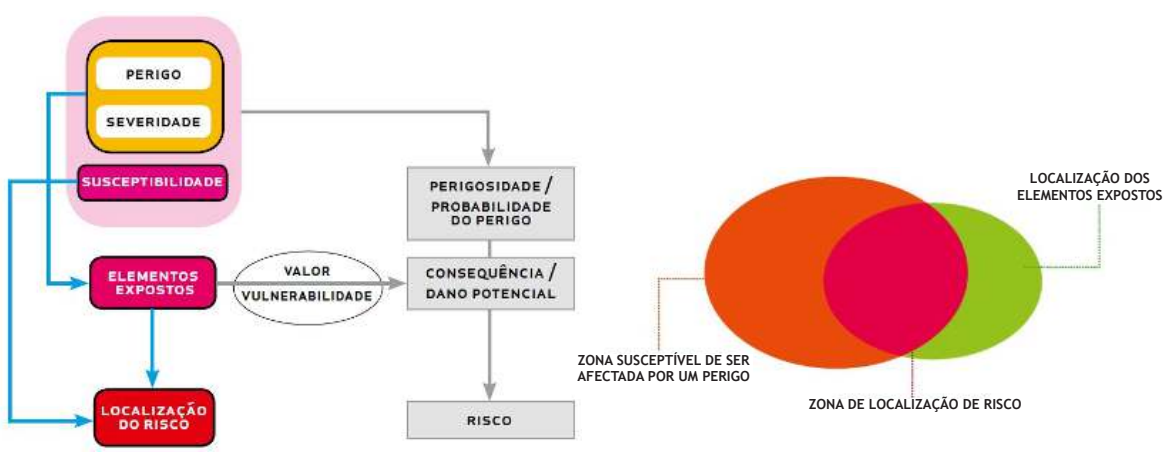

Fig. 6 - Abrangência do Guia.

São ainda providenciados dois importantes anexos onde se apresentam os aspetos metodológicos específicos para a produção das principais peças cartográficas (Cartas de Suscetibilidade e Cartografia de Elementos Estratégicos, Vitais e/ou Sensíveis). De salientar que para a produção do segundo anexo foi efetuado um exercício de compatibilização com o catálogo de objetos da série cartográfica oficial à escala 1:10 000 .

\section{Capacitação dos municípios}

Em Portugal a adoção das novas tecnologias associadas à informação geográfica foi, desde muito cedo, incentivada através de vários programas governamentais. Com efeito, a criação do Sistema Nacional de Informação Geográfica (SNIG) em 1990 e a sua posterior abertura à Internet em 1995, bem como um conjunto de outras iniciativas promovidas pelo Centro Nacional de Informação Geográfica (posteriormente integrado no Instituto Geográfico Português), criaram condições para a grande capacidade nacional e o reconhecimento internacional do nosso País. 


\section{Guia metodológico para a cartografia de risco.}

Um produto do diálogo ciência/utilizadores

Importa aqui destacar a significativa evolução registada pelos municípios. Desde as iniciativas pioneiras do PROGIP e do PROSIG, da década de 90, tem-se assistido à rápida consolidação das suas capacidades.

Se à época existiam pouco mais de uma dezena de exemplos, hoje a realidade é completamente diferente. Vários estudos, realizados nos últimos anos, mostram que há uma cobertura quase integral de utilização dos SIG por parte dos municípios portugueses (JuLião e QueIRós, 2009).

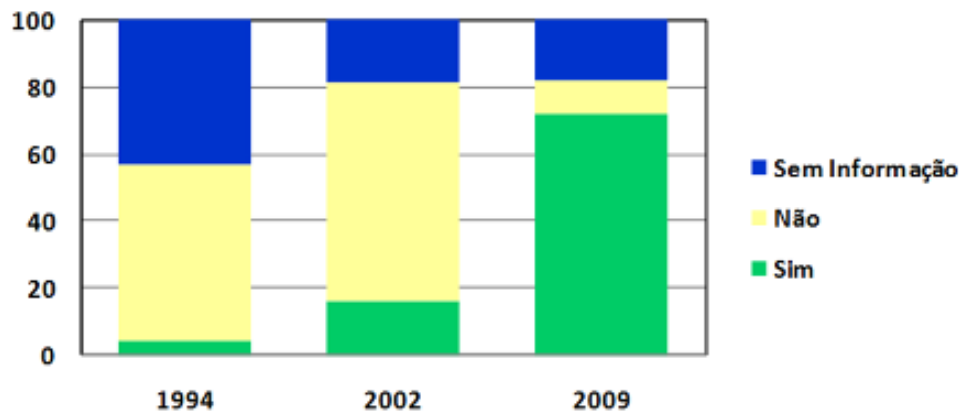

Fig. 7 - Evolução dos SIG nos municípios 1994-2009.

A realidade de utilização dos SIG por parte dos municípios evoluiu assim rapidamente ao longo das últimas três décadas.

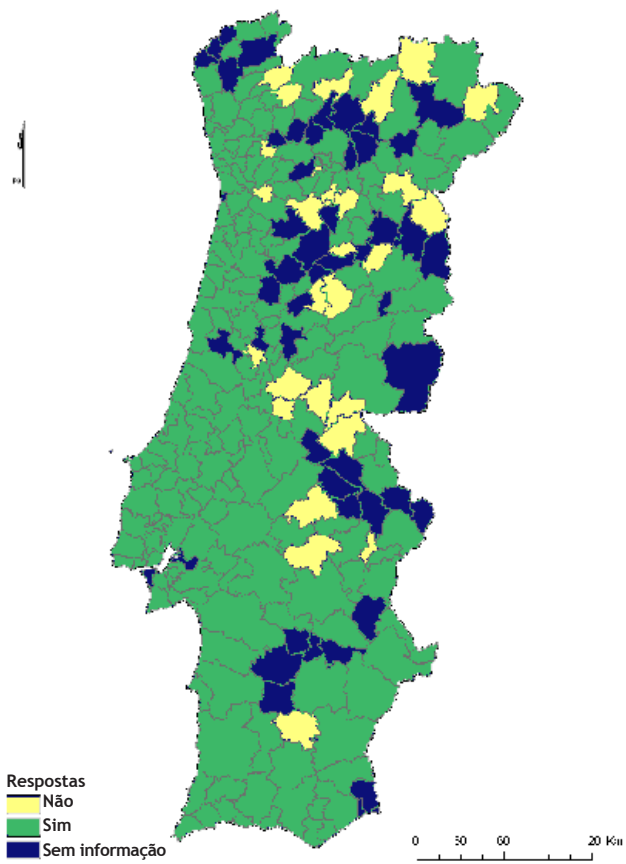

Fig. 8 -Distribuição geográfica da utilização dos SIG nos municípios em 2009. 


\section{Realidades e desafios na gestão dos riscos \\ - Diálogo entre ciência e utilizadores -}

Como muito bem se pode observar pela fig. 7 é possível considerar-se hoje que há uma base instalada de âmbito municipal capaz de responder cabalmente aos desafios de uma moderna gestão e disponibilização de dados geográficos.

\section{Modelos de negócio}

A construção e exploração de uma infraestrutura que promova o incremento do conhecimento territorial é imprescindível para o desenvolvimento. Mas a construção desta infraestrutura implica a necessária mudança de algumas perspetivas e paradigmas que ainda subsistem, senão veja-se:

- Não faz sentido não haver uma maior articulação do investimento público, por forma a assegurar a existência de uma série de conjuntos de dados geográficos estratégicos para o país, de qualidade, bem como a sua contínua atualização;

- Não faz sentido não haver uma maior descentralização do processo produtivo de conjuntos de dados geográficos vetoriais básicos, envolvendo diretamente os municípios ou as comunidades intermunicipais;

- Não faz sentido não haver condições de acesso aos conjuntos e serviços de dados geográficos estratégicos para o país que promovam a sua efetiva utilização pública, a criação de valor acrescentado e o suporte à investigação e docência;

- Não faz sentido não haver um maior aproveitamento e integração do contributo participativo dos cidadãos.

O caminho a percorrer e os passos a dar são conhecidos e Portugal tem de construir uma agenda para o fazer, não por os outros países já o estarem a praticar, mas para incrementar a sua competitividade e promover o desenvolvimento.

Um território bem pensado e gerido e uma administração ágil são peças imprescindíveis numa sociedade moderna. FERRão (2011:115) refere que "mais e melhor informação, conhecimento, organização e tecnologias inovadoras de suporte" são as componentes-chave que uma moderna política pública de ordenamento do território exige, o que aliás é concordante com a perspetiva de que a "boa gestão do território pressupõe a disponibilidade e difusão alargada de informação e de conhecimentos actualizados sobre os recursos existentes $e$ as dinâmicas e perspectivas de desenvolvimento às escalas nacional, regional e local" (MAOTDR, 2007: 221).

Mas hoje nada se pode fazer sem o envolvimento dos cidadãos. 0 território é deles, dos atuais e das gerações futuras. O conceito de Volunteered Geographic Information (VGI) cunhado por GoodCHILD (2007) é a consolidação de um movimento que emergiu a partir de meados da década passada usufruindo do avanço das plataformas tecnológicas e da crescente sensibilização de todos para consciencialização geográfica. No sentido de que tudo acontece algures e através da espacialização dos fenómenos e interesses, bem como da sua interação é possível melhor compreender, usufruir, potenciar e preservar o território.

Cabe no entanto ao Estado pensar e promover um modelo de organização que providencie o adequado ambiente colaborativo para fomentar a aquisição, gestão e exploração de conjuntos de dados geográficos relativos a temas estruturantes do território ou de elevado interesse para a Administração, muitos deles já preconizados no âmbito da Diretiva INSPIRE.

A criação deste ambiente passa necessariamente pela discussão e formalização de novos modelos de negócio que viabilizem económica e financeiramente a sua concretização. 0 atual sistema de financiamento da produção e gestão de dados geográficos impele os organismos públicos responsáveis por estas tarefas para uma atitude mercantilista, muitas vezes concorrencial, com os profundos efeitos negativos que todos acabamos por sentir.

No atual paradigma da sociedade da informação e conhecimento, as economias relacionadas com a informação são cruciais para o crescimento, competitividade e emprego, garantindo 
aos cidadãos uma melhor qualidade de vida enquadrada numa lógica de desenvolvimento sustentável. As infraestruturas de informação são os pilares deste novo paradigma (Castells e Himanen, 2002).

Os EUA, confirmando os bons resultados das iniciativas lançadas no final do século passado (entre outras a criação dos precursores ficheiros TIGER), vieram agora reafirmá- las, conforme se pode verificar pela nota disponibilizada pelo National States Geographic Information Council (NSGIC) em novembro de 2011 onde afirma que "strongly believes that open sharing of geospatial data is in the best interest of our communities, states and nation. One of our goals is to make all non-sensitive geospatial data, produced or maintained using taxpayer funds, a part of the public record" (NSGIC, 2011).

$\mathrm{Na}$ Europa, onde grande parte dos dados geográficos são criados e geridos por entidades públicas e sempre prevaleceu um modelo de cost-recovery ou mesmo de base comercial (do qual o exemplo paradigmático é o Ordnance Survey, UK), fruto das pressões da União Europeia (de que é um excelente exemplo a Diretiva 2003/98/EC sobre a reutilização dos dados do sector público, vulgarmente conhecida como Diretiva PSI) e de movimentos colaborativos (como por exemplo o Openstreetmap) começa a registar-se alguns sinais de mudança.

O Reino Unido lançou em 2008 a Location Strategy que, de acordo com o relatório que a sustenta, procura "maximise exploitation and benefit to the public, government and UK Industry from geographic information and to provide a framework to assist European, national, regional and local initiatives (...) build a coherent Information and Communication Technology (ICT) oriented information infrastructure for place-based information, which will assist policy, local service delivery and operational decision making" (GI PANEL, 2008: 10).

A Dinamarca, numa iniciativa enquadrada na estratégia de e-Government 2013-2016, estabelecida em conjunto pelo governo e municípios do país, reconhecendo o valor estratégico da informação geográfica e do livre acesso a esta por parte do sector público, das empresas e dos cidadãos, decidiu disponibilizar, desde 1 de janeiro de 2013, livre e gratuitamente, os dados topográficos, cartográficos, cadastrais e endereços.

A Islândia anunciou que a janeiro de 2013 "digital maps and Spatial Data held by the National Land Survey of Iceland has been made free of charge, as determined by Svandís Svavarsdóttir Environment and Natural Resources Minister. The data is used in various projects of state agencies such as registration, planning, nature conservation, natural hazards, energy, research and public projects, but they also benefit the public and businesses in various ways. The purpose of making digital maps and Spatial Data free of charge is to ensure that the general public in Iceland is guaranteed easy access to information about the environment and nature of Iceland. The goal is also to encourage increased use, processing and dissemination of this data, for example in the field of tourism, public administration and education" (LMI, 2013).

São apenas três exemplos de casos europeus onde já se consolidou o pensamento de que a informação geográfica é um pilar imprescindível da sua estratégia de competitividade e desenvolvimento, na linha do que há muito vem a ser defendido, designadamente pelos vários estudos e iniciativas de suporte à Diretiva PSI. É indubitável o valor acrescentado da informação geográfica de qualidade para o bom funcionamento da economia (LoENEN e ZEVENBERGEN, 2010).

\section{Conclusões}

Um território bem pensado e gerido e uma administração ágil são peças imprescindíveis numa sociedade moderna. Para o efeito há vários requisitos que têm de ser reunidos.

Como se viu a informação desempenha um papel crítico no suporte à correta e eficaz gestão do território, mas também é importante haver bases. Bases institucionais, metodológicas e tecnológicas. 


\section{Realidades e desafios na gestão dos riscos \\ - Diálogo entre ciência e utilizadores -}

O Guia aqui referido é um claro exemplo de sucesso do esforço conjunto entre a ciência e os utilizadores. Sem a conjugação do conhecimento e da investigação das universidades nacionais com a experiência dos serviços que estão no terreno, não seria obter uma base de apoio utilizável em contexto real.

No plano institucional, verifica-se que os serviços da administração pública podem ainda incrementar o seu potencial se melhor se explorar o potencial existente ao nível municipal.

Em Portugal, não obstante a iniciativa da Agência de Modernização Administrativa que vem disponibilizar num portal (www.dados.gov.pt) alguns dados produzidos pela Administração Pública para que possam ser acedidos e reutilizados, prevalecem os condicionalismos no que se refere aos dados geográficos, pois é quase nula a sua presença neste portal (resume-se a dois registos: rede de nivelamento geométrico e rede de geodésica nacional).

A iniciativa iGEO (www.igeo.pt), lançada em 2014, veio colmatar algumas lacunas ao nível da disponibilização de dados para efeitos de visualização, mas prevalece ainda o bloqueio na sua acessibilidade para efeitos de manipulação e análise. É este o grande salto que nos falta dar em Portugal, pois o Território é a base e só com a conjugação dos princípios anteriormente referidos e ilustrados e a implementação das políticas e instrumentos que lhes estão subjacentes é que será possível ter uma verdadeira gestão territorial no seu pleno sentido e uma sólida base de promoção da competitividade e desenvolvimento do País.

\section{Referências Bibliográficas}

Afonso, A.; Martins, F.; Dias, R.; Mendes, V.B. (2007) - O projecto SERVIR do IGeoE a suas aplicações, Cartografia e Geodesia 2007, J. CASACA e J. MATOs (Eds.). Lisboa, Lidel, Lda: p. 409-422.

Castells, M.; Himanen, P. (2002) - The Information Society and the Welfare State: The Finnish Model. New York, Oxford University Press, 200p.

Ferrão, J. (2011) - O Ordenamento do Território como Política Pública. Lisboa, Fundação Calouste Gulbenkian, 146 p.

Geirinhas, J.; Gomes, A.L.; Fonseca, A.; Santos, A.S.; Silva, H. e Julião, R.P. (2011) - "Aplicação da Directiva INSPIRE em Portugal - Monitorização 2011”, JIIDE 2011 - II Jornadas Ibéricas de Infra-estruturas de Dados Espaciais, ICC, Barcelona (Espanha).

GI PANEL (2008) - Place matters: the Location Strategy for the United Kingdom. Londres, Communities and Local Government Publications, 38p.

GoodCHILD, M.F. (2007) - Citizens as sensors: the world of volunteered geography". GeoJournal, 69 (4): p. 211-221.

Julião, R.P.; Nery, F.; Ribeiro, J.L.; Castelo Branco, M. e Zêzere, J.L. (2009) - Guia metodológico para a produção de cartografia municipal de risco e para a criação de Sistemas de Informação Geográfica (SIG) de base municipal. ISBN 978-989-96121-4-3, Lisboa, ANPC, 91p.

JuLIão, R.P.; Quelrós, M.I. (2009) - "Realidade Municipal face aos Sistemas de Informação Geográfica”, VII Congresso da Geografia Portuguesa, APG e CEGOT, Coimbra.

Julião, R.P. (2001) - Tecnologias de Informação Geográfica e Ciência Regional - Contributos Metodológicos para a Definição de Modelos de Apoio à Decisão em Desenvolvimento Regional. Doutoramento, Universidade Nova de Lisboa.

Loenen, B. Van; Zevenberben, J. (2010) - “Assessing Geographic Information Enhancement”. International Journal of Spatial Data Infrasrtuctures Research, 5: p. 244-266.

LMI (2013) - Digital cartography and geographic information NLSI made free of charge, disponível em: http://www.lmi.is/stafraen-kort-og-landupplysingar-lmi-gerd-gjaldfrjals/. 
Guia metodológico para a cartografia de risco.

Um produto do diálogo ciência/utilizadores

MAOTDR (2007) - PNPOT. Programa Nacional da Política de Ordenamento do Território. Lisboa, MAOTDR, $226 \mathrm{p}$.

MARTINS, C.; VAsconcelos, M. (2011) - "A evolução da RENEP: produtos, serviços e utilizadores", VII Conferência Nacional de Cartografia e Geodesia, Ordem dos Engenheiros, Porto.

NSGIC (2011) - Geospatial Data Sharing Guidelines for Best Practices, disponível em: http:// www.nsgic.org/public_resources/NSGIC_Data_Sharing_Guidelines_120211_Final.pdf.

PINA, C. (2011). A nova regulamentação da cartografia nos IGT. Lisboa, Ordem dos Engenheiros. 15p, disponível em: http://www.ordemengenheiros.pt/fotos/dossier_artigo/ carlospina17691005044de3c65b5f890.pdf.

Roque, C.; Neto, J.P. e Julião, R.P. (2007) - Cadastro Predial e Informação de base cadastral, Cartografia e Geodesia, J. CASACA e J. MATOS (Eds.). Lisboa, Lidel, Lda: p. 525-536.

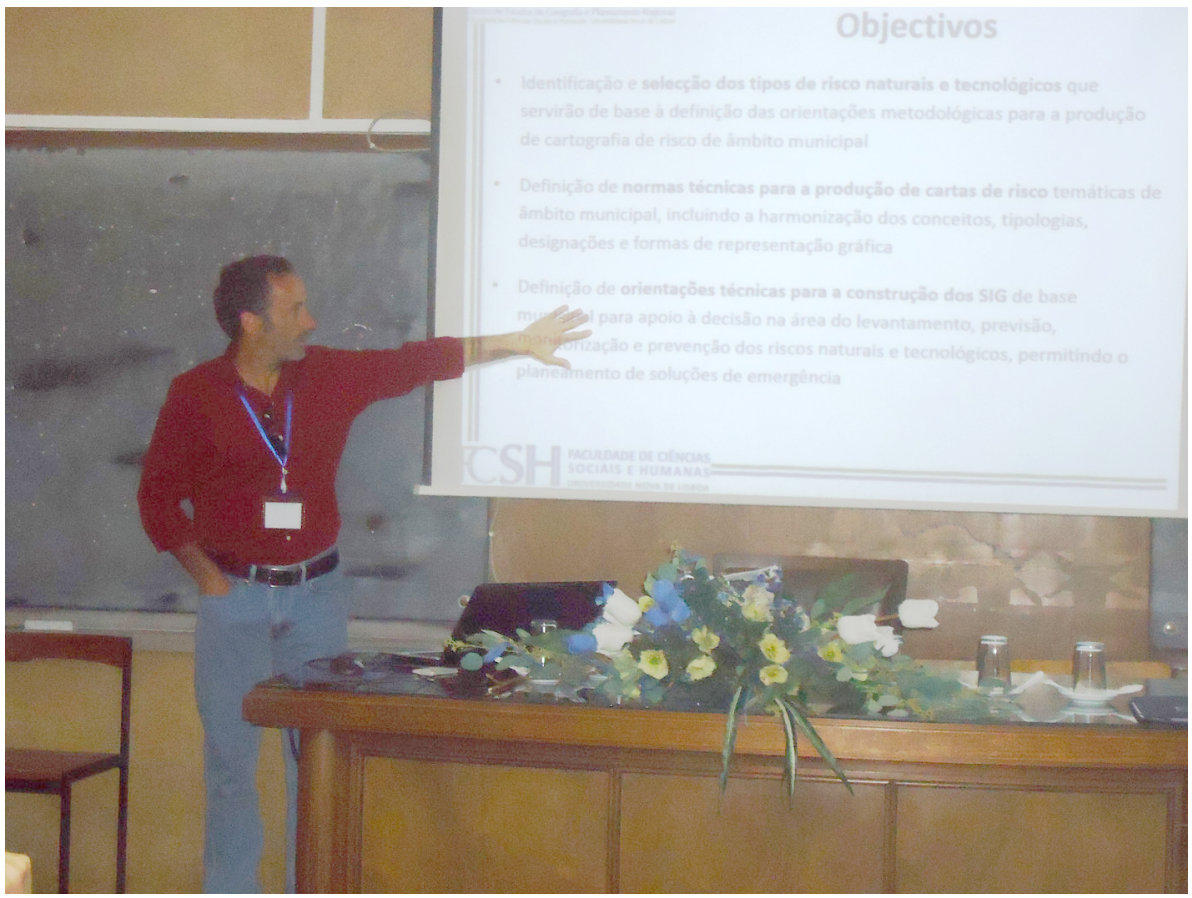





\title{
Capítulo V \\ RISCOS E PERIGOS EM TRADUÇÃO. \\ CONSIDERAÇÕES SOBRE TERMINOLOGIA NAS CIÊNCIAS CINDÍNICAS
}

\author{
Isabel Pedro \\ Faculdade de Letras da \\ Universidade de Coimbra \\ isabel_pedro@sapo.pt
}

\section{Introdução}

$\mathrm{Na}$ "Nota de Abertura" do $\mathrm{n}^{\circ} 16$ da Revista Territorium, em que é publicada uma série de artigos, da autoria de especialistas de diversas áreas científicas e em diferentes línguas, sobre a temática dos riscos, Fernando Rebelo afirma reconhecer que "numa área científica multidisciplinar, como a dos riscos, as divergências de linguagem são perfeitamente aceitáveis". Refere depois, apesar disso, que identifica a existência de "dificuldades em traduzir certas palavras inglesas ou francesas", as quais, diz: "têm levado a muitas confusões". Dados alguns exemplos do problema, que ilustra sobretudo com o termo inglês hazard, e sugerindo algumas hipóteses de solução, o autor convida então os leitores da revista a fazerem "um esforço de entendimento de idiomas e de conceitos". ${ }^{1}$

O contexto em causa é o das Ciências Cindínicas, uma área de conhecimento recente, de natureza multidisciplinar, o que por si só parece poder justificar a ausência de uma terminologia consensual e normalizada. Nos cada vez mais intensos intercâmbios internacionais (e também nos nacionais), nos diversos fora e nas inúmeras publicações da área, a dilucidação de conceitos e de modelos teóricos e o estabelecimento de equivalências terminológicas têm claramente vindo a ser sentidos como uma necessidade. ${ }^{2}$

Nesse âmbito, do ponto de vista de uma estudiosa de línguas e de tradução (e também tradutora), as observações do autor que comecei por citar parecem-me extremamente pertinentes, porquanto, ao invés de pressuporem uma relação unívoca e isenta de tensões entre termos do mesmo sistema linguístico ou, a um outro nível, entre termos ditos "equivalentes" em duas línguas diferentes, deixam perceber um entendimento mais complexo da linguagem e do seu funcionamento e, portanto, uma consciência perspicaz da problemática da tradução (e dos seus riscos).

É, de facto, necessário, fazer-se "um esforço de entendimento de idiomas e de conceitos". Se a língua que usamos parece apresentar-se-nos como "natural", já o confronto de línguas não pode deixar de evidenciar a não linearidade da sua relação com o mundo como o concebemos, percecionamos e sentimos (nas várias línguas, na nossa própria língua).

A linguagem, e refiro sobretudo, claro, a linguagem verbal, é o meio humano privilegiado de descrever o "real" e de o comunicar. É, obviamente também, o meio de "dominarmos" esse real, aliás um dos objetivos de sempre da ciência e dos seus discursos. Porém, é necessária a consciência de que, parafraseando Jonathan Culler, os objetos e os acontecimentos não são simplesmente objetos e acontecimentos em si mesmos e sim objetos e acontecimentos sempre já com significado, ou melhor, com significados, culturalmente atribuídos ou impostos.

\footnotetext{
${ }^{1}$ Cf ainda, do mesmo autor, em número posterior da revista: «Toda esta diversidade vem enriquecendo a Territorium. Por um lado, a variedade temática, por outro lado a dispersão espacial. Mas a formação dos autores leva-os, frequentemente, a utilizar designações diferentes para situações semelhantes. Como já tenho salientado em notas de abertura de números anteriores, isto não cria qualquer problema científico, mas exige grande atenção da parte dos leitores. A dificuldade em traduzir "hazard", por exemplo, continua a dar resultados curiosos quando aparecem palavras de que nunca nos tínhamos lembrado.". (Territorium 19, p. 3).

2 Ver, por exemplo, os «Comentários ao modelo proposto no Guia Técnico para Elaboração do PMDFCl», sob o título «"PERIGOS” DAS “CARTAS DE RISCO”», da autoria de Luciano LouRENço (Territorium 15, pp. 122-126). $O$ autor reconhece que alguns dos conceitos em causa não merecem ainda a concordância da generalidade da comunidade científica e refere inclusivamente a colisão de interpretações de modelos e respetivos conceitos existente entre diferentes organismos do Estado.
} 


\section{Realidades e desafios na gestão dos riscos \\ - Diálogo entre ciência e utilizadores -}

É necessário ainda perceber que tais acontecimentos e objetos, fenómenos e "coisas" não possuem "essências" mas se definem numa rede de relações internas e externas.

Como eles, os signos linguísticos que pretendem referi-los/descrevê-los/comunicá-los/ estabelecer relações entre eles e entre eles e nós não são "naturais" e não têm um significado intrínseco, antes obtêm o seu sentido, em cada contexto específico, no âmbito de uma rede de relações na qual ocupam determinado lugar, um lugar que é caracterizado/ identificado pela sua diferença em relação aos outros signos e thes concede um determinado valor, um - ou mais - sentido(s).

Importante para a presente discussão é a dimensão paradigmática dessa diferença, sendo que o valor/o sentido de um elemento depende das diferenças entre esse elemento e outros elementos que, numa dada sequência discursiva, ou sintagma, poderiam ter ocupado ou ocupar o mesmo lugar (e avancemos já, como exemplo, com os termos ingleses danger, hazard, peril, jeopardy, risk, ou mesmo threat, etc., os quais podem, de uma forma geral, ser considerados sinónimos, mas que, apesar disso - ou por essa mesma razão - não significam exatamente o mesmo. Voltaremos a esta questão mais adiante.

No caso dos signos linguísticos, como há muito ensinou SaUssure, o sentido tem uma base convencional e arbitrária; ou seja, a dinâmica de significação não funciona por semelhança, como um retrato que, por via da sua iconicidade, representa e significa a pessoa retratada, mas sim pela imposição de uma regra, uma lei que liga um significante a um significado (digamos que a forma da palavra, a parte material do signo, ao seu sentido, o conceito que evoca) sem uma prévia relação de semelhança, como a do ícone, ou de contiguidade, como a do índice (o fumo que indica fogo). ${ }^{3}$ Essa regra ou lei que estabelece a relação de significação é então a convenção, indissociável da arbitrariedade.

Isto significa que os laços que possibilitam e ancoram a significação são instáveis - enquanto a convenção é uma força que une significante e significado, gerada pela repetição (a regra no sentido de regularidade, mas também de normatização, dependente esta de uma autoridade reguladora do sentido), a imotivação do signo e a sua arbitrariedade implicam, no sentido oposto, a instabilidade, o carácter não definitivo dessa ligação. Digamos que, por um lado, a convenção permite que a língua possa funcionar como "comunicação", se quisermos, mas a arbitrariedade implica um espaço (o espaço do sujeito?) que impede que o sistema se feche e the confere dinamismo, gerando mudança e a possibilidade de atualização (e, por vezes, voltando a citar ReBelo, "muitas confusões").

Gostaria de observar brevemente que esse carácter arbitrário é aquele que induz a polissemia, os diferentes valores semânticos de uma mesma palavra, que permite o lado criativo da linguagem, que permite a expressão (mais do que a comunicação), que permite a metáfora e a poesia, e que, tradicionalmente, a ciência deveria minimizar na sua necessidade de controlo e (de)limitação do sentido, na sua histórica orientação para a comunicabilidade neutra e objetiva - que a linguagem de facto não permite.

A linguagem não existe sem o sujeito (e vice-versa, como defende BENVENISTE, o sujeito não existe sem a linguagem) e a relação da linguagem com aquilo a que chamamos "o real" é mediada exatamente por essa posição subjetiva, sempre presente. Sendo uma forma de descrever o real e de o conhecer, a linguagem (e qualquer língua) inclui necessariamente uma perspetiva, uma posição dentro desse real e sobre ele. Como facto cultural/ideológico que permite o nosso conhecimento daquilo a que chamamos, por exemplo, a natureza, a linguagem impede de facto que esse conhecimento seja objetivo, neutro, absoluto. Ou seja: a realidade-dita já não é a realidade e sim uma visão dela, tingida das cores da nossa visão do mundo, da organização do real que a nossa língua, a nossa história, a nossa cultura, a nossa "ciência" nos facultam, simultaneamente possibilitando, refletindo e limitando, ou pelo menos condicionando, o nosso contacto com esse real.

\footnotetext{
${ }^{3}$ A clássica tipologia do signo como ícone, índice ou símbolo, três formas diferentes de representação do objeto, deve-se a Charles Pierce.
} 
Assim, resumindo, vários ângulos convergentes nos podem ajudar a perceber esse fenómeno:

1. O sujeito como posição inevitável em qualquer ato de linguagem - porque é a única instância capaz de produzir o discurso, que o implica como situado no centro do sistema da língua e, por assim dizer, no centro do mundo;

2. A perspetiva desse sujeito;

3. A natureza convencional e arbitrária da unidade de sentido: o signo linguístico, cuja dinâmica é gerida, em qualquer ato de linguagem, em qualquer nomeação do real, pelo sujeito.

Há exemplos "clássicos" que nos permitem constatar como a linguagem produz e afeta a nossa experiência e o nosso conhecimento do mundo e como depende também desse mundo e dessa experiência. As diferentes línguas integram diferentes visões do mundo e diferentes formas de organização e conceptualização do real, funcionando cada uma na base de quadros de perceção específicos. 0 já lugar-comum do extensíssimo léxico Esquimó-Inuit relativo a neve, referido no séc. XIX pelo antropólogo Franz BoAs (e até hoje origem de grandes polémicas e de continuada discussão entre especialistas) é de alguma forma corroborado por estudos mais recentes, que revelam, por exemplo, que as línguas Esquimós (Yupic e Inuit) possuem dezenas, se não centenas, de palavras para neve e gelo; os Sami, no norte da Rússia e da Escandinávia, que também possuem pelo menos 180 vocábulos diferentes para neve e gelo, parecem ter um vocabulário de perto de 1000 termos diferentes para "rena", ou seja, existirá para os falantes dessas línguas um milhar de animais diferenciados por determinadas características relevantes, que são para nós - porque falamos Português e só possuímos o termo "rena" - impossíveis de conceptualizar/imaginar ou de distinguir como objetos diferentes! ${ }^{4}$

Mas não é necessário deslocarmo-nos tão longe em termos geográficos para percebermos, por exemplo, pelo contraste entre a língua portuguesa e a língua inglesa, uma diferente estruturação/conceptualização do mundo a partir daquele que é um conceito básico para a geografia: o espaço, e a sua divisão operada pela posicionalidade do sujeito na sua relação de oposição com o outro. Vejamos:

Inglês:

2 pólos

here / there
Português:

3 pólos

\section{Advérbios}

\begin{tabular}{|c|c|c|}
\hline \multirow{2}{*}{ here / there } & & aqui (cá) / aí / ali (lá ou acolá) \\
\hline & Demonstrativos & \\
\hline is (these) / that (those) & & $\begin{array}{l}\text { isto/ isso / aquilo (formas invariáveis } \\
\text { neutras) }\end{array}$ \\
\hline IIs (these) / Chat (triose) & & $\begin{array}{l}\text { este }(\mathrm{a})(\mathrm{s}) \text { / esse }(\mathrm{a})(\mathrm{s}) \text { / aquele }(\mathrm{a})(\mathrm{s}) \\
(\text { formas variáveis também em género) }\end{array}$ \\
\hline
\end{tabular}

A estes signos, que, com outros do mesmo tipo, marcam a posição do sujeito (da pessoa que fala e, dialogicamente, da sua interlocutora), no espaço ou no tempo, sinalizando, na sua auto-referencialidade, as condições específicas de cada enunciação ou ato de fala, chamamos deíticos, sendo os que apresentei conhecidos como topemas, uma vez que designam relações espaciais.

Como podemos ver, a divisão espacial disponível aos falantes de inglês, e, portanto, a sua conceptualização de espaço, é marcada por uma estrutura bipartida, distinguindo apenas o "próximo" (perto do sujeito) e o "distante" (longe do sujeito), enquanto em português

Cf.http://www.washingtonpost.com/national/health-science/there-really-are-50-eskimo-words-forsnow/2013/01/14/e0e3f4e0-59a0-11e2-beee-6e38f5215402_story.html (acedido a 15.5.2014) 


\section{Realidades e desafios na gestão dos riscos \\ - Diálogo entre ciência e utilizadores -}

existem outras distinções mais detalhadas, num paradigma espacial tripartido que tem por base a tríade das pessoas gramaticais: eu / tu / ele-ela. Assim, poderíamos dizer que em inglês o espaço do real é dividido em espaço-perto-de-mim e espaço-longe-de-mim enquanto em português existem "mais" ou "outros" espaços: o espaço-perto-de-mim, o espaço-não-tãoperto-de-mim-mas-perto-de-ti e o espaço-longe-de-mim-e-de-ti, que é o espaço do ele-ela.

Será então que há espaços em português que não existem em inglês? Poderíamos metaforicamente falar de espaços do real que, sendo "ausentes" numa determinada língua, são, por isso, intraduzíveis?

Nesse âmbito se situa, por exemplo, a questão da diferença/oposição entre hazard e risk (ou danger) em inglês, a qual não existe na língua portuguesa. Aqui estamos numa situação inversa: em inglês a noção de "perigo" é mais detalhada do que em português, há mais signos em oposição nessa área semântica na língua inglesa do que na portuguesa; ou seja, parece haver no inglês uma conceptualização mais complexa, mais elaborada, de perigo ou risco do que a que existe na nossa língua, o que, como é de esperar, causa necessariamente dificuldades conceptuais e problemas de tradução.

\section{A Questão da Sinonímia}

Podemos considerar que as palavras inglesas hazard e risk são sinónimas. Diferentes dicionários e thesauri postulam a relação de sinonímia entre esses termos e ainda outros como danger, peril, jeopardy, distress, threat, etc. ${ }^{5}$

Lembremos o que já foi referido sobre a dinâmica de significação: o sentido de um signo linguístico é um valor que depende de uma rede de relações (de contiguidade e de oposição/ potencial substituição num determinado contexto) - isto é, esse valor é uma função, por um lado, da diferença entre esse signo e os que o acompanham no discurso enunciado e, por outro, da diferença entre o mesmo signo e os signos disponíveis que poderiam ocupar o seu lugar. Neste caso estão, por exemplo, os sinónimos.

Ora os nossos sinónimos hazard e risk, ou ainda danger, peril, etc. podem, em determinados contextos, ter valores mais ou menos equivalentes ou relativamente sobreponíveis, mas, por definição, nunca serão absolutamente comutáveis. A questão é que não existem casos de sinonímia perfeita, estando sempre presentes, mesmo numa única língua, diferenças de valor semântico, variações conotativas, registos diversos, sempre dependentes do contexto em que os termos são usados.

Parece, aliás, haver até uma certa "hierarquização" destes vários termos na língua inglesa, segundo a qual, no seu uso comum, danger (perigo) funcionaria basicamente como hiperónimo dos outros, isto é, o termo mais geral cujo significado inclui os significados dos outros, seus hipónimos, cada um com conotações e implicações específicas, para além da área comum que os torna sinónimos. Hazard, ao mesmo tempo que pode ser sinónimo de danger ou de risk, é ainda um termo polissémico que também pode significar, entre outras coisas mais, chance, uncertainty, fortune ou ainda gambling e bunker, por exemplo ativando a ideia do aleatório, da incerteza, do jogo, ou ainda significando, num contexto muito específico, os obstáculos de água ou de areia num campo de golfe.

Assim, torna-se muito complexa a solução dos problemas de tradução de termos como estes, solução que terá sempre de passar pela consideração do contexto em causa, muito especialmente no âmbito daquilo a que os tradutores chamam a Língua de Chegada, a língua para a qual se traduz. Vejam-se algumas questões relativas exatamente à tradução de hazard, termo que, como já foi observado, não tem um equivalente conceptual nem verbal em português, obrigando em muitos contextos à sua substituição por um hiperónimo, como

\footnotetext{
${ }^{5}$ Como curiosidade, lembremos que existem ainda sinónimos menos próximos ou metáforas, como, por exemplo, crisis, dynamite, emergency, endangerment, exposure, havoc, hot potato, imperilment, insecurity, instability, menace, minefield, pitfall, storm, thin ice, trouble, uncertainty, venture, vulnerability...
} 


\section{Considerações sobre terminologia nas ciências cindínicas}

"perigo" ou "risco", termos e conceitos estes que levam necessariamente à perda de parte do significado específico da palavra inglesa em causa.

É óbvio que a tradução por um dos hiperónimos referidos, ou ainda, eventualmente, por outros termos, depende do contexto em causa e de todo um quadro conceptual específico, que ditará a opção tradutiva desta palavra sem equivalente imediato em português e lhe dará sentido. Há contextos em que, por exemplo, uma expressão como "hazardous materials" se traduz como "materiais perigosos" ou até se pode encontrar na base terminológica da UE, IATE, a expressão “contamination hazards" traduzida tanto por "risco de contaminação" como por "perigo de contaminação", com atribuição do mesmo grau de fiabilidade ${ }^{6}$.

Por outro lado, autores como Fernando ReBeLo e Luciano Lourenço, entre outros, têm defendido, no âmbito da Teoria do Risco e das Ciências Cindínicas e em contextos específicos como, por exemplo, o dos "incêndios florestais", que hazard deve ser traduzido por "risco" - e fazemno a partir de um quadro conceptual que situa o risco (em português) numa sequência de risco-perigo-crise, justificando assim teoricamente a opção de tradução do termo inglês em causa por "risco" e não por "perigo", já que aquele precede este, o que parece coadunar-se com o conceito original da palavra inglesa. Torna-se assim explícita a lógica conceptual que, num contexto muito preciso, preside a esta opção tradutória e a clarifica, legitimando-a e assegurando de algum modo o controlo do sentido.

É claro que, embora funcione satisfatoriamente no contexto em causa, não se pode dizer que se trata de uma tradução definitiva e absoluta, a única tradução "correta" ou possível. Evidentemente, ao traduzir-se hazard por "risco", termo que traduz diretamente o inglês risk, se perde a especificidade da diferença entre os dois conceitos ingleses discretos de hazard e risk (diferença ativa, por exemplo, no título de uma obra recentemente reeditada por GLADE e.a., Landslide Hazard \& Risk).

Notemos um exemplo simples da diferença entre os dois conceitos na linguagem comum: a existência de gelo ou neve numa estrada é um "hazard", mas o "hazard" não implica por si só que haja "risk" - se essa estrada for cortada ao trânsito, o risco desaparece, embora se mantenha o "hazard". Para que exista risco tem de haver uma exposição a esse "hazard"; portanto, a existência de "hazard" não implica em si a existência de risco se não houver exposição a ele. De facto, uma estrada com gelo ou neve cortada ao trânsito é um "hazard" mas não um risco - o nosso problema é que não existe essa distinção em português.

Assim, ao traduzir-se, agora na direção inversa, para inglês, o termo português "risco", por exemplo na aceção na qual ele é definido por REBELO e outros autores, poderá ser necessário fazê-lo usando em simultâneo os dois conceitos ingleses - "hazard and risk". Foi esta a solução encontrada no "Abstract" do artigo "Um novo olhar sobre os riscos? 0 exemplo das cheias rápidas (flash floods) em domínio mediterrâneo" (Territorium 15), de Fernando Rebelo, em que uma das palavras-chave do Resumo, "risco", surge traduzida no Abstract como "hazard and risk". Aliás, claramente consciente da inevitável imperfeição da tradução de hazard por "risco", o autor tem o cuidado de, na obra Geografia Física e Riscos Naturais, definir "hazard" como "o risco em sentido restrito" (p. 33), já que o articula, com DAUPHINÉ e outros autores, como uma das duas principais componentes do risco (sendo a outra a "vulnerabilidade").

Assistimos assim a um esforço de definição e demarcação do sentido a dar a determinados termos para que eles adquiram uma função específica no discurso especializado e se tornem, num determinado contexto e numa situação comunicativa específica, para além de signos da linguagem comum, unidades terminológicas, ou seja, para que facilitem a comunicação entre a comunidade de especialistas e a comunicação desta com os interessados, os utilizadores e o público em geral.

\footnotetext{
${ }^{6}$ http: / / iate.europa.eu/SearchByQuery.do?method=searchDetail\&lilld=1445118\&langld=\&query=hazard\&sourc eLanguage=en\&domain=0\&matching=\&start=50\&next=1\&targetLanguages=pt (acedido a 15.5.2014)

${ }^{7}$ No respetivo resumo francês, "risco" surge traduzido por "aléa et risque".
} 


\section{Realidades e desafios na gestão dos riscos \\ - Diálogo entre ciência e utilizadores -}

Como nota final, foi muito interessante verificar como os teóricos, os cientistas e os autores ligados às Ciências Cindínicas estão conscientes dos problemas colocados pelo uso da linguagem e pela complexidade da tradução, preocupando-se com, ou sentindo mesmo a necessidade de constante reflexão, clarificação/especificação de contextos, e definição e justificação de opções tradutivas e terminológicas. Longe de encararem comodamente a língua como um "instrumento de comunicação" objetivo e unívoco, ao serviço de uma visão positivista do mundo e da ciência, parecem exercer um permanente "esforço de entendimento de idiomas e de conceitos", mostrando-se disponíveis para lidar com as dinâmicas da linguagem e da tradução e, portanto, com os respetivos riscos.

\section{Bibliografia e Referências}

Benveniste, Émile (1974) - Problèmes de linguistique générale, 1. Paris: Gallimard, 1966; Problèmes de linguistique générale, 2 . Paris: Gallimard.

Culler, Jonathan (1975) - Structuralist Poetics: Structuralism, Linguistics and the Study of Literature. Ithaca: Cornell UP.

Glade, Thomas, e. a. (2005) - Landslide Hazard \& Risk. Chichester: John Wiley \& Sons Ltd.

LOURENço, Luciano (2008) - “«Perigos» das «Cartas de Risco». Comentários ao modelo proposto no Guia Técnico para Elaboração do PMDFCl”. Territorium, 15, p. 122-126. Disponível em: http:// www.uc.pt/fluc/nicif/riscos/Documentacao/Territorium/T15_artg/T15NNR11.pdf.

Rebelo, Fernando (2008) - "Um novo olhar sobre os riscos? O exemplo das cheias rápidas (flash floods) em domínio mediterrâneo". Territorium 15, p. 7-14. Disponível em: http:// www.uc.pt/fluc/nicif/riscos/Documentacao/Territorium/T15_artg/T15art02.pdf.

Rebeto, Fernando (2009) - “Nota de Abertura”. Territorium 16, p.3-4. Disponível em: http:/ / www. uc.pt/fluc/nicif/riscos/Documentacao/Territorium/T16_artg/T16Nota_de_abertura.pdf.

Rebelo, Fernando (2010) - Geografia Física e Riscos Naturais. Coimbra: IUC, 2010.

Rebelo,Fernando (2012) - "Nota de Abertura". Territorium 19 (2012), p. 3. Disponível em: http:// www.uc.pt/fluc/nicif/riscos/Documentacao/Territorium/T19_artg/Nota_de_Abertura.pdf.

Saussure, Férdinand de (1916) - Curso de Linguística Geral. Trad. José Victor Adragão. Lisboa: Publicações D. Quixote, 1986.

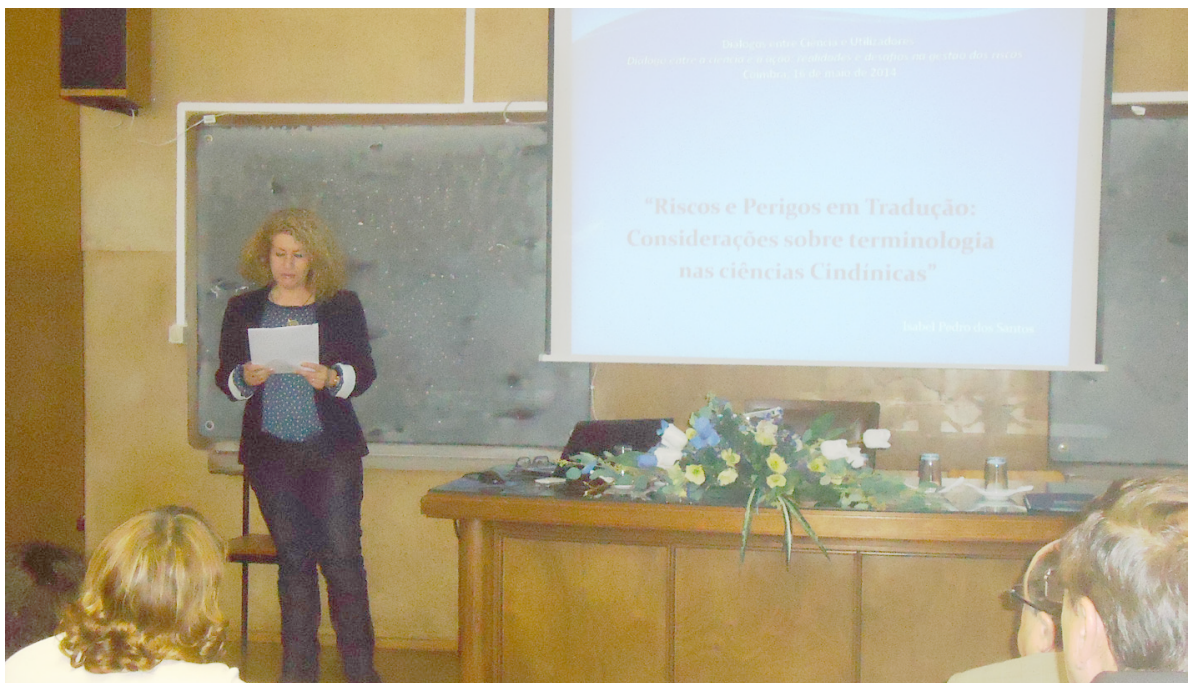




\title{
Capítulo VI \\ RISCO, PERIGO E CRISE. \\ TRILOGIA DE BASE NA DEFINIÇÃO DE UM MODELO CONCEPTUAL-OPERACIONAL
}

\author{
Luciano Lourenço \\ CEGOT e Departamento de Geografia \\ Faculdade de Letras da Universidade de Coimbra \\ luciano@uc.pt
}

\section{Introdução}

Depois do trabalho precursor de Lucien FAugères (1990) sobre "La dimension des faits et la théorie du risque", em que fez o enquadramento de diversos conceitos e que apresentou aos participantes no Seminário "Risques naturels, risques technologiques. Gestion des risques, gestion des crises", que decorreu em Saint-Valery-sur-Somme, de 2 a 7 de outubro de 1989, onde se lançaram os fundamentos da teoria do risco, muito se tem escrito sobre o assunto e poucas vezes este e outros trabalhos apresentados ao Seminário aparecem referidos, muito provavelmente por terem sido redigidos em francês e por não se encontrarem disponíveis na internet.

Todavia, a referência ao trabalho de Lucien FAUGĖres parece-nos fundamental em qualquer estudo que aluda à teoria do risco, na medida em que nele se hierarquizaram claramente os conceitos de risco, perigo e crise, ao contrário do que sucede noutros trabalhos onde, por vezes, alguns destes termos se confundem, porventura em resultado da dificuldade de tradução de certos vocábulos, como, aliás, é comprovado por especialistas em alguns dos textos que antecedem este capítulo.

Sendo assim, pretendemos dar mais uma modesta contribuição ${ }^{1}$, no sentido de clarificar o que entendemos por cada um destes termos, dentro da tal sequência hierarquizada e num quadro de intervenção dos diferentes agentes de proteção civil, pelo que o modelo conceptual que the está subjacente visa a sua aplicabilidade em termos operacionais, independentemente do tipo de agente interveniente (serviços de proteção civil, bombeiros, forças de segurança,...).

Por isso, este texto não procura apresentar o estado da arte sobre este assunto, pelo que não haverá preocupação em o sustentar com muitas referências bibliográficas, uma vez que ele visa sobretudo a divulgação do trabalho supramencionado e a clarificação do que os portugueses tradicionalmente têm entendido por perigo, independentemente da confusão que a divulgação científica de alguns conceitos associados a este termo, como é o caso de perigosidade, tem vindo a instalar. Com efeito, o argumento de que se trata apenas de visões diferentes, do

\footnotetext{
1 Após a publicação do Guia Técnico para Elaboração do PMDFCI (DGRF, 2006), redigimos uma pequena nota que intitulámos “Perigos das cartas de risco" (L. LouREnço, 2008), onde descrevemos algumas das razões pelas quais não concordamos com o uso que tem sido dado ao conceito de perigosidade, nota que, talvez por ter sido de difusão algo restrita ou por outras razões, não teve consequências práticas.

Porque a questão terminológica é algo que sempre nos preocupou entendemos não dever deixar cair este assunto. Já muito antes dessa nota e a nosso pedido, o grande divulgador da teoria do risco em Portugal, o Professor Doutor Fernando ReBELo, abordou na conferência de abertura do II Encontro Pedagógico sobre Risco de Incêndio Florestal, Coimbra, 21 a 23 de fevereiro de 1994, o tema "Risco e Crise. Grandes Incêndios Florestais" (F. REBELO, 1994), uma primeira intervenção em que clarificou "os conceitos de risco, perigo e crise e a sua aplicação ao estudo dos grandes incêndios florestais", título com que veio a ser publicada, no ano seguinte, na revista Biblos (F. REBELO, 1995).

Aliás, os temas "risco, perigo e crise" passaram a ser recorrentes nos anos subsequentes em diversas publicações do autor, de entre as quais mencionamos: F. ReBelo 1996, 1997a, 1997b, 1998, 1999, 2001 e 2008, trabalhos onde podem ser encontrados mais argumentos e, sobretudo, expostos de forma bem mais eloquente, a favor da sequência que defendemos e, por isso, entendemos ser oportuno voltar agora ao assunto, designadamente para dar resposta a algumas das questões que ficaram em aberto quando redigimos a supramencionada nota.
} 


\section{Realidades e desafios na gestão dos riscos \\ - Diálogo entre ciência e utilizadores -}

mesmo problema, resultantes de estarem associadas a Escolas diferentes, a Universidade de Lisboa e a Universidade de Coimbra, não nos parece que seja convincente.

De facto, os portugueses sabem distinguir muito bem as situações em que estão em risco daquelas outras em que correm perigo, pelo que as expressões "estar em risco" e "correr perigo" assumem significados bem distintos e implicam medidas de prevenção e de segurança bem diferentes.

Assim, a nossa reflexão parte da existência de um limiar, que poderemos comparar a uma linha amarela ou vermelha, que representa "perigo", pelo que não deverá ser transposta, uma vez que faz a transposição do risco para a crise.

\section{Perigo, como limiar de transição entre Risco e Crise}

Se respeitarmos a sequência que serve de título a este texto, parece não fazer muito sentido apresentar o perigo antes de descrever o risco. Todavia, se entendermos o "perigo" como o limiar de transição entre o "risco" e a "crise", esse papel de soleira ou de patamar de transposição torna-se mais facilmente percetível se ele for descrito de início, uma vez que, nesse caso, o perigo corresponderá à situação em que o risco deixa de estar latente para se passar a manifestar, ou seja, só "corremos perigo" quando a manifestação do risco passa a estar iminente, bem como durante o lapso de tempo em que acontece e enquanto acaba de se manifestar. Por isso, o perigo é por nós entendido como algo instantâneo, fugaz, pois tão depressa está iminente, como, instantes depois, está a acontecer e, muito rapidamente, se transforma em algo que é passado (fig. 1).

Por outro lado, o perigo reconhece-se através de sinais de alerta, a que poderemos chamar perigosidade ${ }^{2}$, ou seja, a qualidade do que é perigoso, pois permitem reconhecer a existência de perigo, exatamente através desses sinais que indiciam que a manifestação do risco - o perigo - está iminente.

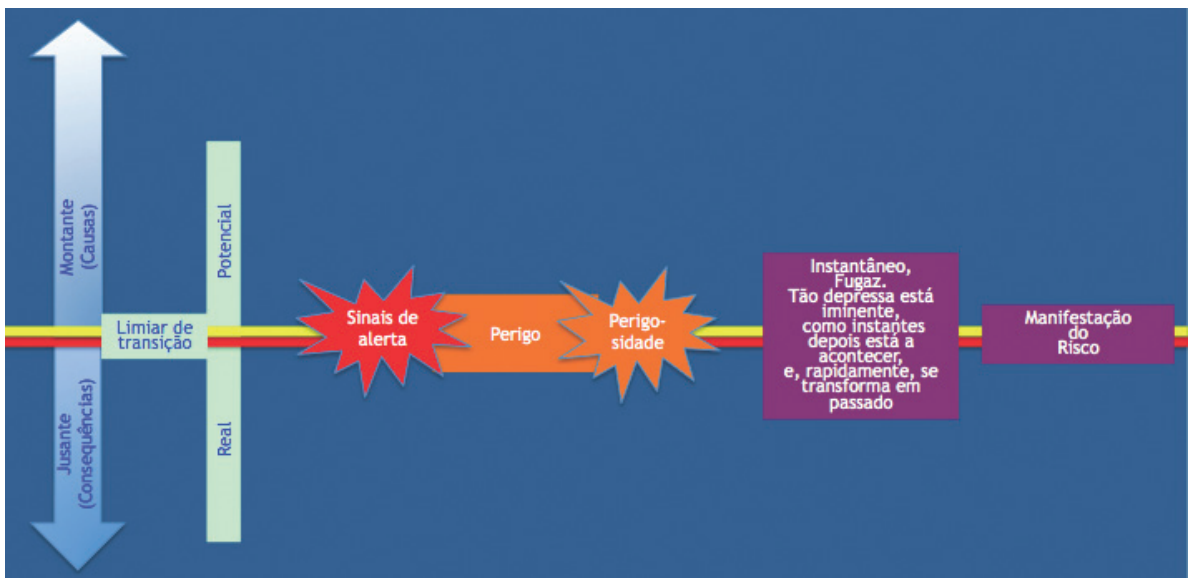

Fig. 1 - 0 perigo entendido como limiar de transição entre algo que estará a montante, que é potencial, bem como a jusante, que passa a real depois de ultrapassar esse limiar.

\footnotetext{
2 Perigosidade é aqui entendida num sentido diferente do habitual e que quanto a nós se instalou nos países latinos devido a uma deficiente tradução do conceito de hazard.

Com efeito, a perigosidade tem sido entendida como um dos elementos que integram o risco, juntamente com a vulnerabilidade, o que na nossa perspetiva não faz sentido, atendendo a que o perigo, sendo posterior ao risco, como é entendido na teoria do risco, não lhe poderá ser anterior.

Aliás, a clarificação do conceito perigosidade e do seu posicionamento, em termos de teoria do risco, é a razão de ser deste texto e esteve na origem da organização deste "Diálogo entre a ciência e os utilizadores".
} 
Ora, esses sinais variam consoante o tipo de risco que está prestes a manifestar-se. Por exemplo, é sabido que no caso da manifestação do risco sísmico, muitas vezes os cães ladram antes de acontecer o tremor de terra, ao "sentirem" as ondas premonitórias, insensíveis ao ser humano, mas que são registadas nos sismógrafos. Do mesmo modo, a manifestação do risco vulcânico é, muitas vezes, antecedido de sismos que alertam para uma atividade anormal nas câmaras magmáticas. Um terceiro exemplo pode ser dado pelo aparecimento de fissuras na área que, mais tarde, irá ficar assinalada como tendo sido a cicatriz de arranque do deslizamento. Por sua vez, a rápida descida do nível do mar para cotas abaixo das habituais é sinal da aproximação de ondas gigantes, conhecidas por maremotos ou tsunami.

Com estes exemplos de sinais de alerta, e outros poderiam ser dados para outros tantos riscos, apenas pretendemos distinguir as situações em que estamos em risco, mas em que nada de grave acontece, daquelas em que corremos perigo, quando estes sinais alertam para a iminente manifestação do risco e que, quando acontece, gera a crise.

Por isso, Lucien FAUGÈres (1990, p. 53), ao mencionar que o perigo "caracteriza uma situação de desregulação do sistema que torna perceptível e desencadeia toda uma série de reações de defesa e de tentativas para restabelecer o modo de funcionamento anterior", deixa subentender o posicionamento antes mencionado, considerando-o como limiar de transição entre o risco e a crise.

Deste modo, o perigo corresponde ao início da manifestação da crise, que nos é dado pelos sinais de alerta antes referidos, e que por outros que nos sistemas de segurança são identificados por desvios, que não têm grande significado para a segurança, e por anomalias (fig. 2), que representam violação das situações operacionais autorizadas, as quais não põem em risco a segurança mas revelam deficiências nos sistemas (L. LouRENço, 2003, p. 91).

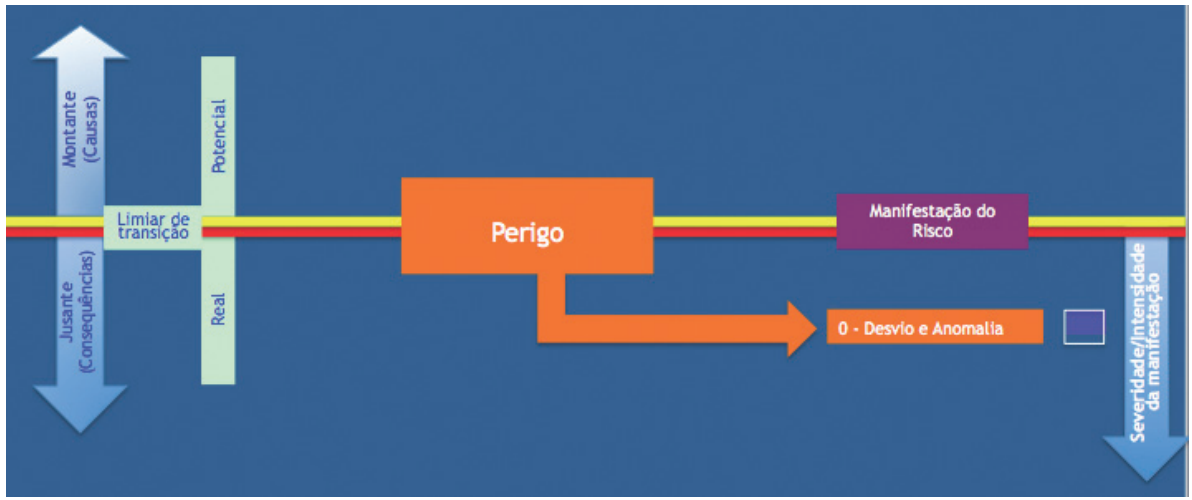

Fig. 2 - 0 perigo, como limiar de transição, que inicia a manifestação do risco.

\section{Risco}

O risco corresponde, no dizer de Lucien Faugères (1990, p. 53), a um "sistema complexo de processos cuja modificação de funcionamento é susceptível de acarretar prejuízos diretos ou indiretos (perda de recursos) a uma dada população". Trata-se de uma definição simples, mas simultaneamente completa, pois comporta os processos inerentes à manifestação de determinado risco (F. ReBeLo, 1995), bem como a incerteza que decorre do que é suscetível e, ainda, as consequências (A. Betâmio de ALMEIDA, 2011), plasmadas no acarretar prejuízos, que o risco comporta para uma dada população e que, naturalmente, serão maiores ou menores em função da vulnerabilidade desta.

De facto, a incerteza sobre o desfecho, traduzida no "é suscetível", significa que pode ou não manifestar-se e, neste caso, nunca haverá perigo, razão pela qual, salvo melhor opinião, não faz sentido mencionar a perigosidade neste contexto, uma vez que ela pode nem sequer existir. 


\section{Realidades e desafios na gestão dos riscos \\ - Diálogo entre ciência e utilizadores -}

Por isso, entende-se o risco como algo de potencial, que pode vir a manifestar-se ou não e, nessas circunstâncias, parece-nos fazer todo o sentido situá-lo a montante do perigo.

Para as Nações Unidas, o risco resulta da "combinação da probabilidade de ocorrência de um evento com as suas consequências negativas" (ISDR, 2009, p. 25), definição que segue de perto a do ISO/IEC Guia 73, em que a palavra "risco" tem duas conotações distintas: normalmente, em linguagem popular, a ênfase é colocada no conceito de acaso ou de possibilidade, de que é exemplo "o risco de um acidente"; por sua vez, em termos técnicos, a ênfase é posta, quase sempre, nas consequências, avaliadas em termos de "perdas potenciais", decorrentes de algum motivo particular, local e período.

Estes aspetos levam-nos a pensar em algumas interrogações clássicas na interpretação de fenómenos geográficos (e não só!), designadamente, neste caso, as de saber “onde”, "quando", "como" e "porquê" é que os riscos se manifestam. A resposta às três primeiras questões tem a ver com as características dos processos que desencadeiam a manifestação, pelo que, embora mereçam análise individualizada, poderão ser agrupadas sob o denominador comum dos processos potencialmente perigosos, que passamos a explanar.

\section{Processos envolvidos}

Desde logo, saber onde houve anteriores manifestações de risco, permite identificar a localização espacial dos eventos ocorridos e, por conseguinte, estimar as áreas mais suscetíveis à sua ocorrência, pelo que esta qualidade costuma ser designada por suscetibilidade.

Por sua vez, saber quando foi que se manifestaram, ajuda a situar os fenómenos ao longo do tempo, histórico ou geológico, e inferir da eventual possibilidade de repetição, que pode ser traduzida em termos de probabilidade de ocorrência do processo em análise.

Feita a localização no espaço e no tempo, importa agora saber como é que se manifestou, o que é fundamental para estimar as consequências em caso de repetição de situações análogas. Trata-se, pois, de analisar algumas características inerentes ao fenómeno em apreço, normalmente traduzidas pela sua intensidade, mas que também se podem expressar através de outras unidades, designadamente a magnitude e a velocidade, que expressa a maior rapidez ou lentidão com que o processo atua, durante um determinado intervalo de tempo, e que normalmente são determinantes para a explicação dos danos causados.

Sendo assim, a resposta a estas três questões, ajuda a explicar os processos envolvidos, pelo que, na nossa ótica, o termo processo(s) será o mais adequado para agrupar este conjunto de características. Todavia, como já foi referido anteriormente, sabemos que em termos de literatura, nos países de expressão latina, muitas vezes ele tem sido expresso por perigosidade, o que não nos parece correto, tendo em conta a sequência lógica e hierarquizada dos conceitos apresentados. Assim, na falta de um vocábulo português que expresse não só o modo como decorrem, mas também as características associadas a estes processos, atrevemo-nos a propor o de processualidade, para substituir o atualmente usado.

\section{Vulnerabilidade}

Passando à última das interrogações, o porquê, porventura de todas elas a mais complicada em termos de resposta, uma vez que resulta de um conjunto de circunstâncias que poderemos agrupar em torno do conceito de vulnerabilidade e que, no entendimento das Nações Unidas, diz respeito às "características e circunstâncias de uma comunidade que a tornam suscetível aos efeitos nocivos do processo" (ISDR, 2009, p. 30).

Também tem havido discussão sobre os elementos que devem ser considerados como parte integrante da vulnerabilidade. Do nosso ponto de vista, entendemos que a maior ou menor vulnerabilidade das comunidades depende essencialmente de três fatores: exposição, sensibilidade e capacidade, tanto de antecipação como de resposta. 
A exposição diz respeito aos "elementos presentes nas zonas de risco - as pessoas e os seus bens e haveres - que, por esse motivo, ficam sujeitos a eventuais perdas" (ISDR, 2009, p. 15).

Por sensibilidade ou fragilidade entende-se, de acordo com CUTTER (2011), o nível e a extensão dos danos que os elementos expostos podem sofrer, os quais estão associados às características intrínsecas dos elementos expostos, bem como ao seu grau de proteção.

A capacidade, quer de antecipação quer de resposta, é um dos elementos que menos se integra nas análises de risco, apesar de ser um dos elementos primordiais para explicar as diferenças registadas entre manifestações que, à partida, poderiam ter consequências semelhantes mas que, depois, apresentam efeitos substancialmente diferentes, constituindo, por isso, a chave do sucesso de determinadas operações. Sabemos da dificuldade em obter elementos fiáveis e dados estatísticos normalizados que permitam quantificar com precisão estas capacidades, mas isso não invalida que não se deva fazer um esforço no sentido de os obter e de introduzir esta componente nas análises de risco, mesmo que ela se revista apenas de um carácter qualitativo.

Com efeito, a capacidade pode ser entendida como sendo "a combinação de todos as forças e recursos disponíveis dentro de uma comunidade, na sociedade ou numa organização que possam ser utilizados para atingir os objetivos" (ISDR, 2009, p. 5-6). Estes passam pela redução do risco a que essa sociedade está exposta (capacidade de antecipação) ou, no caso da sua manifestação, pela redução dos danos que por ela possam ser causados (capacidade de resposta).

Deste modo, a capacidade de antecipação é anterior à manifestação do risco para a qual nos devemos preparar previamente e, por isso, diz respeito à possibilidade de implementar ações e realizar atividades que permitam reduzir danos, no caso do risco se vir a manifestar. Estas passam por medidas de prevenção, com vista a evitar essa manifestação ou a minimizar os seus efeitos, e por medidas de preparação para o socorro, por forma a que este venha a atuar de modo adequado, com o objetivo de também reduzir os danos ao mínimo possível.

Por sua vez, a capacidade de resposta, embora tenha de ser dimensionada e preparada antecipadamente, só é chamada a intervir imediatamente após a manifestação do risco, também com o mesmo objetivo de reduzir os danos causado por essa manifestação. Deste modo, a capacidade de resposta diz respeito às várias organizações que integram a proteção civil, designadamente de socorro e segurança, de emergência e assistência, com vista ao socorro durante a ocorrência e à reabilitação a área afetada (intervenção de emergência), bem como à posterior recuperação dessas áreas (intervenção de consolidação/reconstrução) com o objetivo de minimizar os danos, caso volte a repetir-se a manifestação de risco.

Ora, com o objetivo de produzir os menores danos, o socorro organiza-se, assim, de forma diferente, por exemplo no que respeita às previsíveis vítimas, sejam elas fatais, psicológicas ou físicas. Do mesmo modo, dentro destas, a definição de prioridades também será diferente entre os possíveis feridos, que poderão ser muito graves, graves e ligeiros, os quais, por sua vez, deverão ter uma avaliação e um tratamento separado dos prováveis desalojados e desabrigados, que, naturalmente, será ainda diferente daquele que estará reservado a eventuais desaparecidos.

Deste modo, a capacidade de resposta, no que respeita ao socorro de urgência, para ser eficaz carece de prévia organização, formação e treino, aspetos que se revelam fundamentais para a eficiência do sistema de proteção e socorro. Normalmente, está mais organizada e vocacionada para prestar socorro em termos de ações de "salvamento", relacionadas com os feridos, e de "busca" para encontrar desaparecidos, do que para dar resposta eficaz às vítimas psicológicas e aos desalojados.

Com efeito, na primeira fase, designada de reabilitação, a capacidade de resposta satisfaz, uma vez que está relacionada com medidas de emergência e, normalmente, mobiliza ajuda internacional, pois trata-se de prestar assistência para suprir necessidades básicas vitais dos afetados, designadamente em termos de alimentação e alojamento provisórios, tendentes a minorar, no imediato, os impactes da crise. 


\section{Realidades e desafios na gestão dos riscos \\ - Diálogo entre ciência e utilizadores -}

Todavia, no que respeita a medidas de médio e longo prazo, designadas de recuperação, a capacidade de resposta deixa mais a desejar, se é que alguma vez chega, sobretudo porque implica continuidade e persistência ao longo do tempo. Na realidade, estas medidas implicam uma série de aspetos complementares, com o duplo objetivo de, por um lado, atenuar as consequências da crise e, por outra parte, de minorar os efeitos de plenas manifestações futuras, os quais passam pela reconstrução dos bens e haveres destruídos, pela redução das vulnerabilidades e por programas de desenvolvimento, fundamentais para um rápido retorno à situação de normalidade.

Todos nos recordamos do catastrófico terramoto do Haiti, de 11 de janeiro de 2010, que, segundo a Amnistia Internacional, causou 316 mil mortos, 300 mil feridos e 1,3 milhões de deslocados, mais de 97 mil casas destruídas e 188 mil afetadas parcialmente, bem como da importante resposta que foi dada em termos de reabilitação, traduzida em ajuda humanitária, conseguida através de uma impressionante mobilização internacional. Todavia, no que toca à recuperação da área devastada, não se pode afirmar o mesmo, dado que, quase cinco anos depois, continuam ainda desalojadas mais de 85 mil pessoas, prova evidente de que a recuperação é bem mais difícil e demorada do que a reabilitação, ao ponto de até deixar de ser notícia.

Deste modo, na nossa perspetiva é fundamental ter em conta estes três aspetos: exposição, sensibilidade e capacidade, para se poder intervir em termos da redução da vulnerabilidade, pois é a vulnerabilidade das comunidades e da sociedade, constituída pelos seres humanos e pelos seus bens e haveres, que liga obrigatoriamente os processos ao risco, pois "sem o homem não há risco, há outra coisa..." (F. ReBeLo, 1999, p. 12).

Todavia, o risco só é objeto de estudo porque acarreta consequências, sempre que se manifesta com intensidade. Embora essas consequências façam parte da crise, dado que só ocorrem após a manifestação, em termos de avaliação de risco podemos estimá-las e, por isso, é possível ter uma ideia dos danos que, eventualmente, se possam vir a ocasionar, pelo que o dano potencial poderá ser o terceiro elemento a considerar na análise do risco.

\section{Dano potencial}

Do nosso ponto de vista, o dano potencial comporta dois aspetos que carecem de análise separada. Por um lado, trata-se de estimar as perdas humanas, traduzidas pelo número de vítimas, dado que não é possível contabilizar o valor económico da vida humana. Pela outra parte, importa avaliar o valor económico das perdas materiais, ambientais ou funcionais que determinada manifestação de risco poderá ocasionar.

No que respeita às perdas humanas, trata-se de prever o número de vítimas, que poderão ser de três tipos:

1. Fatais, correspondentes às vítimas mortais;

2. Físicas, que englobam os feridos, com distintos níveis de gravidade (ferido grave, ferido leve, enfermo, mutilado,...), e, num segundo conjunto, os desalojados, desabrigados e desaparecidos;

3. Psicológicas, aquelas que ficaram afetadas em termos psicológicos.

De facto, os aspetos psicológicos e sociais, que tantas vezes não são tidos em consideração nestas circunstâncias, são dos que deixam marcas mais profundas e duradouras neste tipo de vítimas, os desalojados, que, assim, se veem despojados das suas raízes, das suas ligações preferenciais a um espaço/território/comunidade que deixou de existir após a plena manifestação de risco que os afetou, ou a que deixaram de ter acesso por esse espaço ter ficado profundamente transformado.

No que concerne às perdas materiais, ambientais e funcionais, poderá estimar-se o valor monetário ou estratégico do(s) diferente(s) elemento(s) exposto(s) ao risco, correspondente ao custo de mercado para a respetiva recuperação, naturalmente tendo em conta não só o tipo e as caraterísticas do elemento exposto mas também outros fatores que poderão influenciar 
Risco, perigo e crise.

Trilogia de base na definição de um modelo conceptual-operacional

esse custo, tais como outras perdas económicas, diretas e indiretas, resultantes da cessação da funcionalidade, atividade ou laboração (Julı̃ão et al., 2009).

Em síntese, o modelo de risco que propomos (fig. 3) agrupa, numa perspetiva conceptual, todos estes considerandos e, na ótica de aplicação operacional, permite o estabelecimento de diferentes níveis para cada risco em concreto (normalmente consideram-se de 1 a 5 ), tendo em conta o modo de atuação dos respetivos processos, as vulnerabilidades existentes e os danos estimados.

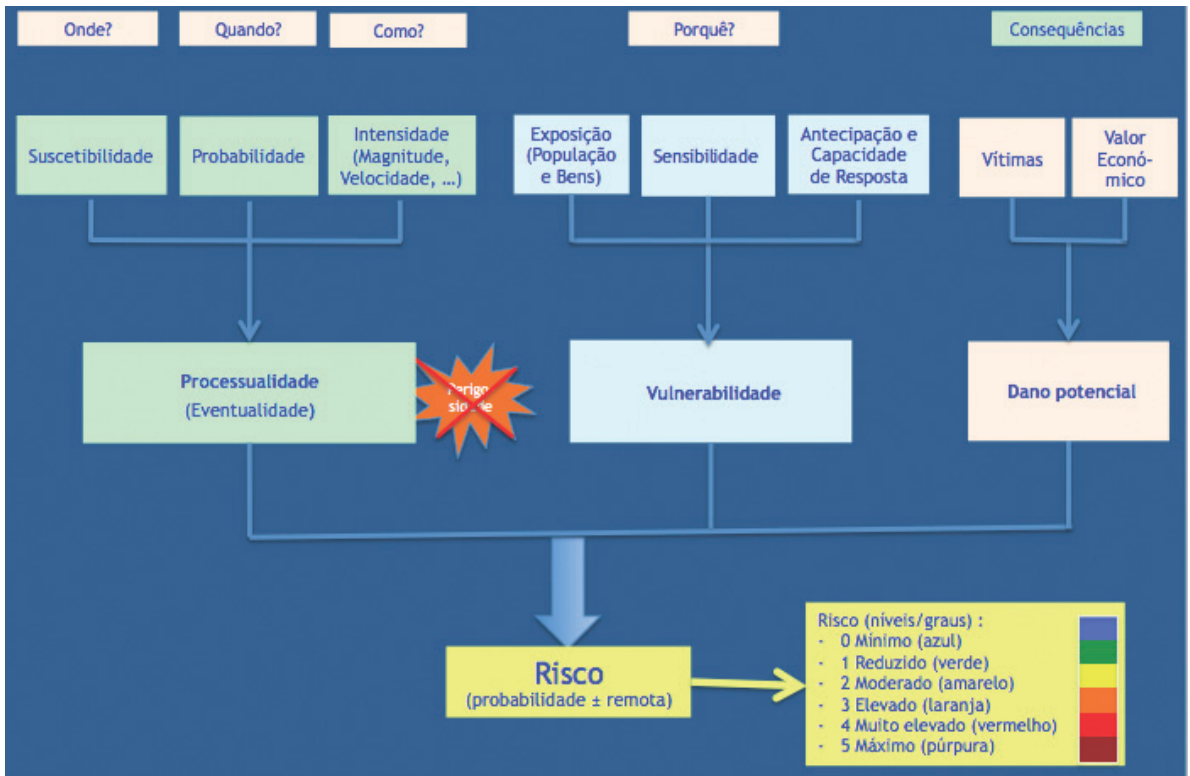

Fig. 3 - Modelo conceptual para estimar um determinado tipo de risco e sua tradução numa classificação para resposta em termos operacionais e previsão das possíveis consequências.

\section{Crise}

A crise pode ser entendida, de forma simples, como a "plena manifestação do risco" e, por isso, as Nações Unidas entendem as crises como emergências, ou seja, como manifestações de risco que requerem uma ação urgente (ISDR, 2009, p. 13), certamente porque os limiares normais foram ultrapassados.

Por seu lado, Lucien FAUGĖRES (1990, p. 53) considera que ocorre uma crise sempre que:

- As defesas ou as tentativas de restabelecer o funcionamento anterior se tornam inoperantes;

- Certos limiares são ultrapassados;

- É iniciada uma escalada;

- O curso dos fenómenos em causa não pode ser previsto ou controlado, o que, de certo modo, ajuda a um melhor enquadramento das diferentes crises.

Com efeito, parece-nos fundamental distinguir as grandes das pequenas crises, estas traduzidas quer por incidentes, em que não há necessidade de intervenção dos meios de socorro, quer por acidentes, em que apesar da intervenção dos meios de socorro dos bombeiros e, eventualmente, das forças de segurança, raramente têm gravidade, pelo que passam perfeitamente despercebidas e raramente são notícia, integrando-se nas situações ditas de rotina. 


\section{Realidades e desafios na gestão dos riscos \\ - Diálogo entre ciência e utilizadores -}

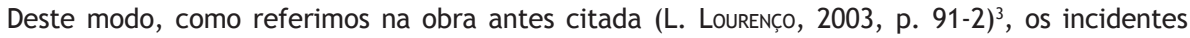
correspondem a episódios repentinos que reduzem significativamente as margens de segurança sem, contudo, as anular, pelo que apenas apresentam consequências potenciais para a segurança.

Por sua vez, os acidentes são acontecimentos repentinos e imprevistos, provocados pela ação do ser humano ou da natureza, com danos significativos e efeitos muito limitados, no tempo e no espaço, suscetíveis de atingirem as pessoas, os seus bens ou o ambiente.

De facto, estas pequenas manifestações de risco nada têm a ver, em termos de consequências, comparativamente com as que decorrem das plenas manifestações de risco, que assumem maior gravidade e que se traduzem por acidentes graves e catástrofes.

Os acidentes graves distinguem-se dos acidentes pela maior gravidade das suas consequências e correspondem a acontecimentos repentinos e imprevistos, também provocados pela ação do ser humano ou da natureza, com danos graves e efeitos relativamente limitados no tempo e no espaço, suscetíveis de atingirem as pessoas, os seus bens ou o ambiente.

As catástrofes são entendidas como acontecimentos súbitos ou séries de acontecimentos graves, quase sempre imprevisíveis, de origem natural ou antrópica, com efeitos prolongados no tempo e no espaço, em regra previsíveis, suscetíveis de provocarem elevados prejuízos materiais e, eventualmente, vítimas, afetando gravemente a segurança das pessoas, as condições de vida das populações e o tecido socioeconómico dum país, em áreas extensas do seu território.

Tendo em conta o número de vítimas e os danos ocasionados, as catástrofes podem ser divididas em menores e maiores, com as quais termina a sequência das manifestações de risco (fig. 4).

Neste contexto, as crises, são habitualmente associadas às plenas manifestações de risco, correspondendo a uma "Situação delicada, em que por circunstâncias de origem interna ou externa, se verifica uma ruptura violenta da normalidade ou do equilíbrio dinâmico de um sistema, o que favorece a sua desorganização e descontrolo" (M. SILVA et al., 2009, p. 17). E, citando FARAZMAND (2001), estes autores prosseguem: "As crises envolvem acontecimentos $e$ processos que acarretam ameaça severa, incerteza, um resultado desconhecido e urgência... A maioria das crises deixa marcas importantes nos indivíduos, organizações e nas próprias nações. As crises podem ter diferentes origens, como actos de terrorismo (World Trade Center, de Nova lorque), desastres naturais (Furacões Hugo e Andrew, na Flórida), acidentes nucleares (Chernobyl), acontecimentos revolucionários (Greve Geral em Maio de 1968, em França), crises de negócio, e crises de organização... As crises consistem numa série de acontecimentos que destroem ou enfraquecem uma condição de equilíbrio e a eficácia de um sistema favorecendo o seu descontrole dentro de um determinado período de tempo..."

Com feito, são estas plenas manifestações de risco que, normalmente, associamos às crises que, assim, correspondem a uma situação anormal e grave, traduzida pela incapacidade de agir sobre os processos e pela incerteza absoluta sobre o desenvolvimento da crise e dos seus impactes.

Aliás, incerteza e consequências são dois aspetos que não se podem desligar do risco e das suas manifestações, as quais, por sua vez, estão dependentes da intensidade de atuação do(s) processo(s), pelo que a construção do conceito de risco está, assim, intimamente ligado a estes três fatores (A. Betâmio de AlmeidA, 2011, p. 25).

Posto isto, a determinação dos impactes e a avaliação dos danos deve iniciar-se de imediato, ainda durante a manifestação do risco, mas, muitas vezes, é só no pós-crise que se consegue concluir. Esses levantamentos são fundamentais para, numa primeira fase, organizar a reabilitação de emergência e, depois, são essenciais para se proceder à recuperação a médio e longo prazo, com vista à reconstrução da área afetada (fig. 4) que, se for bem efetuada, poderá permitir intervir no território, com o objetivo de, no futuro, exercer algum controlo sobre os

\footnotetext{
3 Nem todos os conceitos a seguir apresentados coincidem exatamente com os descritos no trabalho supramencionado porque, entretanto, com a publicação da nova Lei de Bases da Proteção Civil (Lei n. ${ }^{\circ}$ 126, de 3 de julho de 2006), alguns deles passaram a ter novo significado e enquadramento, como sucedeu, por exemplo, com o de calamidade.
} 
Risco, perigo e crise.

Trilogia de base na definição de um modelo conceptual-operacional

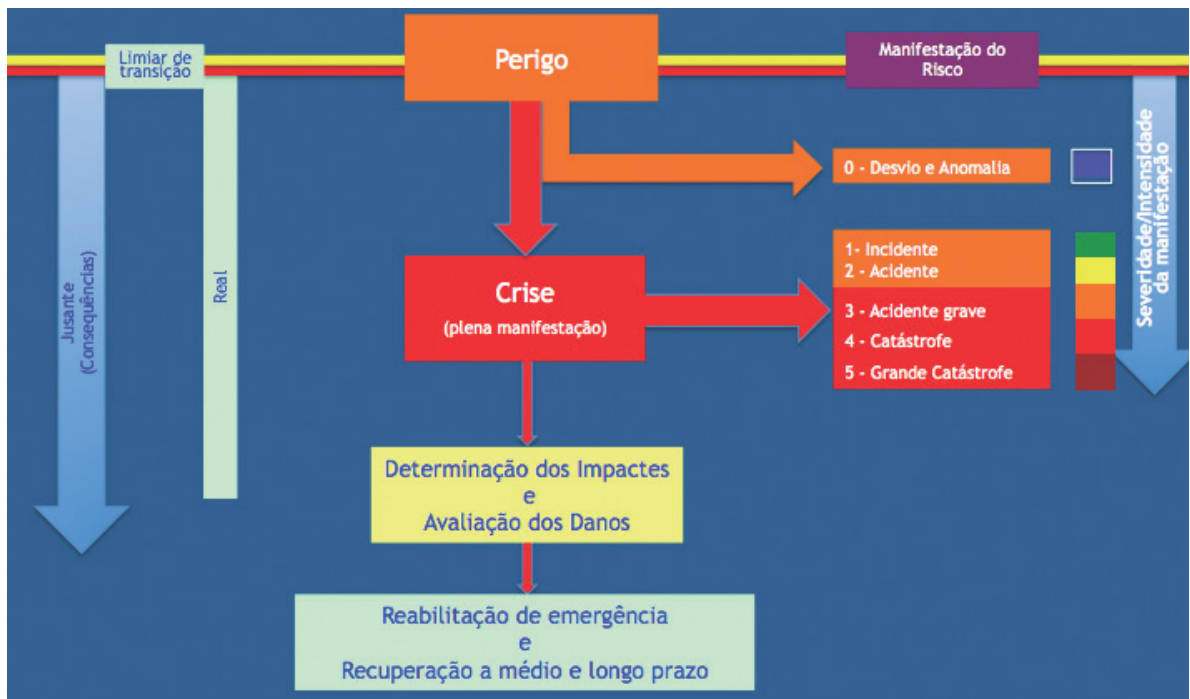

Fig. 4 - Manifestação do risco, que se inicia com a situação de perigo e materializa através da crise, organizada em diferentes níveis de acordo com a respetiva severidade, e que termina com a recuperação das vítimas e da área afetada.

processos naturais e as suas dinâmicas, e, muito em particular, na sociedade, uma vez que o ser humano está na origem dos riscos antrópicos, pois é produtor e gestor de tecnologias, de que decorrem riscos tecnológicos, é gerador de conflitos, que estão na génese dos riscos sociais, e é transmissor de doenças, causa dos riscos biofísicos (L. Lourenço, 207, p.110).

Além desta intervenção a nível das causas, é imperioso atuar com o claro objetivo de reduzir as vulnerabilidades, tornando todo o conjunto mais resiliente e, deste modo, minimizar as consequências de futuras manifestações, fechando-se assim o círculo da catástrofe (fig. 5), que começa pela existência de risco, passa por sinais evidentes da sua manifestação, que correspondem ao perigo e pela plena manifestação do(s) processo(s) envolvido(s), que geram a crise e que será de maior ou menos gravidade, em função das vulnerabilidades existentes e, finalmente, termina com a reabilitação e recuperação da área afetada, designadamente através da redução das vulnerabilidades, de modo a tornar todo este conjunto bem mais resiliente.

\section{Conclusão}

Ao contrário do que porventura se possa pensar, o modelo proposto não pretende ser inovador, pois na generalidade considera aspetos que são mais ou menos consensuais, mas não deixa de ser diferente, ao preocupar-se em clarificar o significado de alguns conceitos ou, então, no seu posicionamento no modelo, como é o caso da perigosidade, propondo a substituição deste termo por um novo conceito, o de processualidade.

Com efeito, na sequência da divulgação desse conceito em vários Guias Metodológicos e Técnicos orientadores da elaboração de diversos Planos, alguns deles bem conhecidos, tem-se instituído uma "Lei" que não é consensual e, por conseguinte, carece de discussão.

Por isso, este texto destina-se sobretudo à reflexão sobre o significado dos conceitos e, muito em particular, do significado do termo perigosidade, em português, para não se the desvirtuar o sentido. Se essa reflexão vier a ter eco junto das entidades responsáveis pela edição dos manuais e se tiverem a coragem de em futuras revisões dessas edições, atualizarem esse conceito pelo que propomos ou por outro que não gere confusão, então a realização deste Diálogo, teria importantes consequências. Sabemos quão difícil é proceder a alterações, sobretudo quando não são oriundas do interior das próprias instituições, pelo que temos consciência de que tal dificilmente acontecerá. 


\section{Realidades e desafios na gestão dos riscos \\ - Diálogo entre ciência e utilizadores -}

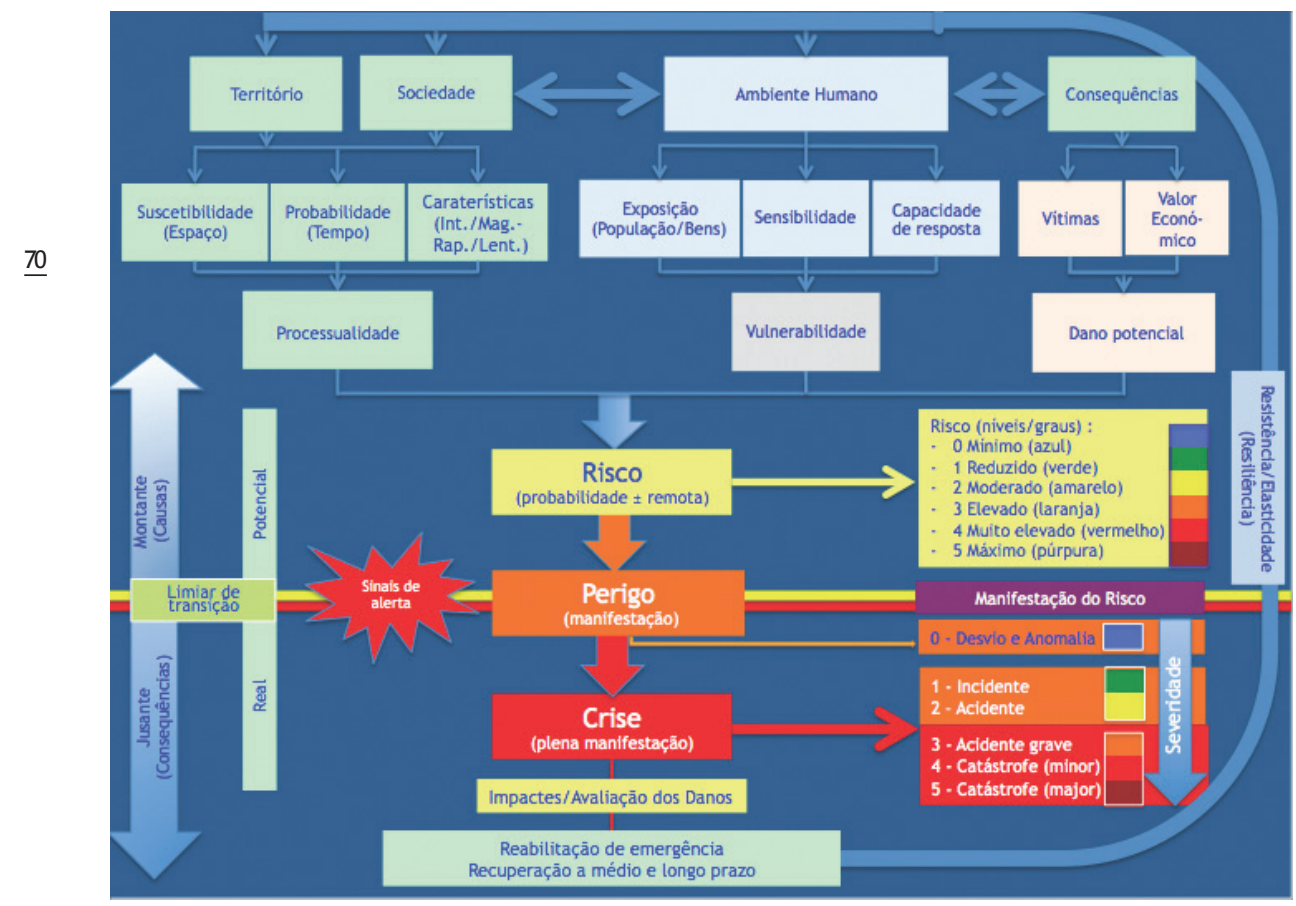

Fig. 5 - Esquema de um modelo usado para análise de manifestações de risco, através da representação das suas três principais componentes: risco-perigo-crise e que termina com a fase de recuperação.

No entanto, ficamos com a consciência mais tranquila por termos cumprido com o nosso dever cívico de alertar para o uso de um termo que não nos parece correto, pois levanta dúvidas sobre a sua adequabilidade, e estamos certos que esta reflexão terá servido, pelo menos, para uma melhor consciencialização dos riscos e melhor perceção do perigo, o que certamente ajudará todos aqueles que tenham de planear e/ou gerir crises, bem como os que trabalhem na sua prevenção, com vista a reduzir tanto as suas manifestações como a minimizar os seus efeitos.

\section{Agradecimento}

Aos conferencistas, cujo contributo foi fundamental para estabelecer pontes de diálogo entre ciência e utilizadores, que nesta primeira abordagem estiveram muito centradas na teoria do risco e na sua aplicabilidade à gestão do território.

Às diversas entidades que disponibilizaram os seus técnicos para participarem nesta reunião científica, em particular à Guarda Nacional Republicana, que esteve representada através do SEPNA e do GIPS/UI, à Autoridade Nacional de Proteção Civil e Serviço Regional de Proteção Civil da Madeira, ao Instituto de Conservação da Natureza e das Florestas, bem como às Autarquias, Corpos de Bombeiros Sapadores, Municipais e Voluntários, e a todos os demais participantes que contribuíram para estimular este "diálogo".

Ao CEGOT - Centro de Estudos de Geografia e de Ordenamento do Território, pelo apoio financeiro emprestado à realização da reunião técnico-científica e à publicação dos resultados.

À Faculdade de Letras da Universidade de Coimbra, pela cedência das instalações para a realização do Seminário, ao Departamento de Geografia, que colaborou na organização do evento, e ao Núcleo de Investigação Científica de Incêndios Florestais - NICIF, que se responsabilizou pela execução desta edição. 
Risco, perigo e crise.

Trilogia de base na definição de um modelo conceptual-operacional

Aos investigadores do projeto PREFER - Space-based Information Support for Prevention and REcovery of Forest Fires Emergency in the MediteRranean Area, em curso nas Universidades de Coimbra e do Minho, designadamente às Doutoras Sandra Oliveira e Adélia Nunes, bem como aos Professores Doutores António Bento Gonçalves e António Vieira e, ainda, ao Mestre Fernando Félix, pelas suas valiosas contribuições para o estudo da vulnerabilidade, uma das componentes do referido projeto.

Por último, estamos gratos a todos aqueles que se disponibilizaram para participar neste "Diálogo" ou que de qualquer outra forma contribuíram para a sua realização. Bem-hajam!

\section{Referências bibliográficas}

Almeida, A. Betâmio de (2011) - "Risco e gestão do risco. Questões filosóficas subjacentes ao modelo técnico conceptual”. Territorium 18, p. 23-31. Disponível em: http://www. uc.pt/fluc/nicif/riscos/Documentacao/Territorium/T18_artg/Antonio_Betamio_de_ Almeida.pdf.

CUTTER S. (2011) - “A ciência da vulnerabilidade: modelos, métodos e indicadores”. Revista Crítica de Ciências Sociais, 93, p. 12. Disponível em: http://rccs.revues.org/165.

DGRF-DIRECÇÃO-GERAL DOS RECURSOS FLORESTAIS (2006) - Guia metodológico para elaboração do Plano Municipal /Intermunicipal de Defesa da Floresta contra Incêndios: I - Introdução e Considerações Gerais ao Guia Metodológico, 4 p.; II - Caderno I - Plano de Acção, 47 p.; III - Caderno II - Informação de Base, 51 p.; IV - Apêndices. DGRF, Lisboa, 36 p.

Faugères, Lucien (1990) - "La dimension des faits et la théorie du risque". Le Risque et la Crise, European Coordination Centre for Research and Documentation in Social Sciences, Foundation for International Studies, Malta, p. 31-60.

ISRD - INTERNATIONAL STRATEGY FOR DISASTER REDUCTION (2009) - 2009 UNISDR Terminology on Disaster Risk Reduction. UNISDR - United Nations International Strategy for Disaster Reduction, Geneva, Switzerland, United Nations, 30 p. Disponível em: http://www. unisdr.org/files/7817_UNISDRTerminologyEnglish.pdf.

Julião, R. P., Nery, F., Ribeiro, J. L., Branco, M. C. E Zêzere, J. L. (2009) - Guia metodológico para a produção de cartografia municipal de risco e para a criação de sistemas de informação geográfica (SIG) de base municipal. Autoridade Nacional de Protecção Civil, DGOTDU/IGP, Lisboa, 91 p. Disponível em: http://www.proteccaocivil.pt/Documents/ guia_metodologico_SIG.pdf.

Lourenço, Luciano (2003) - "Análise de riscos e gestão de crises. 0 exemplo dos incêndios florestais”. Territorium, 10, p. 89-100. Disponível em: http://www.nicif.pt/riscos/ Documentos/T_PDF/T10Artigos/T10artigo06.

LOUREnÇO, Luciano (2007) - “Riscos naturais, antrópicos e mistos”. Territorium, 14, p. 109-113. Disponível em: http://www.uc.pt/fluc/nicif/riscos/Documentacao/Territorium/T14_ artg/T14NNR01.pdf.

Lourenço, Luciano (2008) - "Perigos das cartas de risco. Comentários ao modelo proposto no Guia Técnico para Elaboração do PMDFCl”. Territorium, 15, p. 122-126. Disponível em: http:// www.uc.pt/fluc/nicif/riscos/Documentacao/Territorium/T15_artg/T15NNR11.pdf.

Rebelo, Fernando (1994) - "Risco e Crise. Grandes Incêndios Florestais". Actas - II Encontro Pedagógico sobre Risco de Incêndio Florestal, Coimbra, 21 a 23 de Fevereiro de 1994, p. 19-32. Disponível em: http://www.uc.pt/fluc/nicif/Publicacoes/Edicoes_PROSEPE/ Edicoes_Pedagogicas/EPRIF_Documentos/IIEPRIF_Atas_pdf.pdf.

Rebelo, Fernando (1995) - "Os conceitos de risco, perigo e crise e a sua aplicação ao estudo dos grandes incêndios florestais”. Biblos, 71, p. 511-527. 


\section{Realidades e desafios na gestão dos riscos \\ - Diálogo entre ciência e utilizadores -}

Rebelo, Fernando (1996) - "Alguns livros recentes sobre riscos, perigos e crises". Territorium, 3, p. 61-64. Disponível em: http://www.uc.pt/fluc/nicif/riscos/Documentacao/ Territorium/T03_artg/T03_NNR6.pdf.

Rebelo Fernando (1997a) - "Risco e crise nas inundações rápidas em espaço urbano. Alguns exemplos portugueses analisados a diferentes escalas”. Territorium, 4, p. 29-47. Disponível em: http://www.uc.pt/fluc/nicif/riscos/Documentacao/Territorium/T04_ artg/T04_Artg04.pdf.

ReBeLo, Fernando (1997b) - "O estudo dos riscos e das crises discutido em reuniões internacionais", Territorium, 4, p. 145-148. Disponível em: http://www.uc.pt/fluc/nicif/riscos/ Documentacao/Territorium/T04_artg/T04_NNR04.pdf.

Rebelo Fernando (1998) - "Livros recentes sobre a problemática dos riscos e das crises". Territorium, 5, p. 75-79. Disponível em: http://www.uc.pt/fluc/nicif/riscos/ Documentacao/Territorium/T05_artg/T05_NNR03.pdf.

Rebelo, Fernando (1999) - "A teoria do risco analisada sob uma perspectiva geográfica". Cadernos de Geografia, 18, p. 3-13. Disponível em: http://www.uc.pt/fluc/depgeo/ Cadernos_Geografia/Numeros_publicados/CadGeo18/artigo01.

Rebelo, Fernando (2001) - "Os movimentos em massa na perspectiva da teoria do risco". Revista Técnica e Formativa ENB, Escola Nacional de Bombeiros, 5 (17), Jan./Mar p. 7-15.

Rebelo, Fernando (2008) - “Um novo olhar sobre os riscos? O exemplo das cheias rápidas (flash floods) em domínio mediterrâneo". Territorium, 15, p. 7-14. Disponível em: http:// www.uc.pt/fluc/nicif/riscos/Documentacao/Territorium/T15_artg/T15art02.pdf.

Rebelo, Fernando (2010) - Geografia Física e Riscos Naturais. Coimbra, Imprensa da Universidade, 215 p.

Silva, Miguel Correia da, Santos, Alexandra e Anderson, Maria (2009) - Glossário de Protecção Civil, ANPC - Autoridade Nacional de Proteção Civil, 399 p. Disponível em: http://www. prociv.pt/GLOSSARIO/Documents/GLOSSARIO-31_Mar_09.pdf.

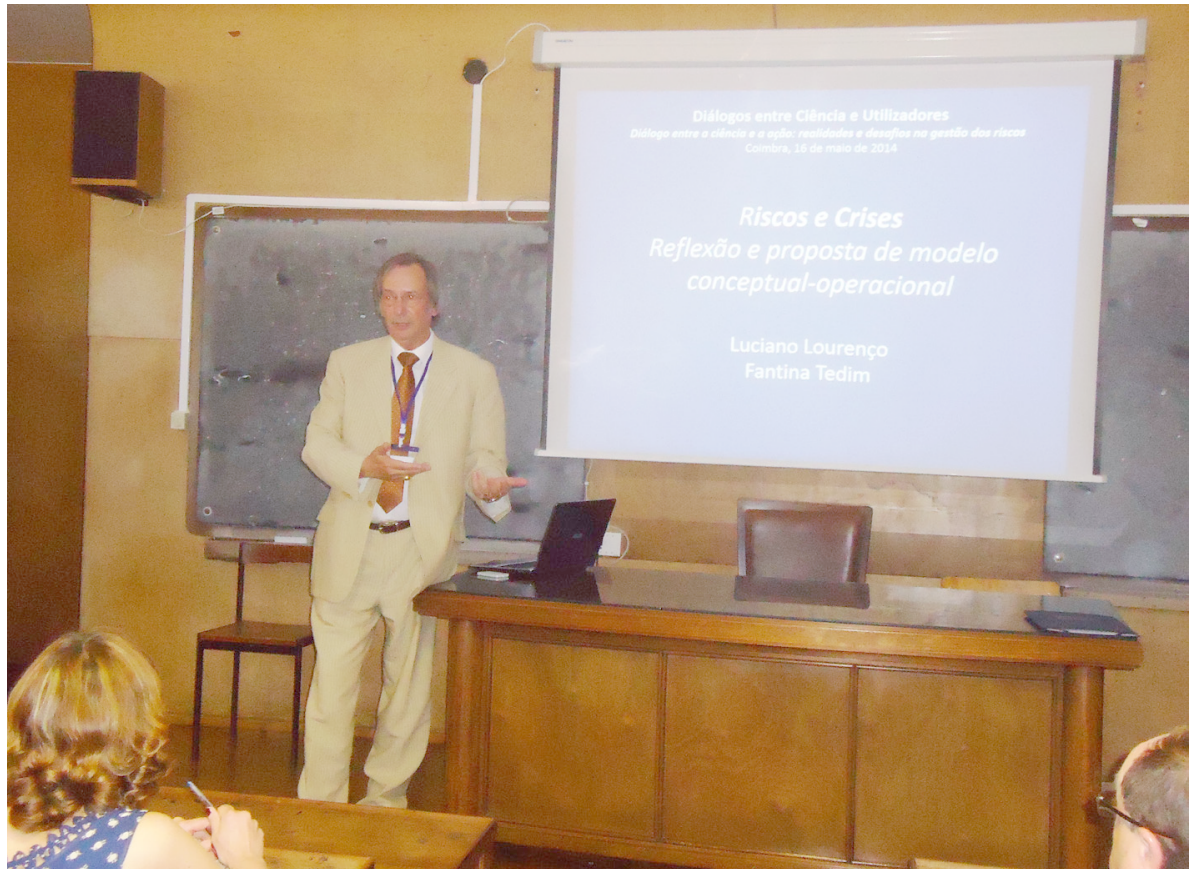




\title{
Capítulo VII \\ DIÁLOGO ENTRE A CIÊNCIA E OS UTILIZADORES \\ POTENCIALIDADES E FRAGILIDADES NA TEMÁTICA DOS RISCOS
}

\author{
Fantina Tedim \\ CEGOT e Departamento de Geografia \\ Faculdade de Letras da Universidade do Porto \\ ftedim@letras.up.pt \\ Sandra Oliveira \\ NICIF- Núcleo de Investigação Cientifica de Incêndios Florestais \\ Universidade de Coimbra \\ sisoliveira@gmail.com \\ Adélia Nunes \\ CEGOT e Departamento de Geografia \\ Faculdade de Letras da Universidade de Coimbra \\ adelia.nunes@ci.uc.pt \\ Cármen Ferreira \\ CEGOT e Departamento de Geografia \\ Faculdade de Letras da Universidade do Porto \\ dra.carmenferreira@gmail.com \\ Luciano Lourenço \\ CEGOT e Departamento de Geografia \\ Faculdade de Letras da Universidade de Coimbra \\ luciano@uc.pt
}

\section{Introdução}

O diálogo entre os investigadores e os atores sociais, como um processo estruturado de comunicação, tem assumido nos últimos anos uma atenção crescente (WELP et al., 2006). A orientação estratégica do Horizonte 2020, no sentido de promover o desenvolvimento de soluções para responder aos desafios societais, reforça a necessidade do diálogo entre os investigadores e os utilizadores, fundado na interatividade e complementaridade que responsabilize ambos pela cocriação de conhecimento (WeLP et al., 2006), a sua operacionalização e otimização.

No domínio dos riscos e da gestão de crises, este diálogo assume particular importância, considerando o âmbito alargado desta temática, a interdisciplinaridade que a envolve e, por conseguinte, a diversidade de conceitos e linhas de pensamento que se cruzam. De facto, a gestão dos riscos e das crises é cada vez mais complexa, requerendo muita informação e conhecimentos multidisciplinares que se encontram dispersos assim como um reforço de abordagens de investigação-ação-investigação para otimizar conhecimentos e recursos.

A presente investigação resultou de uma reunião de trabalho que ocorreu no âmbito do Seminário "Diálogos entre Ciência e Utilizadores: Realidades e desafios na gestão do risco", que permitiu reunir investigadores e operacionais provenientes da Autoridade Nacional de Proteção Civil (ANPC), do Instituto de Conservação da Natureza e das Florestas (ICNF), da Guarda Nacional Republicana (GNR) e dos Corpos de Bombeiros (CB). Orientou-se em torno de três objetivos:

1. Identificar as vantagens e limitações da prática atual de gestão dos riscos e das crises, segundo a opinião dos operacionais;

2. Discutir a proposta de um modelo do risco apresentado na primeira sessão de trabalho do já referido seminário; 


\section{Realidades e desafios na gestão dos riscos \\ - Diálogo entre ciência e utilizadores -}

3. Compreender como os utilizadores se relacionam com a comunidade científica e percecionam o impacto da produção científica nacional na gestão dos riscos e das crises.

A apreciação do modelo atual de gestão de riscos e crises, por parte de atores sociais e de investigadores, foi o primeiro passo para compreender a importância de promover o estabelecimento de uma cultura de parceria entre os investigadores e os utilizadores que permita desenvolver sinergias, sem esgotarem o campo de atuação de cada um dos intervenientes. Para além disso, a análise das características da relação entre investigadores e utilizadores forneceu informações cruciais para identificar a necessidade de reforçar a colaboração entre as duas comunidades, orientar o desenvolvimento da investigação científica, aumentar a visibilidade e o impacto social da produção científica, assim como para compreender problemas que os utilizadores enfrentam na avaliação e gestão dos riscos e das emergências e, consequentemente, as respostas que gostariam que a investigação científica fornecesse.

Neste artigo argumenta-se que reforçar a comunicação e a colaboração entre a comunidade científica e a comunidade dos utilizadores, contribuirá para aumentar a eficácia na gestão dos riscos e das crises bem como para criar uma sociedade mais resiliente. Por um lado, permitirá aos utilizadores ter acesso mais rápido e fácil à produção científica; facilitará a avaliação da eficácia das estratégias e medidas de gestão do risco e das crises; e poderá contribuir para melhorar a comunicação entre as organizações e os cidadãos, promovendo o seu envolvimento na construção de uma sociedade mais resiliente. Por outro lado, a colaboração entre as duas comunidades fomentará o impacto societal da investigação científica, ao direcioná-la para a resolução de problemas concretos da sociedade e para a apresentação de medidas inovadoras e mais eficazes de gestão dos riscos e das crises; facilita a implementação de um modelo de investigação-ação-investigação, aumentando a responsabilidade dos investigadores na orientação das políticas; e motiva os investigadores a preocuparem-se com a operacionalização da sua investigação e a forma de a comunicar aos utilizadores e ao setor político. Uma dinâmica colaborativa permitirá aumentar a eficácia na gestão e um impacto mais alargado da investigação científica.

\section{Metodologia}

A realização de um seminário com duas sessões distintas (uma que decorreu de manhã, foi constituída pelos Painéis "Ciência" e "Ação" e, a outra, realizada durante a tarde, foi organizada por grupos de trabalho, seguida por uma mesa redonda) foi o método eleito para promover o diálogo entre os utilizadores e a comunidade científica. Nos Painéis "Ciência" e "Ação" vários investigadores, provenientes de diferentes áreas científicas, apresentaram questões conceptuais e metodológicas dos riscos (ver capítulos I a VI). Na sessão da tarde, os participantes do seminário foram divididos por quatro grupos de trabalho, nos quais os utilizadores expressaram livremente a sua experiência e opinião sobre a temática dos riscos, de que todos eles são próximos devido à sua atividade profissional. Nesta sessão de grupos de trabalho, participaram 32 pessoas, das quais 23 utilizadores (ANPC - 3, ICNF-1, GNR - 16; CB - 3; 3 estudantes de $2 .^{\circ}$ e $3 .^{\circ}$ ciclos e 6 investigadores.

O principal método de investigação social utilizado foi o de grupos de discussão que permitiram a partilha de pontos de vista e ideias dos participantes de uma forma estruturada, e, consequentemente, a produção de informação primária. É uma técnica particularmente útil na análise de temas que podem suscitar opiniões divergentes, ou em que se quer aprofundar o conhecimento sobre a temática. A interação em cada grupo foi moderada por um investigador. Previamente, estabeleceram-se seis questões que foram apresentadas e debatidas em cada um dos grupos. Estas questões que estruturaram a discussão destinaram-se a conhecer a opinião dos participantes sobre as potencialidades e as fragilidades do atual modelo de gestão do risco e de emergências, assim como a avaliar em que medida o modelo conceptual do risco apresentado no Painel "Ciência" do seminário contribuiria para uma melhor práxis, quer na prevenção dos riscos, quer na gestão das crises. 
A técnica da discussão em grupo que é uma fonte primária de informação qualitativa foi combinada com uma abordagem quantitativa através da resposta dos utilizadores a um questionário. Após a discussão, foi pedido a cada participante que respondesse a um questionário com 14 questões, das quais sete eram perguntas abertas; estas questões não eram apenas direcionadas para os principais objetivos dos grupos de discussão, mas versaram também sobre a aplicabilidade da produção científica nacional na temática dos riscos naturais e antrópicos, assim como sobre a comunicação e a colaboração entre os investigadores e os utilizadores.

Neste artigo, apresentam-se os resultados dos quatro grupos de discussão e as respostas aos questionários apenas dos 23 profissionais da ANPC, ICNF, GNR e CB, e que são, genericamente, designados de utilizadores. Atendendo ao reduzido número de participantes provenientes de algumas das instituições, os resultados referentes a cada tipo de organização não serão utilizados, tendo-se optado por apresentar apenas os resultados globais. Para a exploração da informação quantitativa recolhida, foi apenas utilizada análise estatística descritiva.

\section{Resultados e discussão}

\section{Grupos de discussão}

A discussão em grupo foi orientada por seis questões em torno de dois aspetos principais. Primeiro, identificar as principais dificuldades na atual gestão do risco; segundo, conhecer a apreciação dos utilizadores sobre o modelo de risco apresentado no Painel "Ciência" (ver capítulo $\mathrm{VI}$ ), de modo a compreender as suas vantagens e limitações para reforçar a política de prevenção e gestão dos riscos naturais e antrópicos.

\section{A atual prática de gestão do risco: identificação de problemas}

\section{a) Prevenção versus mitigação de consequências}

Uma das fragilidades identificadas relaciona-se com a fraca expressão da prevenção dos riscos e uma aposta, fundamentalmente, baseada na mitigação de consequências resultantes da manifestação do risco. Esta situação é extremamente evidente no caso dos incêndios florestais, com o desequilíbrio entre os recursos financeiros destinados à prevenção e ao combate. A prevenção foi considerada, pelos participantes, como um investimento a longo prazo mas com uma melhor relação custo-benefício. Foram apresentados exemplos referentes ao sucesso de campanhas de redução dos incêndios florestais associados à renovação de pastagens no norte de Portugal. A aposta no combate foi considerada uma imposição política, pois os participantes nos grupos de discussão reconheceram a importância de alocar mais recursos à prevenção e menos ao combate.

\section{b) Operacionalização dos planos}

Em relação à operacionalização dos planos foi referido não haver uma clara ligação entre o planeamento de emergência e a ação. A gestão das emergências passou de um modelo em que não havia coordenação e onde havia abusos, excessos e má utilização de recursos, para um modelo demasiado rígido. Não há margem de manobra das organizações locais para decidirem o que fazer. Por exemplo, no passado, os corpos de bombeiros eram autónomos e faziam frequentes saídas do quartel que funcionavam como vigilância. Hoje, para os carros saírem do quartel, têm de comunicar ao Centro Distrital de Operações e Socorro (CDOS) e obter autorização.

Os planos estão bem elaborados em termos de estrutura e de conteúdo, mas na prática não funcionam, por várias razões: não conseguem prever todas as situações e muitas decisões que não foram previstas nos planos têm de ser tomadas no teatro de operações; os planos são impostos por regulamentação nacional, não prevendo a adaptação às realidades locais, o que 


\section{Realidades e desafios na gestão dos riscos \\ - Diálogo entre ciência e utilizadores -}

dificulta e fragiliza a sua aplicação; nem sempre é cumprido o que está estabelecido no plano por falta de recursos (p. ex., nem sempre é feita a gestão de combustível prevista no Plano Operacional Municipal- POM) e/ou existem falhas na atuação das pessoas e das instituições.

Quando se está no terreno, é necessário tomar decisões na hora e lidar com imprevistos, e isso depende da experiência e da formação das pessoas que têm que tomar essas decisões. Existem situações que obrigam a lidar com o "perigo dentro do perigo", que não estão definidas a priori no esquema geral de gestão de riscos, e que exigem um investimento adicional na formação e na aquisição de conhecimentos rigorosos por parte dos operacionais e decisores, para que possam ser aplicadas as ações mais ajustadas e eficientes aos acontecimentos inesperados.

\section{c) Gestão de riscos: legislação e governança}

$\mathrm{Na}$ gestão de riscos, foi defendido valorizar mais as "lições aprendidas", ou seja, avaliar as ações tomadas e os resultados, e integrar o que se aprendeu, a nível técnico e operacional, no processo de análise de risco a montante, de modo a permitir a melhoria constante de todo o sistema. Esta avaliação dos aspetos positivos e limitações e a sua integração na melhoria no processo de prevenção e gestão de riscos não é, atualmente, concretizada de forma sistemática, sobretudo pela rigidez nos conteúdos dos próprios planos.

Foi referido que Portugal possui uma boa legislação relativamente à gestão do risco e redução dos danos, todavia, não há certeza da sua efetiva aplicação. Ainda no que concerne à legislação, apontou-se que esta deveria ser o mais abstrata possível, pois quanto mais específica, mais difícil se torna a sua aplicação. Foi sugerido que a "linguagem" legislativa fosse mais clara, de forma a permitir um maior entendimento da mesma pelo cidadão comum.

Foi, igualmente, mencionada a importância de aumentar o número de incêndios florestais investigados quanto à causa de ignição e incremento da eficácia no apuramento da respetiva causalidade. Foi proposto que, na elaboração da cartografia de risco de incêndio florestal, os tipos de ocupação do solo fossem substituídos por modelos de combustíveis.

Para muitos dos utilizadores, os atuais problemas na gestão dos riscos e das crises estão, sobretudo, relacionados com a governança. Foi salientado que enquanto todas as entidades envolvidas na gestão dos riscos não se entenderem e não se articularem entre si, não haverá "supermodelo" que reforce a política de prevenção. Foi, no entanto, referido que o novo modelo conceptual que foi proposto no Painel "Ciência" pode permitir reforçar a política de prevenção dos riscos naturais e antrópicos, mas terá que ser articulado com todos os outros instrumentos de gestão.

O Plano Nacional de Defesa da Floresta Contra Incêndios foi mencionado como um exemplo muito positivo da atual gestão dos incêndios florestais por requerer a coordenação entre organismos, que passaram a falar uma linguagem comum e a trabalhar em conjunto, nomeadamente ao nível da prevenção. A única fragilidade é a falta de meios para o operacionalizar na íntegra. Há dificuldade em cumprir integralmente as atribuições que estão definidas para cada organização, por manifesta falta de meios.

Relativamente a algumas condições que dificultam a gestão do risco, sobretudo de incêndio florestal, foram salientadas:

- Inexistência de um cadastro da propriedade rústica que facilitaria, nomeadamente, a eficácia da fiscalização das medidas de proteção e prevenção previstas na lei assim como a responsabilização dos privados;

- O absentismo e o abandono dos espaços florestais por parte dos produtores nacionais;

- Os incêndios florestais são vistos como uma oportunidade de negócio para vários atores, pelo que será difícil controlá-los se não se tornar a floresta rentável;

- O Estado não dá o exemplo perante os privados, pois não faz uma adequada gestão do combustível nas suas propriedades. 


\section{O modelo conceptual proposto: apreciação conceptual e terminológica}

\section{a) Esquema conceptual}

O modelo conceptual proposto (ver capítulo $\mathrm{VI}$ ) foi bem recebido pelos intervenientes nos grupos de discussão e, genericamente, obteve o acordo dos participantes. As definições dos conceitos apresentados pareceram claras para os diversos participantes. 0 esquema não foi considerado muito simples, o que foi compreendido pois a realidade é muito complexa. Aliás, para ser completo, o esquema deveria ainda integrar outras informações, como as causas dos riscos e perigos e a análise dos interesses instalados, por exemplo, que não aparecem pela dificuldade de os materializar.

Todavia, como seria expectável e desejável, foram feitas algumas considerações e sugestões. o principal ponto de divergência revelou-se na definição dos conceitos de risco e perigo. Embora a maioria dos participantes concordasse com o esquema apresentado, outros defenderam que o perigo está a montante do risco, e não a jusante como é proposto pelo modelo, uma vez que neste último conceito está inerente a perda de bens. 0 conceito de crise levantou algum debate, pois houve quem referisse que este deveria ser entendido a um nível mais elevado, ou seja, ao nível da capacidade governativa, enquanto outros referiram que a crise é a plena manifestação do risco e que já está presente quando o incidente/acidente é real. Para muitos dos participantes, o aspeto mais relevante do modelo foi a conceptualização da vulnerabilidade.

As principais alterações propostas ao modelo conceptual apresentado foram: substituição do termo capacidade de resposta por capacidade de antecipação (como um elemento integrante da vulnerabilidade); integração da capacidade de resposta ao nível da operacionalização (na manifestação do risco/perigo e na crise); integrar as vertentes individual e das comunidades na capacidade de resposta; e inclusão da incerteza no esquema conceptual.

\section{b) Terminologia}

A nível terminológico, a principal questão prendeu-se com a definição do termo hazard. Habitualmente, tem sido traduzido, na literatura especializada, por perigo (JuLĩ̃o et al., 2009) ou por perigosidade (VERDE, 2008; VERDE e ZÊZZERE, 2010). O modelo apresentado propõe como tradução processo potencialmente perigoso (PPP), que obteve a concordância de alguns dos participantes mas foi amplamente criticada por outros, nomeadamente porque é uma expressão longa e deveria ser apenas uma palavra. Perante a dificuldade de chegar a acordo, foi sugerido que fosse mantido o termo hazard, mas a opinião foi claramente a favor de que deveria ser procurada uma tradução. Foi consensual que, ao nível académico, a tradução de hazard possa não ser necessária; contudo, ao nível operacional, tem que haver uma tradução, não por "processo potencialmente perigoso", mas sim por um termo único, mais simples. Foi salientado pelos participantes que qualquer alteração de terminologia na área dos riscos requer a concordância a nível político e tem de ser publicada em legislação, para que possa ser operacionalizada.

Foi, igualmente, mencionado que muitas vezes, ao nível prático, são utilizados termos que não foram apresentados no esquema e que surgiram da necessidade de ajustar o comportamento ao nível da ação. Por exemplo, a GNR, quando fala com a população, utiliza o termo ameaça e ameaça de risco de incêndio florestal, sendo estes os termos que incitam a tomar medidas de proteção. Noutro exemplo, a ANPC não fala de crise, mas de emergência. Também foi notado no modelo conceptual apresentado, que não foram considerados os conceitos de calamidade e de perigosidade.

Por várias vezes foi reforçada a ideia da necessidade de uma definição clara e uniforme dos conceitos associados ao risco entre os especialistas, que deveriam ser depois aplicados a nível nacional. Foi afirmado que a não uniformização desses conceitos implica, para os operacionais, uma maior dificuldade nos termos a utilizar, podendo estar em causa a capacidade de resposta, pois, como referiram - "É preciso saber do que falamos". 


\section{Realidades e desafios na gestão dos riscos \\ - Diálogo entre ciência e utilizadores -}

\section{Análise do questionário}

\section{O planeamento e a gestão do risco e da emergência}

A maior parte dos utilizadores consideraram que a gestão dos riscos e da emergência evoluíram muito nos últimos anos, o que contribuiu para reduzir os danos, embora reconheçam que os principais progressos se registaram na resposta a situações de crise e menos na prevenção (TABELA I). Todavia, quando questionados sobre se a "redução dos danos se explicava principalmente por uma rápida e eficaz resposta de emergência", as opiniões foram muito diversificadas, o que demonstrou haver utilizadores que consideram que alguns progressos na prevenção dos riscos também puderam ser constatados. Os utilizadores reconheceram que a prevenção é a melhor estratégia para reduzir os impactes da manifestação dos riscos, embora a maioria deles (78\%) tenha considerado haver falta de uma verdadeira política de prevenção.

Uma das áreas em que pode ser desenvolvida a prevenção dos riscos é no ordenamento do território. O Programa Nacional da Política de Ordenamento do Território (Lei n. ${ }^{\circ}$ 58/2007 de 4 de setembro) considerou os riscos um dos vetores que intervêm na estrutura do modelo territorial. Os participantes na reunião consideraram inadequada a integração da prevenção de riscos no ordenamento do território realizada até ao momento, sendo importante reforçá-la.

TABELA I - Opinião sobre o atual modelo de gestão do risco.

\begin{tabular}{|l|c|}
\hline \multicolumn{1}{|c|}{ Questões } & $\% *$ \\
\hline A prevenção é a melhor forma para reduzir os impactos da manifestação dos riscos & 96 \\
\hline Há falta de uma verdadeira política de prevenção dos riscos & 78 \\
\hline $\begin{array}{l}\text { A avaliação e gestão dos riscos evoluíram muito nos últimos anos e têm contribuído } \\
\text { para reduzir os danos relacionados, por exemplo, com as cheias, os incêndios } \\
\text { florestais, a erosão costeira }\end{array}$ & 70 \\
\hline $\begin{array}{l}\text { A atual prática da gestão do risco está muito mais vocacionada para responder a } \\
\text { situações de crise/emergência do que efetivamente prevenir os riscos }\end{array}$ & 65 \\
\hline $\begin{array}{l}\text { A redução dos danos explica-se principalmente por uma rápida e eficaz resposta de } \\
\text { emergência }\end{array}$ & 44 \\
\hline $\begin{array}{l}\text { A forma como a prevenção de riscos é inserida no ordenamento do território é } \\
\text { adequada }\end{array}$ & 26 \\
\hline $\begin{array}{c}\text { *As percentagens referem-se às respostas dos utilizadores que "concordaram" ou “concordaram totalmente" } \\
\text { com o conteúdo dos itens mencionados. }\end{array}$ \\
\hline
\end{tabular}

Os utilizadores consideraram fundamental a elaboração de planos e de cartografia para apoiar a decisão na gestão do risco (TABELA II). Na elaboração de planos, foram identificados quatro constrangimentos:

1. Nem sempre está disponível informação científica para os realizar, de modo a que possam ser instrumentos eficazes, quer na prevenção do risco quer na gestão da emergência;

2. Há planos que são elaborados por imposição legal, embora não thes reconheçam importância no âmbito da gestão do risco e das crises;

3. A estrutura dos planos é demasiado rígida, não permitindo integrar aspetos adequados às realidades locais assim como, segundo a opinião de alguns dos utilizadores, também limita a possibilidade de integração das lições aprendidas com a gestão das crises/emergências na retificação dos planos de prevenção e de emergência;

4. A falta de uma verdadeira política de prevenção, pois os utilizadores consideraram que a gestão do risco está demasiado focada na construção de planos para gerir operacionalmente as crises/emergências. 
TABELA II - Opinião sobre o planeamento da gestão do risco.

\begin{tabular}{|c|c|}
\hline \multicolumn{1}{|c|}{ Questões } & $\%^{*}$ \\
\hline $\begin{array}{l}\text { Há planos que se fazem por imposição legal embora não se reconheça a sua } \\
\text { importância no âmbito da gestão do risco e das crises/emergências }\end{array}$ & 83 \\
\hline $\begin{array}{c}\text { A cartografia de risco atualmente existente é uma ferramenta fundamental para } \\
\text { quem tem de fazer prevenção dos riscos }\end{array}$ & 74 \\
\hline $\begin{array}{l}\text { A prática de avaliação e gestão do risco está demasiado focada na construção de } \\
\text { planos para gerir operacionalmente as crises/emergências }\end{array}$ & 74 \\
\hline $\begin{array}{l}\text { A estrutura dos planos é demasiado rígida e não permite integrar aspetos adequados } \\
\text { às realidades locais }\end{array}$ & 74 \\
\hline $\begin{array}{l}\text { Os planos são extremamente úteis mas frequentemente não há informação para os } \\
\text { realizar de modo a que possam ser instrumentos importantes na prevenção do risco }\end{array}$ & 70 \\
\hline $\begin{array}{l}\text { As liçães aprendidas com a gestão das crises/emergência são utilizadas para retificar } \\
\text { os planos de prevenção e de emergência }\end{array}$ & 48 \\
\hline $\begin{array}{l}\text { *As percentagens referem-se às respostas dos utilizadores que "concordaram" ou “concordaram totalmente" } \\
\text { com o conteúdo dos itens mencionados. }\end{array}$ \\
\hline
\end{tabular}

Gestão do risco e da emergência: disponibilidade de conhecimento científico

Os utilizadores manifestaram opiniões discordantes sobre a existência de conhecimento científico adequado sobre como prevenir os riscos (com 44\% de respostas concordantes e 35\% de respostas discordantes) (TABELA III). Para a maior parte dos participantes, os municípios não dispõem da informação e do conhecimento necessários para promover a redução do risco, mas já em relação à informação e conhecimento necessários para promover a gestão das catástrofes as opiniões são discordantes, o que aponta para experiências distintas.

Questionados sobre o seu próprio conhecimento de conceitos centrais na temática dos riscos (risco, vulnerabilidade e resiliência), os utilizadores afirmaram possuir bom conhecimento, sendo os conceitos de vulnerabilidade e resiliência os que suscitam mais dúvidas, já que $48 \%$ dos inquiridos manifestaram algum ou total desconhecimento.

TABELA III - Opinião sobre o conhecimento científico disponível e a gestão do risco.

\begin{tabular}{|l|c|}
\hline \multicolumn{1}{|c|}{ Questões } & $\% *$ \\
\hline Tenho um bom conhecimento da definição de risco & 78 \\
\hline $\begin{array}{l}\text { Os municípios não dispõem da informação e do conhecimento necessários para } \\
\text { tomarem as decisões adequadas para promover a redução do risco. }\end{array}$ & 52 \\
\hline $\begin{array}{l}\text { Tenho um bom conhecimento sobre a importância da avaliação da vulnerabilidade para } \\
\text { desenvolver ações que reduzam as perdas e danos provocados pela manifestação } \\
\text { dos riscos }\end{array}$ & 52 \\
\hline $\begin{array}{l}\text { Tenho um bom conhecimento sobre o que significa construir sociedades resilientes } \\
\text { aos riscos naturais e antrópicos }\end{array}$ & 52 \\
\hline $\begin{array}{l}\text { É possível reduzir os riscos, há conhecimento sobre como o fazer mas não há recursos } \\
\text { nem financeiros nem técnicos }\end{array}$ & 48 \\
\hline É possível prevenir os riscos mas há pouco conhecimento sobre como o fazer & 44 \\
\hline $\begin{array}{l}\text { Os municípios não dispõem da informação e do conhecimento necessários para } \\
\text { tomarem as decisões adequadas para promover uma gestão eficaz das crises/ } \\
\text { emergências }\end{array}$ & 39 \\
\hline $\begin{array}{c}\text { *As percentagens referem-se às respostas dos utilizadores que "concordaram” ou “concordaram totalmente" } \\
\text { com o conteúdo dos itens mencionados. }\end{array}$ \\
\hline
\end{tabular}




\section{Realidades e desafios na gestão dos riscos \\ - Diálogo entre ciência e utilizadores -}

\section{Pontos fortes da atual política de prevenção dos riscos e de gestão das crises}

A principal vantagem do atual modelo de gestão dos riscos e das crises, mencionada pelos utilizadores, foi a adoção de uma atuação uniforme e sistematizada em todo o território nacional. A criação do Sistema Integrado de Operações de Proteção e Socorro (SIOPS) permite uma resposta muito mais rápida e eficaz em situação de emergência. Segundo os intervenientes no seminário, o enquadramento político e a estrutura organizativa que foram criados permitiram:

- Rentabilizar recursos humanos e materiais;

- Diminuir a vulnerabilidade dos intervenientes quando estão no teatro de operações;

- Preparar melhor a resposta, tentando prever vários tipos de situações e adequando os meios e as estratégias, contribuindo, efetivamente, para a redução de danos.

\section{Alterações propostas à política e praxis vigente}

Foram várias as alterações sugeridas à política vigente, cuja aceitação como foi salientado pelos inquiridos, está dependente da disponibilidade financeira e da vontade dos responsáveis políticos. As principais propostas de alteração surgiram na melhoria da prevenção, na cultura das organizações e na governança dos riscos e das crises (TABELA IV).

\section{Opinião sobre o esquema conceptual}

O esquema conceptual apresentado no seminário (ver capítulo $\mathrm{VI}$ ), foi considerado compreensível, embora cerca de metade dos participantes $(52 \%)$ o tenham classificado como complexo (TABELA V). Para a maior parte dos intervenientes, representa algum avanço face aos modelos existentes, nomeadamente porque permite um melhor suporte conceptual para a prevenção dos riscos. A dupla vertente do esquema, interligando a parte conceptual com a operacionalização, mereceu uma opinião favorável, embora seja importante melhorar alguns aspetos, conforme foi discutido nos grupos de trabalho e antes apresentado no ponto "O modelo conceptual proposto: apreciação conceptual e terminológica” (p. 77).

Em relação à abrangência do esquema para cobrir todo o tipo de opções técnicas, mais de metade dos utilizadores que responderam à questão, avaliaram desfavoravelmente o esquema conceptual.

\section{Opiniões sobre a governança do risco e das crises}

A maioria dos participantes (68\% de respostas concordantes) declararam que o município representa a melhor escala para fazer prevenção dos riscos, assim como para gerir as emergências (TABELA IV). Todavia, também reconheceram como fundamental a articulação entre o nível municipal e as estruturas hierarquicamente superiores (i.e. regional/distrital e nacional).

A Lei de Bases da Proteção Civil (Lei n. ${ }^{\circ} 27 / 2006$, de 3 de julho) no seu artigo $1 .^{\circ}$, menciona que a proteção civil é desenvolvida por todas as instituições e organizações públicas e privadas, assim como pelos cidadãos, mas os inquiridos consideraram que, no atual quadro, a prevenção dos riscos envolve muito pouco os cidadãos, que deverão ser mais ativos na implementação de medidas de prevenção e autoproteção e menos dependentes da proteção civil.

A dificuldade na colaboração, não só entre o setor público e privado mas também entre as instituições com atribuições/responsabilidades na gestão dos riscos e das emergências, foi realçada por $59 \%$ dos participantes, que reconheceram que, apesar dessa dificuldade, há aceitação de sugestões para aumentar a eficácia da atuação. Esta podia ainda ser maximizada se a informação necessária para a gestão do risco e das emergências fosse 
partilhada de uma forma adequada entre as instituições do Estado, o que a maior parte dos participantes acreditam não acontecer. Foram registadas opiniões muito divergentes quanto ao apoio do Estado na resolução dos problemas da prevenção do risco e da gestão da crise/emergência, assim como na manutenção da capacidade técnica das instituições.

TABELA IV - Sugestões para aumentar a eficácia das políticas e da praxis na gestão do risco e das crises.

\begin{tabular}{|c|c|}
\hline \multirow{5}{*}{$\begin{array}{l}\text { Reforçar a } \\
\text { prevenção }\end{array}$} & - Clarificação de conceitos e utilização de designações em português; \\
\hline & $\begin{array}{l}\text { - Melhorar a fundamentação e a prática da avaliação do risco e integrar as } \\
\text { lições aprendidas; }\end{array}$ \\
\hline & - Melhorar o conhecimento local do risco de modo a adequar as estratégias; \\
\hline & $\begin{array}{l}\text { - Fazer cumprir legislação já existente como acontece com a gestão de } \\
\text { combustíveis; }\end{array}$ \\
\hline & $\begin{array}{l}\text { - Sensibilização da população para reforçar o envolvimento dos cidadãos } \\
\text { no processo para que depois possam ser responsabilizados. }\end{array}$ \\
\hline \multirow{3}{*}{$\begin{array}{l}\text { Cultura das } \\
\text { organizações }\end{array}$} & - Reforçar o diálogo e a colaboração entre as organizações; \\
\hline & $\begin{array}{l}\text { - Obrigar as organizações a trabalharem para o bem comum, reforçando } \\
\text { a orientação do seu objeto para criar uma verdadeira cultura de } \\
\text { segurança e garantir a sustentabilidade ambiental; }\end{array}$ \\
\hline & $\begin{array}{l}\text { - A colaboração passaria também por "falarem todos a mesma linguagem", } \\
\text { isto é, terem uma mesma visão estratégica e abordagem tática das } \\
\text { emergências, de modo a evitar a ocorrência de desastres. }\end{array}$ \\
\hline \multirow{7}{*}{$\begin{array}{l}\text { Governança } \\
\text { dos riscos e } \\
\text { das crises }\end{array}$} & $\begin{array}{l}\text { - Junção numa única entidade da responsabilidade da prevenção e do } \\
\text { combate aos incêndios florestais; }\end{array}$ \\
\hline & $\begin{array}{l}\text { - Maior liberdade/flexibilidade do comando das operações mas com uma } \\
\text { maior exigência/formação dos intervenientes; }\end{array}$ \\
\hline & $\begin{array}{l}\text { - Envolver as populações locais na gestão do risco e das crises pois têm } \\
\text { conhecimento e competências que poderiam ser relevantes para uma } \\
\text { prevenção e gestão eficiente; }\end{array}$ \\
\hline & $\begin{array}{l}\text { - Integrar o conhecimento tradicional das populações locais para aumentar } \\
\text { a eficácia da prevenção e da gestão; }\end{array}$ \\
\hline & - Investir mais na formação dos operacionais; \\
\hline & $\begin{array}{l}\text { - Fomentar a colaboração entre municípios para gerir riscos que são } \\
\text { comuns assim como suportar abordagens semelhantes; }\end{array}$ \\
\hline & $\begin{array}{l}\text { - Reforçar a participação dos investigadores, operacionais e populações na } \\
\text { prevenção e na gestão das crises para otimizar competências e recursos. }\end{array}$ \\
\hline
\end{tabular}

Avaliação da comunicação e colaboração entre instituições: os exemplos das cheias/ inundações e dos incêndios florestais

Em relação ao risco de cheia/inundação, os participantes consideraram que a comunicação e a colaboração entre as instituiç̃̃es é, em geral, complexa e muito limitada. Embora tivessem sido relatadas algumas experiências de boa colaboração, há inúmeras possibilidades de melhorar a situação. Foi mesmo sugerido que as instituições "devem colaborar mais entre si e não 


\section{Realidades e desafios na gestão dos riscos \\ - Diálogo entre ciência e utilizadores -}

TABELA V - Opinião sobre o esquema conceptual.

\begin{tabular}{|l|c|c|c|}
\hline \multicolumn{1}{|c|}{ Parâmetros de avaliação } & $\begin{array}{c}\text { Não } \\
\text { (\%) }\end{array}$ & $\begin{array}{c}\text { Sim } \\
\text { (\%) }\end{array}$ & $\begin{array}{c}\text { NR/ NS } \\
\text { (\%) }\end{array}$ \\
\hline Complexo & 48 & 52 & \\
\hline Compreensivel & 9 & 91 & \\
\hline Apresenta algum avanço face aos modelos existentes & 13 & 83 & 4 \\
\hline $\begin{array}{l}\text { Permite um melhor suporte da prevenção dos riscos e consequente } \\
\text { redução dos danos }\end{array}$ & 22 & 74 & 4 \\
\hline \begin{tabular}{l} 
Interliga bem a questão conceptual \\
\hline $\begin{array}{l}\text { O esquema conceptual permite suportar todo o tipo de opções } \\
\text { técnicas }\end{array}$
\end{tabular} & 26 & 70 & 4 \\
\hline NR-Não respondeu; NS-Não sabe & 43 & 9 \\
\hline
\end{tabular}

TABELA VI - Opiniões sobre a governança do risco e das crises.

\begin{tabular}{|c|c|}
\hline Questões & \%* \\
\hline A atual política de prevenção do risco envolve pouco os cidadãos & 73 \\
\hline O município representa a melhor escala para fazer prevenção dos riscos & 68 \\
\hline $\begin{array}{l}\text { A comunicação entre os diferentes atores institucionais com responsabilidades na } \\
\text { prevenção dos riscos e gestão das crises/emergências permite a apresentação } \\
\text { de sugestões para aumentar a eficácia da atuação }\end{array}$ & 64 \\
\hline $\begin{array}{l}\text { Há dificuldade de cooperação entre entidades privadas e instituições públicas } \\
\text { com responsabilidade na prevenção do risco }\end{array}$ & 59 \\
\hline $\begin{array}{l}\text { A comunicação e colaboração entre as instituições com responsabilidade na gestão } \\
\text { dos riscos e das crises/emergências é complexa e difícil }\end{array}$ & 59 \\
\hline O município representa a melhor escala para gerir as crises/emergências & 50 \\
\hline $\begin{array}{l}\text { Geralmente, não encontro nos organismos do Estado o apoio para a resolução dos } \\
\text { problemas da prevenção do risco e da gestão da crise/emergência }\end{array}$ & 32 \\
\hline $\begin{array}{l}\text { Nos últimos anos as instituições do Estado perderam capacidade de auxiliar } \\
\text { tecnicamente as entidades com responsabilidade na prevenção do risco }\end{array}$ & 32 \\
\hline $\begin{array}{l}\text { A articulação com a hierarquia superior da proteção civil apenas é necessária para } \\
\text { a gestão das crises/emergências }\end{array}$ & 18 \\
\hline $\begin{array}{l}\text { A informação necessária para a gestão do risco e das crises é partilhada de uma } \\
\text { forma adequada entre as instituições do Estado }\end{array}$ & 18 \\
\hline $\begin{array}{l}\text { O município é a melhor escala para promover a prevenção dos riscos e não é } \\
\text { necessária a articulação com estruturas hierarquicamente superiores }\end{array}$ & 9 \\
\hline $\begin{array}{l}\text { A proteção civil deverá assegurar a segurança das populações pelo que os cidadãos } \\
\text { não terão de desenvolver medidas de prevenção e autoproteção }\end{array}$ & 5 \\
\hline
\end{tabular}




\section{Diálogo entre a ciência e os utilizadores. Potencialidades e fragilidades na temática dos riscos}

estarem preocupadas com a sua "quinta", ou seja devem unir esforços no mesmo sentido e não virarem as costas umas às outras como, por vezes, se verifica" (opinião de um participante). Os progressos mais significativos ocorreram ao nível da troca de informação, nomeadamente meteorológica, sendo necessário avançar para uma maior partilha de conhecimento científico, superação de algumas barreiras burocráticas e simplificação de procedimentos. Para alguns dos participantes, uma das razões que justificam os problemas de comunicação e colaboração é a existência de demasiados intervenientes no processo. É possível melhorar a prevenção, a gestão da crise, o sistema de monitorização e os sistemas de aviso à população.

Em relação aos incêndios florestais, a colaboração entre instituições foi considerada adequada por $30 \%$ dos inquiridos Outros intervenientes não manifestaram uma opinião tão positiva, embora reconheçam ter havido progressos. Durante o combate, a articulação é adequada, mas falta na vigilância pós incendio e também no caso da prevenção. Todavia, ainda persiste uma cultura de competição entre instituições e não de colaboração. Os Planos Municipais de Defesa da Floresta Contra Incêndios foram referidos como um bom exemplo da importância de colaboração de várias entidades no planeamento da Defesa da Floresta Contra Incêndios.

Foram várias as sugestões apresentadas para aumentar a eficácia da gestão do risco de incêndio florestal e da supressão:

- Reforçar a colaboração entre os 3 pilares do Sistema de Defesa da Floresta Contra Incêndios e envolver como $4 .^{\circ}$ pilar os municípios, pois a prevenção e o combate são vistos como atividades distintas e desconexas mas deveriam estar integradas e serem concertadas;

- Deveria existir o cumprimento da legislação, no âmbito da prevenção, pois por vezes há o levantamento de contraordenações, mas os processos não são instruídos;

- Melhor programação das atividades de prevenção pois, por vezes, no momento de, por exemplo, colocar vigilantes no terreno e ainda não se sabem os recursos existentes;

- Deveria haver mais uniformização doutrinária.

\section{A relação dos utilizadores com os investigadores}

A avaliação da produção científica na temática dos riscos suscitou opiniões divergentes, com apenas $44 \%$ dos participantes a considerarem que a produção científica geralmente é útil e responde às necessidades dos utilizadores. Um dos participantes revelou desconhecer o trabalho dos investigadores.

As experiências ao nível da comunicação entre a comunidade científica e os utilizadores também suscitaram opiniões muito diversas por parte dos participantes (TABELA VII). Embora a maior parte dos inquiridos tenha avaliado positivamente a sua comunicação com os cientistas/investigadores, apenas $9 \%$ dos participantes revelaram ter uma boa colaboração baseada num modelo de investigação-ação-investigação procurando responder aos desafios societais. A maior frequência de respostas refere-se aos inquiridos que, embora avaliem como boa a sua relação com os cientistas, são da opinião que a investigação não é utilizada para fins operacionais. Nalguns casos, a comunicação restringe-se à participação em congressos.

Para aumentar a frequência da comunicação entre as duas comunidades e promover uma maior partilha de informação e de saberes, foi sugerida a realização de seminários temáticos, como aquele em que participaram e em que puderam expressar as suas opiniões, a implementação de trabalho conjunto no terreno e, ainda, a realização de ações de formação e de divulgação.

Ampliar a visibilidade e o impacto da investigação científica na resolução de problemas concretos da sociedade requer: uma melhor divulgação e acesso ao trabalho científico; direcionar a investigação para questões que respondam a necessidades concretas dos utilizadores, isto é, procurar que a ciência responda a problemas e desafios fundamentais da sociedade; e utilizar linguagem acessível. 


\section{Realidades e desafios na gestão dos riscos \\ - Diálogo entre ciência e utilizadores -}

TABELA VII - Avaliação da comunicação entre os utilizadores e os investigadores.

\begin{tabular}{|l|c|}
\hline \multicolumn{1}{|c|}{ Tipo de relação } & $\% *$ \\
\hline $\begin{array}{l}\text { Boa comunicação, boa colaboração mas os resultados da investigação não são } \\
\text { utilizados embora sejam adequados para a prática da gestão do risco e da } \\
\text { emergência }\end{array}$ & 39 \\
\hline $\begin{array}{l}\text { Relação fraca ou esporádica e apenas através da participação em congressos e } \\
\text { seminários }\end{array}$ & 17 \\
\hline $\begin{array}{l}\text { Boa comunicação, boa colaboração. É adotado um modelo de investigação-ação- } \\
\text { investigação para aumentar a eficácia de procedimentos }\end{array}$ & 9 \\
\hline $\begin{array}{l}\text { Boa comunicação, boa colaboração. O uso da investigação é considerado útil e aceite } \\
\text { pra uso operacional }\end{array}$ & 9 \\
\hline $\begin{array}{l}\text { Boa comunicação, boa colaboração mas os resultados da investigação não são } \\
\text { utilizados pois não respondem às necessidades dos utilizadores }\end{array}$ & 9 \\
\hline Relação fraca ou esporádica e apenas por solicitação dos investigadores & 9 \\
\hline Relação fraca ou esporádica e por solicitação dos utilizadores & 4 \\
\hline Outra & 100 \\
\hline Nenhuma relação & 4 \\
\hline Total & *As percentagens referem-se às respostas dos utilizadores que “concordaram” ou “concordaram totalmente” \\
\hline com o conteúdo dos itens mencionados. & 9 \\
\hline
\end{tabular}

\section{Conclusão}

A realização do seminário "Diálogos entre Ciência e Utilizadores: Realidades e desafios na gestão do risco" para discutir uma proposta de conceptualização dos riscos naturais e antrópicos e para compreender as dificuldades com que os atores sociais se confrontam atualmente na sua gestão, foi muito bem acolhida pelos utilizadores, que claramente se empenharam na discussão e na apresentação da sua experiência ao nível da prevenção dos riscos, da preparação e da gestão das emergências.

A discussão em grupo permitiu conhecer opiniões diversas motivadas por questões de perceção, mas também de perspetiva. Os resultados foram francamente positivos e traduziram-se em três direções distintas:

- Contribuíram para motivar os proponentes do modelo a continuar a sua reflexão sobre a conceptualização proposta e a agilização da sua operacionalização para que possa ser mais eficaz. Foi pedido aos investigadores que vejam para além de meras discussões académicas e epistemológicas;

- Possibilitaram conhecer as fragilidades no diálogo entre os investigadores e utilizadores;

- Permitiram que os próprios utilizadores tivessem identificado algumas fragilidades ao nível da governança que deverão fazer refletir e motivar a intervenção dos investigadores. 
Os utilizadores consideraram importante a clarificação e a estabilização da terminologia e a existência de um modelo conceptual do risco que traduzisse a realidade que fosse aceite por todos os operacionais. A maior parte das propostas para melhorar a prática da gestão de riscos e de crises referiram-se à governança, tendo sido sugerido que os planos deveriam ser simplificados e o seu conteúdo adequado às realidades locais mantendo o rigor. Foi salientado que a colaboração entre instituições apresenta várias fragilidades. Importa exortar as organizações a dialogar e a trabalhar em conjunto, procurando colocar o interesse público acima dos corporativos de modo a permitir um conhecimento mais integrado da complexa realidade dos riscos e da definição de procedimentos mais eficazes (TEDIM et al., 2012).

Os resultados obtidos, quer através do questionário quer da discussão em grupo, evidenciam fragilidades na colaboração entre os investigadores e os utilizadores, a qual está muito aquém do que seria esperado e mesmo aconselhável, numa ótica de otimização de recursos humanos e materiais. Os casos de sucesso parecem muito mais baseados em estratégias individuais, do que numa cultura efetiva de cooperação. É fundamental reforçar a comunicação efetiva e produtiva, uma vez que a gestão dos riscos e das crises é cada vez mais complexa, requerendo conhecimentos multidisciplinares que se encontram dispersos por diversas áreas de investigação e de atuação.

O desenvolvimento de sinergias entre organizações, assim como entre os investigadores e utilizadores, é essencial e deve assentar no diálogo. Este tem de ser um processo bidirecional, em que os investigadores e os utilizadores procurem compreender os diversos pontos de vistas, o funcionamento dos processos e quais os resultados que pretendem alcançar (EASAC, $\mathrm{s} /$ data). Este diálogo pode servir vários propósitos, nomeadamente: aumentar a visibilidade e aplicação social da ciência; orientar a investigação para a resolução de problemas específicos da sociedade; facilitar o acesso à produção de conhecimento científico; conhecer os problemas que os utilizadores enfrentam no dia-a-dia e a resposta que necessitam dos cientistas; otimizar procedimentos, avaliar e corrigir políticas.

Um método de investigação participada é fundamental para que a gestão não seja orientada meramente para a concretização de determinadas metas ("output", como p. ex., elaborar um plano de emergência) mas sim para atingir determinados resultados ("outcome") ao nível de desempenho ou realizações. "Os investigadores têm de aceitar o desafio de melhor comunicar a sua investigação em formatos preferidos pelos utilizadores, dedicar mais tempo a "educar" os utilizadores a compreender a usar os resultados produzidos, enquanto os utilizadores têm de "educar" os investigadores a produzirem conhecimento mais relevante e útil” (de la VEGA-Leinert e SCHRöter, 2008: p. 30). Só desta forma se poderão obter os maiores benefícios da interação entre a ciência e os utilizadores, como suporte fundamental do desenvolvimento da sociedade.

\section{Referências bibliográficas}

de la Vega-Leinert, Anne Cristina and Schröter, Dagmar (2008) - Stakeholder dialogue as a communication and negotiation tool in scientific inquiry, in CARVALHO, Anabela (ed.) Communicating Climate Change: Discourses, Mediations and Perceptions.Braga: Centro de Estudos de Comunicação e Sociedade, Universidade do Minho, p. 13-33 Available from: http://www.lasics.uminho.pt/ojs/index.php/climate_change.

EUROPEAN ACADEMICS SCIENCE, Advisory Council (s/data) - EASAC Guidelines: Good Practic in the Dialogue between Science Academies and Policy Communities http://www.easac.eu/ fileadmin/ppt/Science-Policy-Dialogue/Short_EASAC_Guidelines_PDF.pdf.

Julião, R. P., Nery, F., Ribeiro, J. L., Branco, M. C. e Zêzere, J. L. (2009) - Guia metodológico para a produção de cartografia municipal de risco e para a criação de sistemas de informação geográfica (sig) de base municipal. Lisboa, Ed ANPC, co-Ed. DGOTDU e IGP, 91 p. 


\section{Realidades e desafios na gestão dos riscos \\ - Diálogo entre ciência e utilizadores -}

Tedim, Fantina; Barros, Ivo; Carvalho, Salete; Felguelras, João (2012) - Os incêndios florestais em Áreas Protegidas: uma realidade com distintas representações sociais, in TEDIM, F. e Paton, D., A dimensão social dos incêndios florestais: para uma gestão sustentável, Estratégias Criativas, Porto, p. 101-128.

VERDE, J. C. (2008) - Avaliação da perigosidade de incêndio florestal. Dissertação de Mestrado, Universidade de Lisboa, Faculdade de Letras, Departamento de Geografia.

Verde, J. C. e Zêzere, J. L. (2010) - “Assessment and validation of wildfire susceptibility and hazard in Portugal". Natural Hazards and Earth System Science, Vol. 10/n. ${ }^{\circ} 3$, p. 485-497.

Welp, Martin; de la Vega, Leinerta Anne, Stoll-KleEmannb, Susanne; C. Jaegera, Carlo (2006) Science-based stakeholder dialogues: Theories and tools Global Environmental Change 16, p. $170-181$.

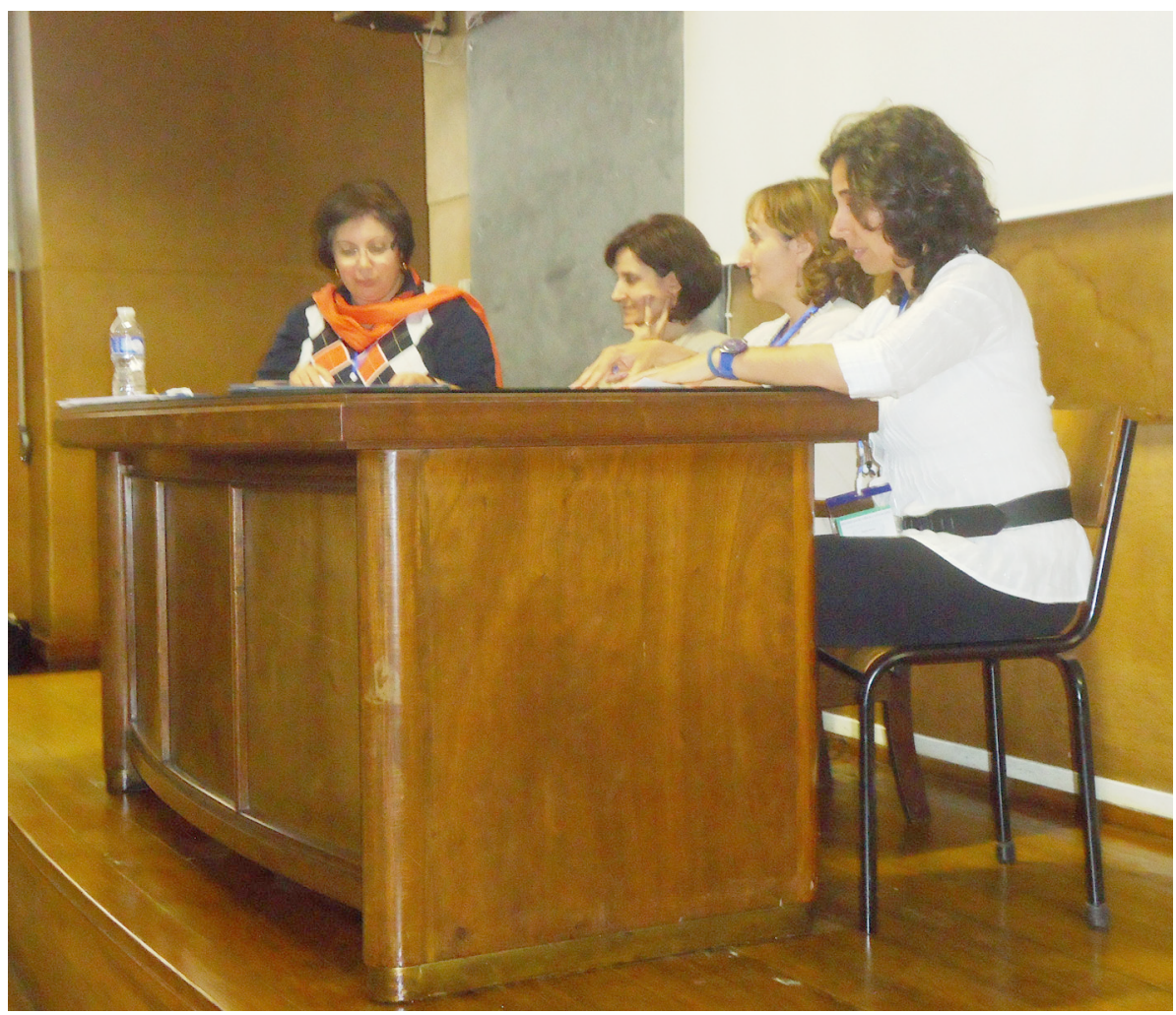




\title{
NOTAS FINAIS
}

\author{
Fantina Tedim \\ CEGOT e Departamento de Geografia \\ Faculdade de Letras da Universidade do Porto \\ ftedim@letras.up.pt \\ Luciano Lourenço \\ CEGOT e Departamento de Geografia \\ Faculdade de Letras da Universidade de Coimbra \\ luciano@uc.pt
}

\section{Introdução}

O seminário "Diálogos entre Ciência e Utilizadores: Realidades e desafios na gestão do risco" constituiu o primeiro evento de uma iniciativa que se pretende periódica, focalizada no fomento da interação entre a comunidade científica e a comunidade dos utilizadores (decisores políticos e operacionais). A ideia-chave foi, desde início, "dar voz" aos utilizadores, sobretudo para escutar e compreender as suas experiências, os seus problemas e anseios, ou as suas perspetivas e expectativas.

0 mote proposto para este seminário foi a terminologia associada aos riscos naturais e antrópicos, a qual tem "dividido" a comunidade científica portuguesa, nomeadamente a constituída pelos geógrafos.

Os riscos e a sua materialização, as catástrofes, são uma temática multidisciplinar e interdisciplinar, transversal à sociedade e à investigação, e embora a ausência de concordância terminológica e mesmo conceptual não constitua um obstáculo para os investigadores prosseguirem os seus estudos e objetivos científicos, revela-se, no entanto, um fator de perturbação e de desinteresse para os utilizadores. Com efeito, foi por estes demonstrado, muito claramente, que gostariam de uma maior clareza e estabilidade terminológica.

Todavia, tentar obter consensos dentro da academia, uma tarefa que pode ser realizada sem a participação dos utilizadores, poderá parecer o caminho mais fácil, mas, no nosso entender, não se deverá procurar este desiderato sem considerar também a experiência própria de quem, no quotidiano, gere os riscos e as suas manifestações (emergências) e que, por conseguinte, dispõe de informação prática privilegiada, pelo que sendo embora um desafio muito maior é bem mais aliciante, o que significa que valerá a pena continuar por este caminho.

Talvez por isso, a iniciativa ora realizada foi positivamente avaliada pelos intervenientes diretos:

- Participantes, que muito claramente evidenciaram a sua adesão a um "espaço de diálogo" onde não são apenas meros destinatários mas em que também são participantes muito ativos. 0 interesse na interação ficou claramente evidenciado, quer na sessão da manhã quer na sessão da tarde, ao empenharem-se tanto na discussão, como na apresentação de ideias e experiências, e ainda, ao manifestarem-se muito favoravelmente à ideia da realização de novos eventos com características semelhantes;

- Organizadores, que puderam perceber de que forma as lógicas dos investigadores e dos operacionais se podem cruzar, de modo a resolver problemas concretos da sociedade, focalizando-se mais nos resultados e menos em processos mecanicistas alheios às especificidades sociais, económicas e ambientais locais. 


\section{Realidades e desafios na gestão dos riscos \\ - Diálogo entre ciência e utilizadores -}

De igual modo, foi particularmente importante perceber como é que os participantes se relacionam com os investigadores. Se bem que tenham sido apresentadas algumas experiências de boa relação entre as duas comunidades, baseadas num modelo de investigação-açãoinvestigação, elas foram verdadeiramente minoritárias.

Pelo contrário, as duas opiniões maioritariamente expressas (TABELA VII, Capítulo VII, p. 84), constituem um verdadeiro alerta, não só para os investigadores, mas também para os decisores políticos, mormente para aqueles que tutelam entidades operacionais, as quais deverão ser motivo de reflexão para ambos.

Um outro grupo considera que embora a comunicação seja boa, os resultados da investigação não são utilizados.

Por outro lado, para uma parte significativa dos participantes, não há qualquer relação com os investigadores. Neste caso importa perceber as razões deste alheamento ou afastamento.

Compreender as razões destas situações parece importante, no interesse da sociedade e do ambiente, quer sob o ponto de vista operacional, quer do ponto de vista dos investigadores. Neste último caso importará saber porque é que a investigação produzida não é considerada adequada ou, no caso de o ser, porque é que não é aplicada pelos decisores políticos? Terá a ver com um problema de visões distintas? Será uma questão de conteúdo? Trata-se de um problema de comunicação? Será um problema cultural?

A colaboração entre os investigadores e os operacionais que trabalham na área dos riscos (naturais, antrópicos e mistos) é fundamental para que se possa perceber o que é necessário e o que é que vale realmente a pena fazer. A instituir-se, esta colaboração e troca de experiências criará um contexto mais favorável não só ao desenvolvimento de uma abordagem indutiva de investigação, mas sobretudo para o desenvolvimento de hipóteses dedutivas.

Ao terminar, queremos expressar o nosso mais profundo agradecimento a todos os participantes neste seminário e, como não podemos nem queremos frustrar as expetativas então criadas, em 2015 esperamos por vós no Porto, para dialogarmos sobre incêndios florestais.

Até breve.

Fantina Tedim

Luciano Lourenço 


GRUPOS DE TRABALHO 
Realidades e desafios na gestão dos riscos

- Diálogo entre ciência e utilizadores -

\section{GRUPO 1}

Moderadora: Prof. ${ }^{a}$ Doutora Fantina Tedim

Ana Rosa Manuel

André Barreiro Gonçalves

Anselmo Casimiro Ramos Gonçalves

António Cândido de Resende Lopes

António Oliveira

António Vieira

Catarina Isabel Carvalho dos Santos

Fernando Ricardo Ferreira Félix

João José da Silva Felgueiras

Nuno Miguel Casado Alberto

Nuno Prada

Romero Manuel Bandeira Gandra

Rui Pedro Julião

Vera Lúcia Carvalheira Mendes 


\section{GRUPOS DE TRABALHO}

GRUPO 2

Moderadora: Prof. ${ }^{a}$ Doutora Cármen Ferreira

Alberto Augusto Mota dos Santos

Andreia Susana Dinis Martins

Carlos Flores Bispo

Carlos Luís Tavares

Carlos Manuel C. Mesquita Guimarães

César Manuel Guedes

Fernando Manuel da Silva Rebelo

Jorge Miguel dos Santos Ferraz

José Manuel Ribeiro Teixeira

Luís Neri

Marco Filipe Neves Dias

Miguel Tato Diogo

Salvador de Pinho Ferreira de Almeida

Sofia Pires Fernandes 
Realidades e desafios na gestão dos riscos

- Diálogo entre ciência e utilizadores -

\title{
GRUPO 3
}

Moderadora: Prof. ${ }^{a}$ Doutora Adélia Nunes

\author{
António Betâmio de Almeida \\ António Bento Gonçalves \\ António José da Cruz \\ Joana Carinhas \\ João Carlos da Silva Fernandes \\ João Victor Gonçalves da Silva Pereira \\ José António Batista Simões Coelho \\ José Henrique de Almeida Gaspar \\ José Pedro Godinho Oliveira Lopes \\ Luciano Fernandes Lourenço \\ Nélson Amado de Oliveira \\ Paulo Jorge de Oliveira Acúrcio \\ Pedro Matias Pedro \\ Pedro Nuno Rodrigues Costa
}


GRUPO 4

Moderadora: Doutora Sandra Oliveira

António Figueiredo Lopes

Carlos Manuel Fernandes Miranda Cruz

Emanuel Sardo Fidalgo

Filomena Maria O. Rodrigues Pinho

Francisco Costa

Isabel Pedro

José Carlos Caetano

José Carlos dos Santos Gonçalves

Maria Manuel Afonso Lopes Gouveia

Sérgio Miguel Ferreira Alves

Sofia Isabel dos Santos Bernardino

Tiago Costa Pinto

Virgínia Maria Barata Teles

Vitor Manuel da Silva Ginja 



\section{Índice}

Nota de Abertura

pág. 5

\section{Capítulo I}

Terminologia do risco. Origens, dificuldades de tradução e bom senso pág. 7

\section{Capítulo II}

Gestão do risco e da incerteza. Conceitos e filosofia subjacente pág. 19

Capítulo III

A conceptualização nos riscos naturais: impactes na ciência e na ação pág. 31

\section{Capítulo IV}

Guia metodológico para a cartografia de risco. Um produto do diálogo

ciência/utilizadores pág. 43

\section{Capítulo V}

Riscos e perigos em tradução: considerações sobre terminologia nas ciências cindínicas pág. 55

\section{Capítulo VI}

Risco, perigo e crise. Trilogia de base na definição de um modelo

conceptual-operacional pág. 61

\section{Capítulo VII}

Diálogo entre a ciência e os utilizadores. Potencialidades e fragilidades na temática dos riscos pág. 73

Notas Finais pág. 87 
Apoios: 